\title{
NEW TECHNIQUES FOR ANALYSIS OF ORGANIC POLLUTANTS IN DRINKING WATER
}

\author{
Larry Dean Kissinger
}

Based on a Ph.D. thesis submitted to Iowa State University

Ames Laboratory, USDOE

Iowa State University

Ames, Iowa 50011

\begin{abstract}
Date Transmitted: January 1979
PREPARED FOR THE U.S. DEPARTMENT OF ENERGY

UNDER CONTRACT NO. W-7405-eng-82
\end{abstract}




\section{DISCLAIMER}

This report was prepared as an account of work sponsored by an agency of the United States Government. Neither the United States Government nor any agency Thereof, nor any of their employees, makes any warranty, express or implied, or assumes any legal liability or responsibility for the accuracy, completeness, or usefulness of any information, apparatus, product, or process disclosed, or represents that its use would not infringe privately owned rights. Reference herein to any specific commercial product, process, or service by trade name, trademark, manufacturer, or otherwise does not necessarily constitute or imply its endorsement, recommendation, or favoring by the United States Government or any agency thereof. The views and opinions of authors expressed herein do not necessarily state or reflect those of the United States Government or any agency thereof. 


\section{DISCLAIMER}

Portions of this document may be illegible in electronic image products. Images are produced from the best available original document. 


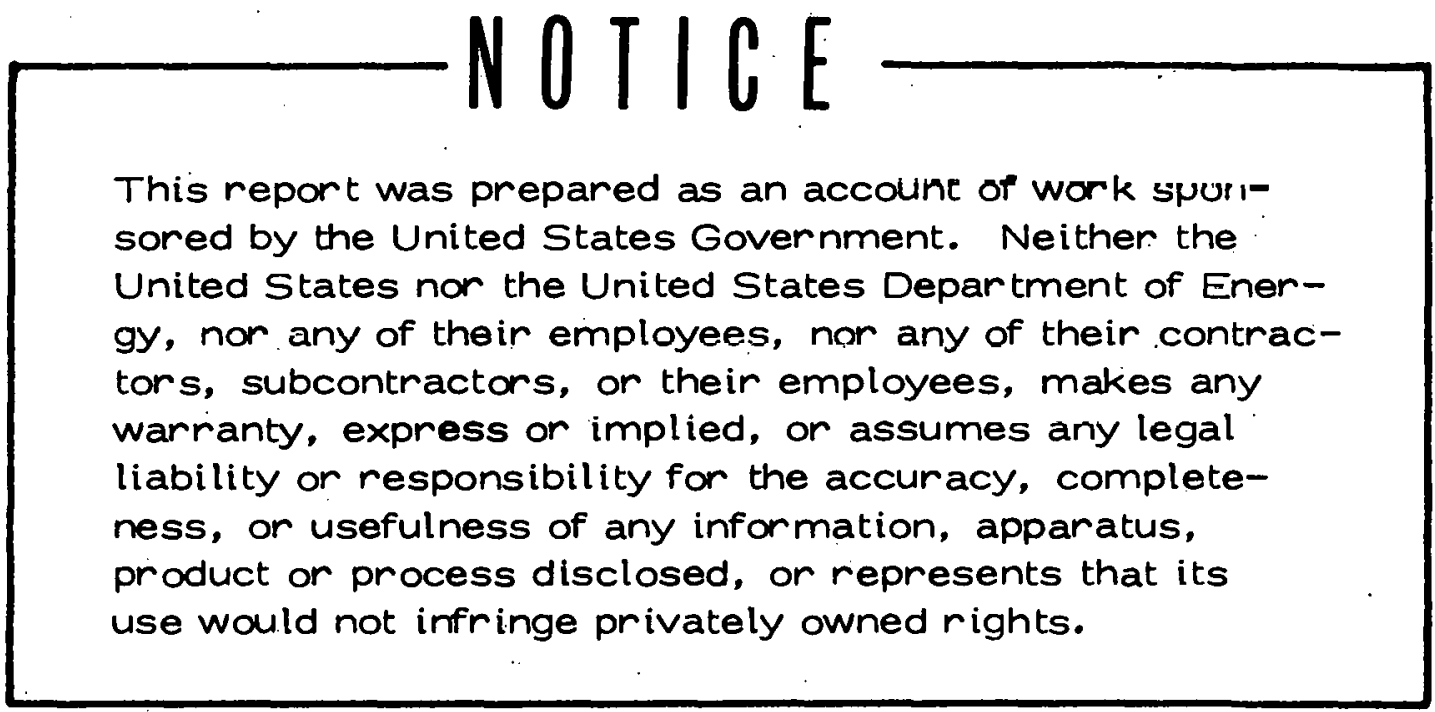

Available from: National Technical Information Service

U. S. Departirient of Commerce

P.O. Box 1553

Springfield, VA 22161

Price: Microfiche $\$ 3.00$ 


\section{New techniques for analysis of organic pollutants in drinking water} by Larry Dean Kissinger

A Dissertation Submitted to the Graduate Faculty in Partial Fulfillment of The Requirements for the Degree of DOCTOR OF PHILOSOPHY

\section{Department: Chemistry \\ Major: Analytical Chemistry}

Approved:
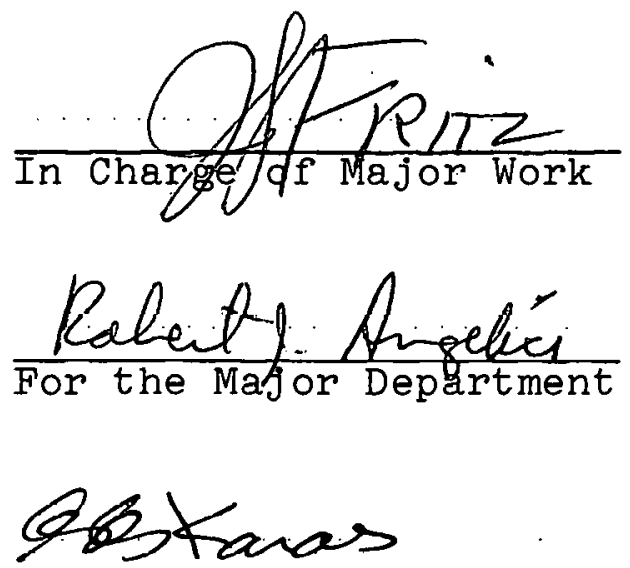

For the Graduate College

Iowa State UnIversity

Ames, Iowa 
Abstract

INTRODUCTION

ABSTRACTION OF AMINES FROM GAS-CHROMATOGRAPHIC STREAMS

Review of Related Work

Experimental

5

Apparatus and reagents

Gas chromatograph

Ahstrastor columns

Analytical columns

Reagents

Techniques and procedures

Preparation of abstractor packing Solutions

Gas-chromatographic technique

Results and Discussion

Development of abstractor packing

Applications of amine-abstractor columns

Conclusions

DETERMINATION OF HALOFORMS IN WATER

Review of Related Work

Experimental

Apparatus and roagents

Gas chromatograph

Water-sampling apparatus

Sorption columns

Gas-chromatographic column 
Techniques and procedures

Preparation of acetyl resin

Sample collection

Analytical procedure for determining haloforms in water

Chlorine solution

31

Chlorlne solution

Results and Discussion

32

Development of analytical technique 33

Storage of water samples 38

Experiments on haloform production and exchange reactions

Conclusions

Review of Related Work $\quad 47$

Experimental 52

Apparatus $\quad 52$

Gas chromatograph $\quad 52$

Columns 52

Inlet system 53

Exit interface $\quad .56$

Exit splitter $\quad 57$

Techniques and procedures 58

Installing the WCOT capillary columns 58

Operation of the inlet system in the
split mode

Operation of the inlet system in the splitless mode 62

Optimization of exit-interface
parameters

Optimization of exit-splitter
parameters

Results and Discussion $\quad 64$

Conclustons 69 
FRACTIONATION OF ORGANIC COMPOUNDS IN WATER EXTRACTS ON FLORISIL

Review of Related Work 72

Organic compounds in drinking waters 72

Evaluation of fractionation techniques $\quad 78$

Quantitative recovery $\quad 78$

Informative $\quad 79$

Noncontaminative $\quad 79$

Semipreparative $\quad 79$

Sample clean-up 79

Rapid 79

Inexpensive $\quad 80$

Selection of fractionation technique for water extracts 96

Mutagenic testing $\quad 98$

Experimental 99

Apparatus and reagents 99

Gas chromatography $\quad 99$

Gravity-flow columns 99

Solution concentrators 99

Florisil 101

Amberlite XAD-2 resin 101

$\begin{array}{ll}\text { Solvents } & 101\end{array}$

Techniques and procedures 102

Determination of Florisil activity $\quad 102$

Fractionation procedure 102

Model compound recoveries 105

Preparation of water extracts 106

Mutagenicity testing 106

Results and Discussion 107

Development of analytical lechnlque 107

Selection of solvent system 107

Effects of water in samples 112

Effects of Florisil activity 113

Elution behaviors of model compounds $\quad 114$

Recovery 
Analytical determinations 121

Gas-chromatographic analysis $\quad 121$

Mutagenic testing 138

Conclusions $\quad 141$

SUGGESTIONS FOR FUTURE WORK 143

$\begin{array}{ll}\text { LITERATURE CITED } & 145\end{array}$

ACKNOWLEDGEMENTS 152 
vii i

\author{
New techniques for analysis of organic \\ pollutants in drinking water ${ }^{1}$
}

\title{
Larry Dean Kissinger
}

\section{Under the supervision of J.S. Fritz From the Department of Chemistry Iowa State UnIversity}

Reported methods of analysis of water for trace organic compounds are limited by the separations and detection techniques used. Techniques of analysis have been developed and applied to the analysis of water samples.

An abstractor packing was prepared by coating Chromosorb G AW/DMCS with copper(II) chloride. The abstractor packing was effective for removal of amines from gaschromatographic streams, but the abstractor packing did not effect the chromatographic behavior of nonamine compounds. By using pre-columns that were packed with the abstractor packing, solventless chromatograms were obtained for samples in pyridine.

A method was developed for determining haloforms in drinking water by sorption of the haloforms on columns packed with acetylated XAD-2. A pre-column of the abstractor packing was used to remove the pyridine solvent from the

${ }^{1}$ DOE Report IS-T-845. This work was performed under Contract W-7405-eng-82 with the Department of Energy. 
samples containing the haloforms concentrated from waters. Detection limits for the four chloro-, bromo- haloforms in a. 100-ml water sample using an electron capture detector were below $1 \mathrm{ppb}(1 \mu g / 1)$. The production of haloforms in chlorinated waters was investigated. Addition of ascorbic acid to chlorinated waters was effective for stopping the production of haloforms.

A system was designed for use of capillary columns in a Tracor model 550 gas chromatograph. The design of the inlet allowed samples to be introduced to the capillary column with or without splitting of the carrier-gas stream. An exit splitter was implemented that carried the effluent from the capillary column to two detectors. The capillarycolumn system was applied to the analysis of trace components in complex mixtures.

Small columns packed with Florisil were used to fractionate mixtures of organic compounds by gravity-flow liquid chromatography. Three fractions of organic compounds were collected from the Florisil columns. The recovery and elution behavior of many organic compounds was investigated. Organic compounds from fifteen waters were fractionated on Florisil. 


\section{INTRODUCTION}

Only in the past few years have drinking waters been analyzed for trace levels of organic pollutants. In the past, the inorganic constituents and the blological organlsms present in potable waters have been wellcharacterlzed, while little was known about the organic matter present in the waters. In an effort to ensure the quality of drinking waters, reliable methods of analysis f'or trace concentrations of organic compounds in water must be developed $(1,2)$.

Early methods of analysis for organic matter present In waters were developed to determine the total-organic carbon (TOC) in samples $(3,4)$. More recently, methods have been developed to concentrate and determine the organic compounds present in drinking waters $(5,6,7)$. Gas chromatography has been used to separate organic pollutants and mass spectrometry has been used to identify organic pollutants present in drinking waters. More than 400 compounds have been identified in drinking waters by gas chromatography/mass spectrometry ( 8 ).

The purpose of th1s research effort was to 1mprove on the methods avallable for determining organic pollutants in drinking waters. For the purpose of organization, the thesis is divided into four sections. A technique to abstract amines from gas-chromatographic streams is 
discussed in the first section. In the second section, an application of the amine abstractor to a gas-chromatographic method of determining haloforms in drinking waters is described. A high-resolution system for gas chromatography with capillary columns is described in the third section. Finaliy, fractionation of organic compounds from drinking waters is discussed. Organic compounds from selected drinking waters were fractionated on Florisil columns, chromatographed on caplllary columns, and assayed for mutagens by the Ames Test. 
ABSTRACTION OF AMINES FROM GAS-CHROMATOGRAPHIC STREAMS

$$
\text { Review of Related Work }
$$

Columns packed with a material that completely removes certain types of compounds from gas-chromatographic streams have sometimes been used. These columns are called subtractors or abstractors. Abstractor columns are usually used to obtain information about the identities of sample components. Innes et al. used columns containing s1lver nitrate and sulfuric acid to abstract unsaturated hydrocarbons (9). A short column of boric acid can be used to remove alcohols selectively from complex mixtures prior to separation of sample components on a gas-chromatographic column (10). Other abstractors have been reported for removal of dienes (11), phenols (1.2), and aclds (13). Fryka and Pospisil used phosphoric acid on Chromosorb W AW/DMCS as an abstractor packing for nitrogen bases (14). A book by Ledthard and shurlock has a chapter discussing the use of abstractors in gas chromatography for compound identification (15).

Various techniques have been developed to obtain chromatograms free of solvent peaks. Chang used thermal desorption from columns of Amberlite XAD-2 and Tenax GC to introduce organic compounds from water samples to a gas chromatograph without using a solvent (16). Bellar and 
Lichtenberg developed a "purge and trap" technique that allows for the analysis of volatile compounds in water without using a solvent (17). Th1s technique uses a Tenax GC column to trap compounds purged from water by a gas flow, then thermally desorbs compounds from the Tenax GC column into a gas chromatograph. A capsule sampler has been marketed by Perkin-Elmer Corporation (18). After evaporating the solvent from a sample in a capsule, the capsule sampler can be used to introduce the capsule into a gas chromatograph. The capsule is ruptured, and a solventless chromatogram is obtained.

Although abstractors have been developed for a number of compound classes, most abstractors have only been used to remove small amounts of material from gas-chromatographic streams. Removal of a solvent from a gas-chromatographic stream could be used when a large solvent peak interferes with peaks for compounds of interest. If an abstractor of high capacity was to be used to remove a solvent, a number of solventless chromatograms could be obtained without changing the abstractor.

In this work, Colin D. Chriswell and myself investigated the use of metal-amine complexes to obtain chromatograms free of a solvent peak (19). Varlous means of subtracting amines from gas streams were investigated before selecting a packing of $25 \%$ copper(II) chloride coated on 
Chromosorb G AW/DMCS as the abstractor packing. Interaction between nonamine compounds and the abstractor packing was minimized by using an inorganic abstractor packing.

\section{Experimental}

Apparatus and reagents

Gas chromatograph. A Hewlett-Packard model 57llA gas chromatograph and a Tracor model 550 gas chromatograph were used for this work. Both instruments were equipped with a linear temperature programmer and a dual flame lonization detector. Chromatograms were recorded using a Houston Instruments Series 5000 strip chart recorder.

Abstractor columns For the Hewlett-Packard 571lA, a 12-in $\times 1 / 8-$ in $0 . d$. stainless-steel tube filled with abstractor packing was connected to the infection port and to the analytical column of the gas chromatograph. A segment of stainless-steel tubling, 7-in $\times 1 / 4-$ in $0 . d$., with a female 1/8-in Swagelok (trademark of Crawford Fitting Company, Solon, Ohio) fitting was used as the abstractor column with the Tracor 550. The tubing was filled with abstractor packing, inserted into the injection port of the Tracor 550, sealed to the Inlet with a brass ferrule, and connected to the analytical column of the gas chromatograph. 
Before use with an analytical column, the abstractor columns were conditioned with a gas flow at $220^{\circ} \mathrm{C}$.

Analyt 1cal columns Chromatograms were obtained

using either a 6-ft $\times 1 / 8$-in o.d. stainless-steel column packed w1th $10 \%$ SE-30 on 100/120-mesh Chromosorb W AW/DMCS or a 2-ft $x$ 1/8-1n o.d. stainless-steel column packed with 80/100-mesh Amberlite XAD-2.

Reagents $\quad$ Pyridine, distilled-in-glass grade and stored under nitrogen, was obtalned from Burdick and Jackson Laboratories, Inc., Muskegon, Michigan.

All grades of Chromosorb (products of Johns-Mansville) were obtained from Applied Sclence Laboratorles, Inc., State College, Pennsylvania. Chromosorbs labeled with AW have been washed with acid. The Chromosorbs which carry the DMCS label have been treated with dimethyldichlorosilane to reduce the activity of their surfaces.

Amberlite XAD-2 (a styrene-divinylbenzene copolymer), Amberlite IRC-50 (a methylacrylic aoid-divinylbenzene copolymer), and Amberlyst A-15 (a sulfonated styrenedivinylbenzene copolymer) were obtained from Rohm and Haas, Philadelphia, Pennsylvania.

Other materials and chemicals were the grade available w1thin the laboratory. 
Techniquies and procedures

Preparation of abstractor packing. Chromosorb G AW/DMCS ( $80 / 100$ mesh) was coated by evaporation of an aqueous solution contalning $2.5 \mathrm{~g}$ of copper(II) chloride to near dryness onto $7.5 \mathrm{~g}$ of Chromosorb using a rotary evaporator. The Chromosorb was wet with acetone and reevaporated in a rotary evaporator to dryness. The material was then dried at $115^{\circ} \mathrm{C}$ for $1 \mathrm{hr}$, sieved, and the $80 / 100-$ mesh fraction collected.

Solutions Solutions for analysis by abstraction gas chromatography were made with distilled-in-glass grade pyridine. Stability of pyridine solutions was increased by storage in a freezer at $-17^{\circ} \mathrm{C}$.

Gas-chromatographic technique Pyridine samples were analyzed by introducing a few microliters of the solution into a gas chromatograph with a Hamilton $701 \mathrm{~N}$ syringe. The analytical column was subfected to temperature programming to affect separations. The abstraetor columns were operated at a temperature below $180^{\circ} \mathrm{C}$. Samples containing polar organic compounds were separated using the XAD-2 analytical column, and samples containing only nonpolar organic compounds were separated using the SE-30 analytical column. 
Results and Discussion

Development of abstractor packing

Cation-exchange resins in various metal-ion forms were examined for use as abstractor packings. The following ion-exchange resins were investigated: Amberlite IRC-50, Amberlyst A-I5, and a low-capacity sulfonated Amberlite XAD-2 (20). Nickel(II) and copper(II) forms of the 80/100mesh fraction of these resins were packed into stainlesssteel columns and installed in the gas chromatograph. Neither form of IRC-50 was effective for removal of amines; however, both nickel(II) and copper(II) forms of A-15 and sulfonated XAD-2 retained amines at elevated temperatures. The nickel(II) forms of A-15 and sulfonated XAD-2 caused peaks for most nonamine compounds to be significantly tailed and some alcohols and alkenes were retained. If the area under a peak after the maximum is greater than the area before the maximum, the peak is tailed. Because tailing. reduces the maximum of a peak, sensitivity for a compound is reduced if the peak is talled. Resolution of chromatographic peaks is reduced by tailing, because tailing broadens peaks. Pyridine and diethylamine were retained by the copper(II) forms of $A-15$ and sulfonated XAD-2 at temperatures up to $275^{\circ} \mathrm{C}$; however, retention times were increased and peaks for many compounds were tailed. 
The effectiveness of columns packed with Chromosorb G AW/DMCS coated with other salts was evaluated. Copper(II) sulfate coated on Chromosorb G AW/DMCS was effective in retaining amines and did not affect the chromatographic behavior of nonamine compounds. Copper(II) sulfate is unstable at temperatures greater than $200^{\circ} \mathrm{C}$ (21); thus, copper(II) chloride was preferred for making the abstractor packing. Chromosorb G AW/DMCS coated with nickel(II). chloride abstracted amines; however, peaks for alkenes and some other compounds were tailed. When temperature programming columns containing Chromosorb G AW/DMCS coated with zinc(II) chloride, the background current from the flame ionization detector increased. The increased background current indicates that pyridine was not completely retained by. the column.

Copper(II) chloride coated on Chromosorb G AW (not treated with dimethyldichlorosilane) retained amines; however, peaks for many compounds were talled. Because of interactions between polar compounds and active hydrogens on the surface of Chromosorb, peaks for polar compounds are often ta1led. Treatment of Chromosorb with dimethyldichlorosilane replaces the active hydrogens and reduces tailing of polar compounds (22).

Chromosorb W AW/DMCS coated with $10 \%$ concentrated phosphoric acid ( $85 \%)$ has been used to abstract amines from 
gas-chromatographic streams (14). Because many compounds interact with strong acids at high temperatures, peaks for alcohols, ketones, and other compounds were talled when Chromosorb coated with phosphoric acid was used to abstract amines. The capacity of a packed column of Chromosorb coated with phosphoric acld was much less than a packed column of Chromosorb coated with copper(II) chloride. Columns packed with the phosphoric-acld packing retain less than a fifth the amount of pyridine retained by the copper(II) chloride packing.

Amines were removed from the gas-chromatographic stream by the abstractor because nonvolatile complexes were formed with copper. The thermal stability of the copper(II)-amine complexes varies with the amine. Aniline, butylamine, diethylamine, triethylamine, and cyclohexylamine were retained at temperatures in excess of $140^{\circ} \mathrm{C}$. Pyridine was retalned up to a temperature of $180^{\circ} \mathrm{C}$, while dibutylamine was retained only at temperatures below $120^{\circ} \mathrm{C}$.

The capac1ty of the abstractor packing was measured by injecting 2- $\mu 1$ aliquots of pyridine' into the chromatograph unt1l break-through was observed. A 12-in $\times 1 / 8-$ in column of the abotractor paoking retained $30 . \mu 1$ of nyridine at $150^{\circ} \mathrm{C}$. The internal volume of the column was $0.75 \mathrm{ml}$, which implies that $1 \mathrm{ml}$ of the abstractor packing can retain $40 \mu \mathrm{l}$ of pyridine at $150^{\circ} \mathrm{C}$. The capacity of an abstractor 
column can be increased by decreasing the operating temperature.

Thermal regeneration of the abstractor columns was investigated. Partial regeneration of the capacity was obtained by heating columns that had been saturated with pyridine. By passing nitrogen through the abstractor columns at $220^{\circ} \mathrm{C}$ for $\mathrm{I} \mathrm{hr}$, one-third of the initial capacity was regained. Rather than regenerate the abstractor columns thermally, the abstractor packing was replaced periodically.

The abstractor packing has no affinity for most organic compounds; thus, retention times for most compounds were not significantly affected by a short pre-column of the abstractor packing. The retention times of the compounds listed in Table 1 were not affected by the abstractor column. Of the compound s listed in Table I, significant reduction of peak height was only observed with methanol. Reduction of the peak height for methanol indicates that some interaction occurs between methanol and the abstractor packing. Some reduction of peak height was observed for all compounds when using the abstractor column, because of peak broadening that occurs during the added column length.

Applications of amine-abstractor columins

Figures 1-4. demonstrate the usefulness of the abstractor columns for the analysis of nonamine compounds 
Table 1. Compounds not affected by abstractor column

\begin{tabular}{|c|c|}
\hline n-pentane & benzene \\
\hline$\underline{n}$-hexane & toluene \\
\hline n-heptane & ethylbenzene \\
\hline$\underline{n}$-octane & isopropylbenzene \\
\hline$\underline{n}$-decane & $\underline{\text { n-butylbenzene }}$ \\
\hline$\underline{n}$-und ecane & naphthalene \\
\hline$\underline{n}$-tridecane & hexene \\
\hline methanol ${ }^{a}$ & heptene \\
\hline ethanol & octene \\
\hline I-propanol & acetonitrile \\
\hline 1-butariol & acetaldehyde \\
\hline 1 -pentanol & benzaldehyde \\
\hline acetone & nitrobenzene \\
\hline butanone & phenol \\
\hline 2-pentanone & o-cresol \\
\hline 3-methyl-2-pentanone & 1,4-dioxane \\
\hline dichloromethane & benzyl a lcohol \\
\hline chlor oform & 1sopropyi ether \\
\hline carbon tetrachloride & ethyl benzoate \\
\hline 1-bromobutane & diethyl. ether \\
\hline 1,3-dichlorobenzene & ethyl acetate \\
\hline
\end{tabular}

${ }^{a}$ Retention time not affected, peak height decreased. 
in an amine solvent. In each figure, one chromatogram is without the abstractor column and has a large peak for pyridine. The other chromatogram in each figure is with the amine abstractor column and has no peak for pyridine. By removing pyridine from the gas-chromatographic stream, peaks for components of the sample are not lost under a large solvent peak. Pyridine was selected as the solvent for samples, because it is commercially avallable in high purity from Burdick and Jackson Laboratories, Inc. In each figure, the peaks that are well-resolved from the solvent peak appear the same in both chromatograms, indicating that the nonamine compounds are not retained by the abstractor column.

Because only amines are removed from gas streams by the abstractor packing, use of the abstractor column makes it possible to analyze amines by gas chromatography for trace levels of nonamine impurities. Analysis of several brands of pyridine revealed that most had significant concentrations of nonamine compounds. Based upon retention times, benzene and toluene were identified in one brand of pyridine at concentrations of 50 and $160 \mathrm{ppm}(\mathrm{mg} / \mathrm{l})$, respectively.

Volatile components were extracted from coal with pyridine and analyzed by gas chromatography. Ground coal (100/120 mesh) was extracted with pyridine in a Soxhlet extractor for $12 \mathrm{hrs}$. Chromatograms for injections of an 
Figure 1. Chromatograms w1th (a) and without (b) abstractor column for a separation of normal alkanes on a SE-30 column. Sample components are:

(A) pentane, (B) hexane, (C) heptane, (D) octane, (E) nonane, and ( $F$ ) dodecane. Temperature:

initial temperature of $70^{\circ} \mathrm{C}$, programmed to $90^{\circ} \mathrm{C}$ at $5^{\circ} \mathrm{C} / \mathrm{min}$, initial hold of $2 \mathrm{~min}$ and final hold of 2 min. 


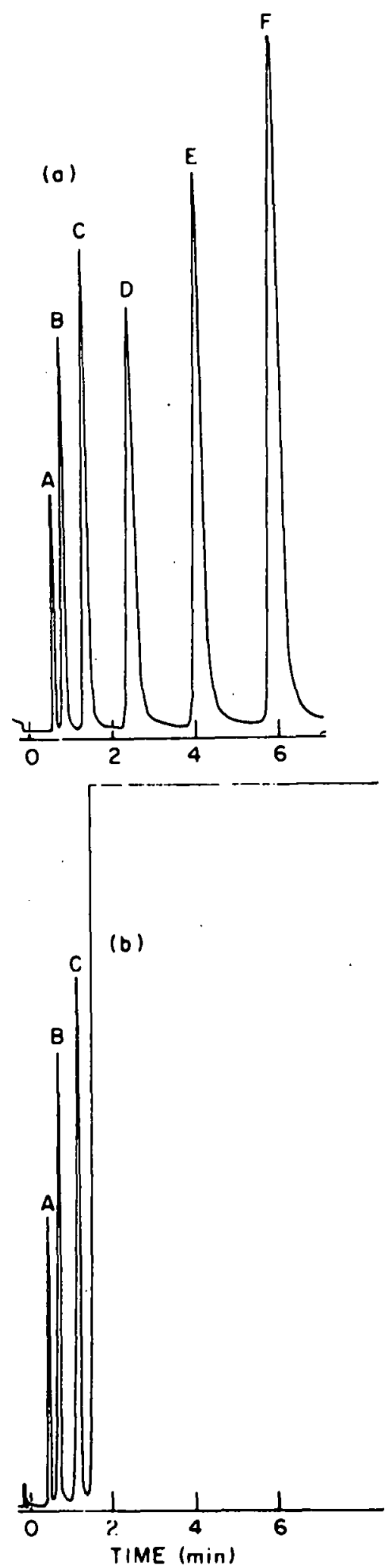


Figure 2. Chromatograms with (b) and without (a) abstractor column for a separation of aromatic compounds on a SE-30 column. Sample components are:

(A) benzene, (B) toluene, (C) ethylbenzene, (D) isopropylbenzene, (E) butylbenzene, and (F) naphthalene. Temperature: initial temperature of $12.0^{\circ} \mathrm{C}$, programmed to $160^{\circ} \mathrm{C}$ at $16^{\circ} \mathrm{C} / \mathrm{min}$. 

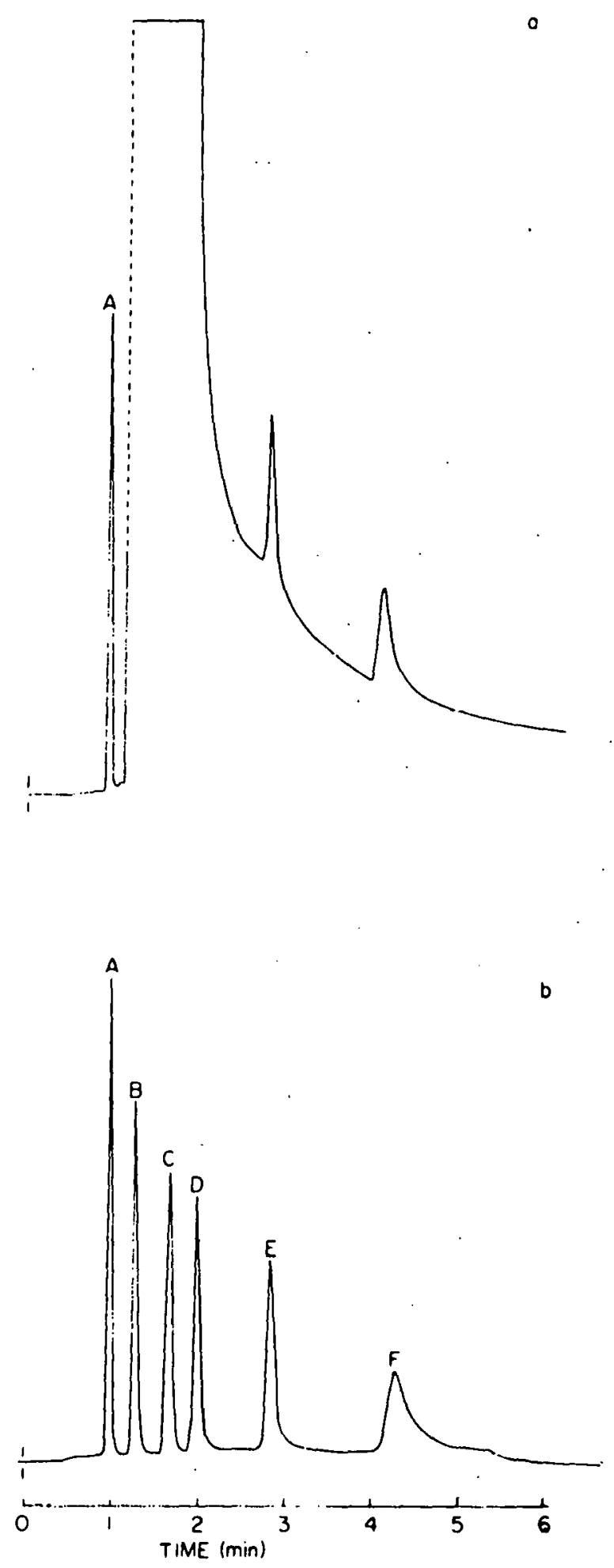
Figure 3. Chromatograms with (b) and without (a) abstractor column for a separation of ketones on a XAD-2 column. Sample components are: (A) acetone, (B) butanone, (C) 2-pentanone, and (D) 4-methyl2-pentanone. Temperature: Isothermal at $150^{\circ} \mathrm{C}$. 

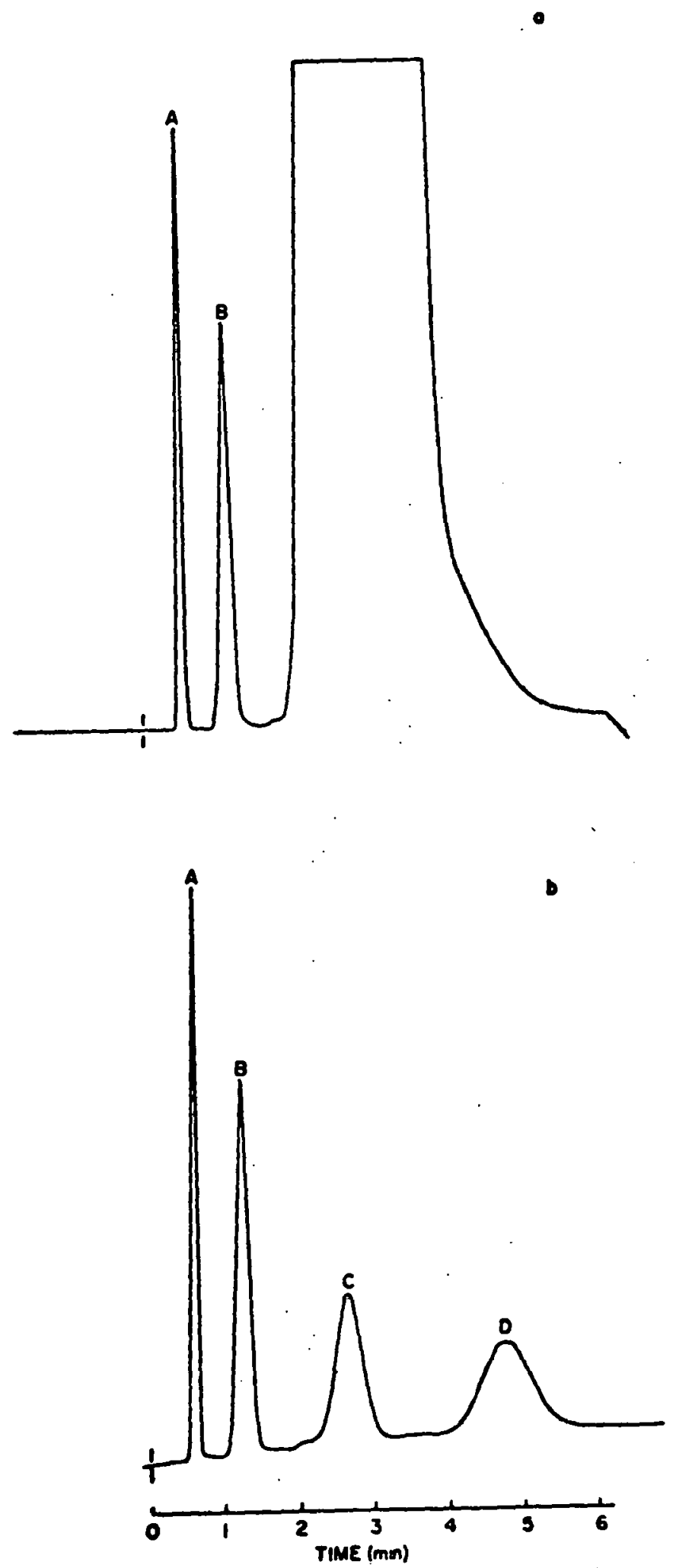
Figure 4. Chromatograms with (b) and without (a) abstractor column for a separation of volatile components extracted from Iowa coal with pyridine on a SE-30 column. Temperature: Initial temperature of $120^{\circ} \mathrm{C}$, programmed to $160^{\circ} \mathrm{C}$ at $32^{\circ} \mathrm{C} / \mathrm{min}$. 

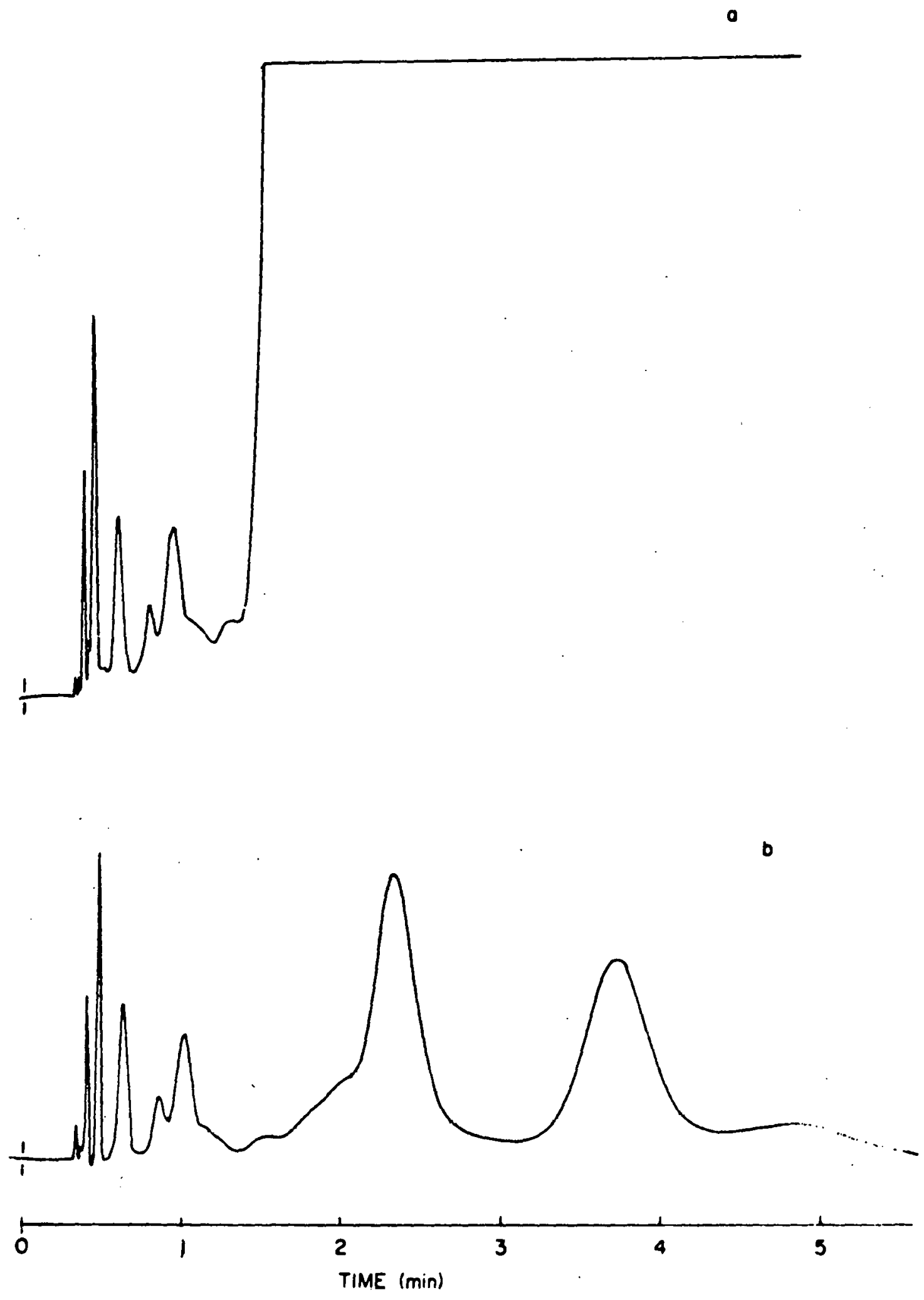
Iowa-coal extract are in Figure 4. This application demonstrates the usefulness of the abstractor column when Interferences caused by a solvent peak are to be avolded.

Organic compounds in synthet1c-water samples were concentrated on Amberlite XAD-2 and analyzed by gas chromatography. A solution containing $100 \mathrm{ppb}(\mu \mathrm{g} / 1)$ of benzene, toluene, ethylbenzene, Isopropylbenzene, butylbenzene, and naphthalene in triple-distilled water was analyzed. A 100-ml allquot of the synthetic-water sample was passed. through a 15-cm x 6-mm o.d. (4-mm 1.d.) column of XAD-2 by gas pressure. After removing excess water by passing gas through the resin bed, organic compounds were eluted with $2 \mathrm{ml}$ of pyridine. A 10-4l aliquot of the pyridine extract was infected into a gas chromatograph containing a SE-30 column in series with an abstractor column. All compounds were quantitatively recovered from the synthetic-water sample. Small amounts of water in the pyridine did not interfere with the chromatographic determination. Slow elution of water from the abstractor column and the low response of the flame lonization detector for water are factors that caused water present in the pyridine sample to have little effect on the gas chromatograms. Organic compounds can be eluted from XAD-2 with a smaller volume of pyridine than diethyl ether. Because diethyl ether solutions can be reduced in volume by distillation without significant 
losses of sample components, more sensitivity may be obtalned when using diethyl ether to elute XAD-2 columns than when using pyridine.

\section{Conclusions}

Columns packed with copper(II) chloride coated on Chromosorb G AW/DMCS have been shown to be effective when used as a pre-column to remove amine solvents from gaschromatographic streams. Chromatographic interferences caused by a solvent peak are eliminated by using the abstractor column and pyridine as the solvent for samples.

The abstractor columns could be used to gain information about the components of a sample or to simplify the chromatograms from complex mixtures. Techniques have been developed that use the selective abstraction of classes of compounds as a means of ldentifying sample components (15). Comparison of chromatograms with and without the amine abstractor would indicate which chromatographic peaks were caused by amines. It may be feasible to simplify the analysis of nonamine compounds in samples that have a large amount of amines. A possthie application may be to screen blological fluids for a potentially harmful substance such as benzene.

The ability of the abstractor packing to remove amines quantitatively from a gas stream indicates that the 
amine-abstractor column may be useful for concentrating amines. Chriswell used the abstractor packing to concentrate amines from water samples (23). Amines were purged from water samples with a flow of inert gas, then the amines were sorbed from the gas stream on the abstractor packing. Two techniques were used to quantify the amines sorbed on the amine packing. One technique of quantification was to measure the length of the band formed by the copper(II)amine complex. Alternatively, amines were eluted from the abstractor column with an aqueous potassium-hydroxide solution and analyzed by gas chromatography. 
DETERMINATION OF HALOFORMS IN WATER

Review of Related Work

In 1974 the presence of chloroform and other volatile halogenated hydrocarbons in drinking-water samples was reported (24). In 1975 a United States Environmental Protection Agency (USEPA) study of 79 cities indicated that chloroform and related halogenated hydrocarbons occur in virtually all chlorinated-drinking waters (25). The concentrations of halogenated hydrocarbons in drinking waters ranged from less than $1 \mathrm{ppb}(\mu \mathrm{g} / 1)$ to greater than $300 \mathrm{ppb}$. The amount of haloforms in drinking water is a matter of concern because recent information indicates that chloroform may be carcinogenic (26).

Rook suggested that chloroform and other volatile halogenated hydrocarbons are produced in drinking water by the reaction of chlorine with humic matter $(27,28)$. For purposes of this discussion, chlorine will refer to all oxidizing forms of chlorine present in water, including: chlorine, hypochlorous acid, hypochlorite ion, and chloramines. Rook investigated the production of haloforms by chlorinating humic matter from various sources. Experiments were also performed on chlorinating model compounds. The results of the experiments suggest chlorine reacts with the polyhydroxybenzene building blocks of humic matter to 
yleld chloroform. Bromide present in chlorinated-water samples was correlated with the presence of brominated haloforms.

Analysis of water for volatile halogenated hydrocarbons has most frequently been done by "purge and trap" techniques $(17,29,30)$. Essentlally, volatile compounds are purged from water samples with a gas stream, then sorbed from the gas stream onto a solid sorbent such as Tenax GC. By passing nitrogen, the heated sorbent compounds are eluted from the sorbent and introduced into a gas chromatograph. The gaschromatographic separation is usually monitored with a special type of conductivity detector. The Hall detector is an electrolytic-conductivity detector that is quite specific for halogenated compounds (31).

Sometimes a water sample is heated to speed up. strippling of volatile compounds. Kopfler et al. showed that heating to $95^{\circ} \mathrm{C}$ increased substantially the amount of haloforms obtained from chlorinated-water samples (29). The increased temperature increases the reaction rate of residual chlorine with organic matter. Using direct injections of water samples, Nickolson and Meresz observed similar results (32). By directly injecting chlorinatedwater samples into the hot injection port of a gas chromatograph, higher haloform concentrations were obtained than by the "purge and trap" technique. 
Rook partitioned haloforms between the aqueous phase and a gas phase, then analyzed an aliquot of the gas phase to determine haloforms in water samples $(27,28,33)$. Mieure (34) and Richard and Junk (35) have used solvent extraction to analyze water samples for haloforms. Although haloforms are not extracted from water quantitatively into a gas or organic phase, the efficiency of extraction can be determined and greater sensitivity obtained than by direct aqueous injection.

Th1s research effort had two objectives. One was the development of a new method for measuring the concentrations of haloforms in drinking waters. The second objective was to investigate the reactions that produce haloforms in chlorinated-drinking waters. Once the parameters affecting production of haloforms are understood, methods of handling samples can be implemented which will ensure that correct values are obtained for haloform concentrations.

\section{Experimentai}

Apparatus and reagents

Gas chromatograph A Tracor model 550 gas chromatograph equipped with a Iinear. temperature programmer, heated injection ports, and an electron capture detector (ECD) was used to determine haloforms in water extracts. The ECD was equipped with an electronic linearizer and nickel-63 as the 
ionization source. Chromatograms were recorded on a Houston Instruments series 5000 strip chart recorder.

Water-sampling apparatus The apparatus that was fabricated to pass water samples through small resin beds is shown in Figure 5. Connection of the sorption column was accomplished with glass connectors from Altex Scientific, Inc., Berkeley, California. The apparatus was pressure tested at 45 psig:

Sorption columns Glass columns, $10-\mathrm{cm} \times 4-\mathrm{mm} 1 . \alpha$. (2-mm i.d.), with Altex glass connectors on one end, were packed with acetyl XAD-2 (100/120 mesh). Before using the columns, the columns were conditioned by passing $20 \mathrm{ml}$ of pyridine through the column with a syringe.

Gas-chromatographic column A 6-ft $\times 1 / 4$-in $0 . d$. glass column was used in the gas chromatograph to separate samples containing haloforms. The 7-in portion of the column that fit into the injection port of the Tracor model 550 gas chromatograph was packed with 25\% copper(II) chloride coated on 100/120-mesh Chromosorb G AW/DMCS (19) and the remainder of the column was packed with $10 \%$ FFAP on 80/100-mesh Chromosorb W AW. Chromosorb G AW/DMCS and the FFAP coated phase were obtained from Applied Science Laboratories, Inc., State College, Pennsylvania.

Water Volatile organic compounds were purged from laboratory-distilled water with helium. A helium flow of 


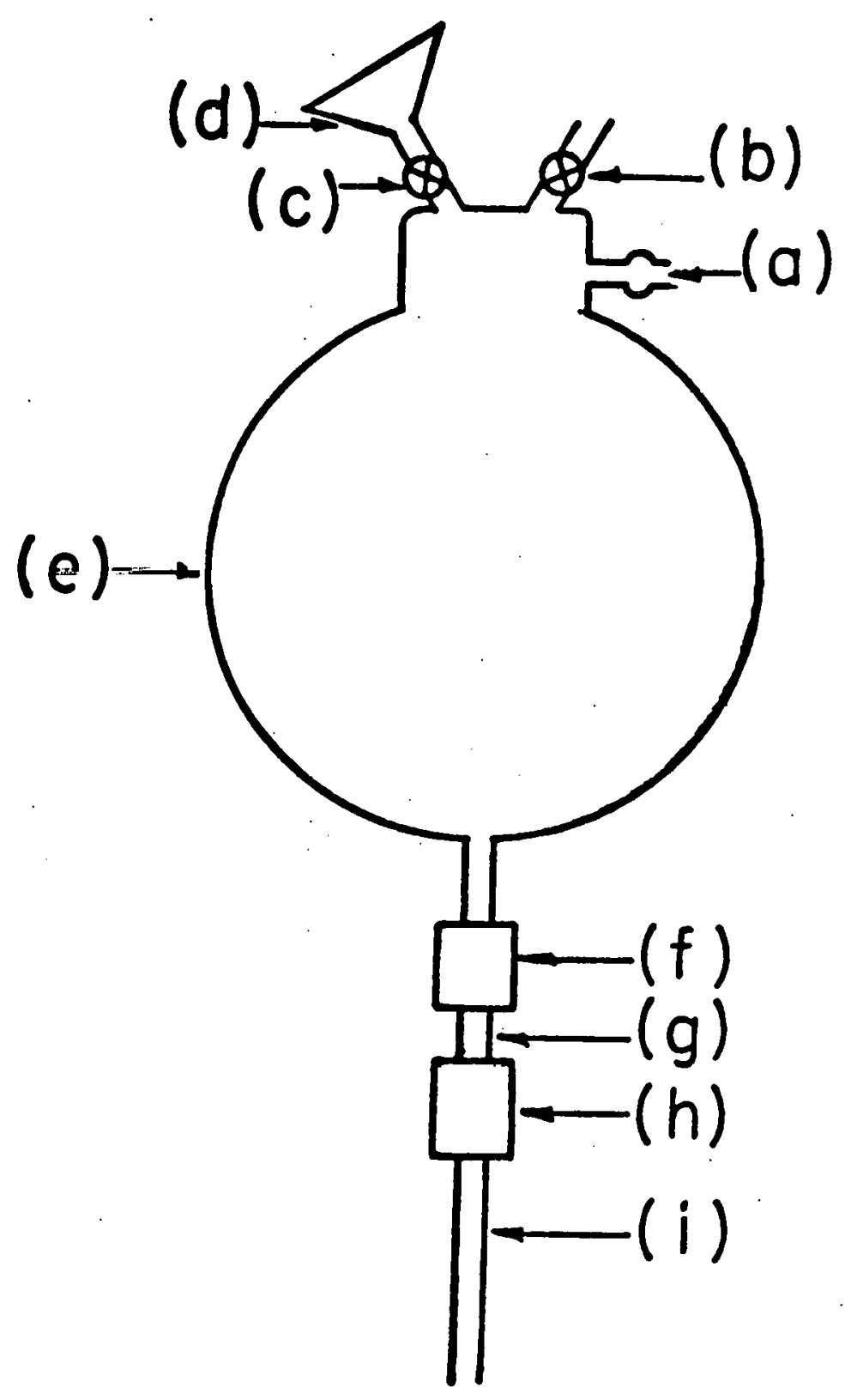

Figure 5. Apparatus for water sampling: (a) inlet for helium; (b) valve for gas venting; (c) valve for filling; (d) glass funnel; (e) 1-1 glass reservoir; ( $f$ ) Altex glass connector; ( $g$ ) Kel-F connector; (h) Altex glass connector; (1) 2-mm i.d. glass column. 
$90 \mathrm{ml} / \mathrm{min}$ was passed through $2 \mathrm{l}$ of water with a gas dispersion tip. Fresh water was prepared daily to ensure a low blank:

Reagents Pyridine, distilled-in-glass grade and stored under nitrogen, was obtained from Burdick and Jackson Laboratories, Muskegon, Michigan. The pyridine was stored until used in an automatic filling buret with a positive pressure of nitrogen.

L-Ascorbic acid and chloroform were obtained from Fisher Scientific Company, Fair Lawn, New Jersey. Bromodichloromethane and technical-grade humic acid were purchased from Aldrich Chemical Company, Inc., Milwaukee, Wisconsin. Dibromochloromethane was obtained from Columbia Organic Chemicals Company, Inc., Columbia, South Carolina and bromoform was purchased from Eastman Organic Chemicals, Rochester, New York.

Chlorine gas from Matheson Gas Products, East Rulherford, New Jersey, was used to make aqueous chlorine solutions.

Amberlite XAD-2 was obtained from Rohm and Haas, Philadelphia, Pennsylvania.

other materials and chemicals were the grade available within the laboratory. 
Techniques and procedures

Preparation of acetyl resin Amberlite XAD-2 was cleaned by. Soxhlet extraction with methanol for $24 \mathrm{hrs}$. The cleaned resin was dried, ground, and sieved. The 100/120mesh fraction was collected by dry sieving. Acetylation of the resin was performed under mild conditions using a method similar to that used by Moyers (36). To $4 \mathrm{~g}$ of XAD-2, $30 \mathrm{~g}$ of anhydrous aluminum trichloride, and $30 \mathrm{ml}$ of petroleum ether, $5 \mathrm{ml}$ of acetic anhydride was added slowly with stirring. The reaction mixture was heated to $50-60^{\circ} \mathrm{C}$ and stirred for 3 hrs. After allowing the reaction mixture to cool, the mixture was poured into a beaker containing hydrochloric acid and ice. The resin was filtered off and washed several times with concentrated hydrochloric acid and ammonium hydroxide.

Sample collection Glass bottles, $300 \mathrm{ml}$, with standard-tapered necks were filled to overflowing with as little aeration as possible. Standard-tapered stoppers were slowly inserted into the filled bottles to ensure that no air was trapped in the bottles. For chlorinated-water samples, $2 \mathrm{mg}$ of L-ascorbic acid was placed in the bottles before taking the samples.

Analytical procedure for determining haloforms in water Water samples, usually $100 \mathrm{ml}$, were passed through the sorption column using the sampling apparatus shown in Figure 
5. Hellum pressure was adjusted to give a flow rate of 5 to $10 \mathrm{ml} / \mathrm{min}$. After passing the water through the resin bed, approximately two liters of helium was passed through the column to remove excess water.

After removing the column from the sampling apparatus and connecting a luer adaptor to it, haloforms were eluted from the column with 1 inl of pyridine. A few microliters of the pyridine solution were analyzed for haloforms by gas chromatography with electron capture detection. While maintaining the injection-port temperature at $140^{\circ} \mathrm{C}$ and the column-oven temperature at $90^{\circ} \mathrm{C}$, haloforms were separated on a column with FFAP as the stationary phase. A flow of $10 \%$ methane in argon was maintained at approximately $60 \mathrm{ml} / \mathrm{min}$ to affect the separation. Haloforms from water samples were quantified by comparison of peak heights. Peak heights for haloforms from water samples were compared to peak heights for haloforms from standard samples.

Chlorine solution Chlorine gas was slowly bubbled through triple-distilled water for $5 \mathrm{~min}$. The chlorine solution was neutralized by adding sodium hydroxide. After allowing the chlorine solution to stand for $24 \mathrm{hrs}$, the chlorine in the solution was measured colorimetrically with $\mathrm{N}, \mathrm{N}$-diethyl-p-phenylenediamine (DPD). Chlorine quantitatively reacts with DPD to produce a color that can be 
measured at $515 \mathrm{~nm}(37,38)$. Bromine solutions were also analyzed using DPD.

Results and Discussion

Development of analytical technique

Copper(II) chloride coated on Chromosorb G AW/DMCS was packed into the first portion of the gas-chromatographic column to remove pyridine from the gas stream (19). Because haloforms are volatile and elute quickly from most gaschromatographic columns, removal of pyridine from the gaschromatographic stream eliminates interferences caused by large solvent peaks. When the abstractor packing is used to remove pyridine, resolution of the solvent from the components of a sample is not important. After the pyridine is removed from the gas-chromatographic stream, any gaschromatographic column that separates the haloforms from each other will provide the desired separation.

Pyridine is an effective solvent for eluting halof'orms from the resin bed. Haloforms were completely eluted from the sorption columns with $0.5 \mathrm{ml}$ of pyridine. Because haloforms were eluted from the resin bed with a small volume of pyridine, the concentrations of haloforms in the pyridine solution was much greater than the concentrations present in the water sample. To ensure that recovery of the haloforms 
from the sorption columns was complete, $1.0 \mathrm{ml}$ of pyridine was used to elute the sorption columns.

When the injection port was maintained at $140^{\circ} \mathrm{C}$, the abstractor packing would retain more than $60 \mu l$ of pyridine. Before the capacity of the abstractor packing was exceeded, the first section of the gas-chromatographic column was replaced with fresh abstractor packing.

Although ordinary $X A D-2$ resin could be used to recover haloforms from water samples, better recoveries were obtained using the acetyl resin. Low recoveries for haloforms using XAD-2 were confirmed by Chang (16). Using water samples containing $0.5 \mathrm{ppb}$ of each haloform, Chang observed $56,68,80$, and $98 \%$ recoveries from chloroform, bromodichloromethane, dibromochloromethane, and bromoform, respectively. A potassium-bromide pellet was made of the acetyl resin, then the pellet was analyzed by infrared spectroscopy. Only a small band for a carbonyl group was present at $1685 \mathrm{~cm}^{-1}$ on the infrared spectrum of the peliet which indicates only a few acetyl groups were introduced to the resin. The low yield of acetyl groups and the lack of an apparent mechanism for haloforms to interact with the acetyl groups indicate that the increased recoveries were a result of changes in the surface or pores of the resin. Incomplete recoveries of the haloforms were also observed with XAD-4, XAD-7, XAD-8. amd XAD-11 resins. 
Stock solutions of haloforms were made with methanol as the solvent. A few microliters of the stock solutions were added to triple-distilled water to produce dilute aqueous solutions of the haloforms. At concentrations between 100 and $0.1 \mathrm{ppb}$, haloforms were essentially quantitatively recovered from $100 \mathrm{ml}$ of water. Ultimate detection limits for haloforms can be reduced to below $0.1 \mathrm{ppb}$ by altering the gas-chromatographic conditions or using a larger water sample. Using a column-oven temperature of $90^{\circ} \mathrm{C}$, the limit of detection for chloroform was imposed by the presence of an impurity peak from the pyridine.

The amounts of haloforms found in water samples from various central-Iowa cities are shown in Table 2 . The data in Table 2 indicate that concentrations of haloforms in various water supplies are very different. A typical chromatogram for an extract of a water sample is shown in Figure 6. Water from a tap in the laboratory was collected and analyzed on eeveral days in January 1976. The data in Table 3 demonstrate the daily variations of haloform concentrations in water samples from a single source. Water source and sampling time are two variables that affect the haloform concentrations. In general, the range of haloform concentrations in water samples from a single source was small compared to range of haloform concentrations from water samples from various sources. 
Table 2. Concentration of haloforms (in $\mathrm{ppb}$ ) in centralIowa cities on January 15, 1976

\begin{tabular}{|c|c|c|c|c|}
\hline City & $\mathrm{CHCl}_{3}$ & $\mathrm{CHBrCl}_{2}$ & $\mathrm{CHBr}_{2} \mathrm{Cl}$ & $\mathrm{CHBr}_{3}$ \\
\hline Huxley & 28.3 & 7.1 & 11.0 & 1.0 \\
\hline Slater & 16.0 & 4.8 & 4.2 & --- \\
\hline Ankeny & 9.7 & 1.2 & 3.2 & --- \\
\hline Clive & 6.8 & 0.1 & --- & --- \\
\hline Des Moines & 22.5 & -- & -- & -- \\
\hline Altoona & 10.9 & --- & --- & $-\infty$ \\
\hline Marshalltown & 7.0 & --- & --- & -- \\
\hline Ncvada & 13.8 & --- & -- & -- \\
\hline
\end{tabular}

Table 3. Concentration of haloforms (in $\mathrm{ppb}$ ) in laboratory tap water

\begin{tabular}{lcccc}
\hline Date & $\mathrm{CHCl}_{3}$ & $\mathrm{CHBrCl}_{2}$ & $\mathrm{CHBr}_{2} \mathrm{Cl}$ & $\mathrm{CHBr}_{3}$ \\
\hline $1 / 6 / 76$ & 19.6 & 1.2 & 1.7 & -- \\
$1 / 7 / 76$ & 13.1 & 4.0 & 7.1 & 1.4 \\
$1 / 8 / 76$ & 12.3 & 5.5 & 8.6 & 2.3 \\
$1 / 12 / 76$ & 20.3 & 5.9 & 9.1 & 1.4 \\
$1 / 13 / 76$ & 13.8 & 4.8 & 8.6 & 1.4 \\
\hline
\end{tabular}




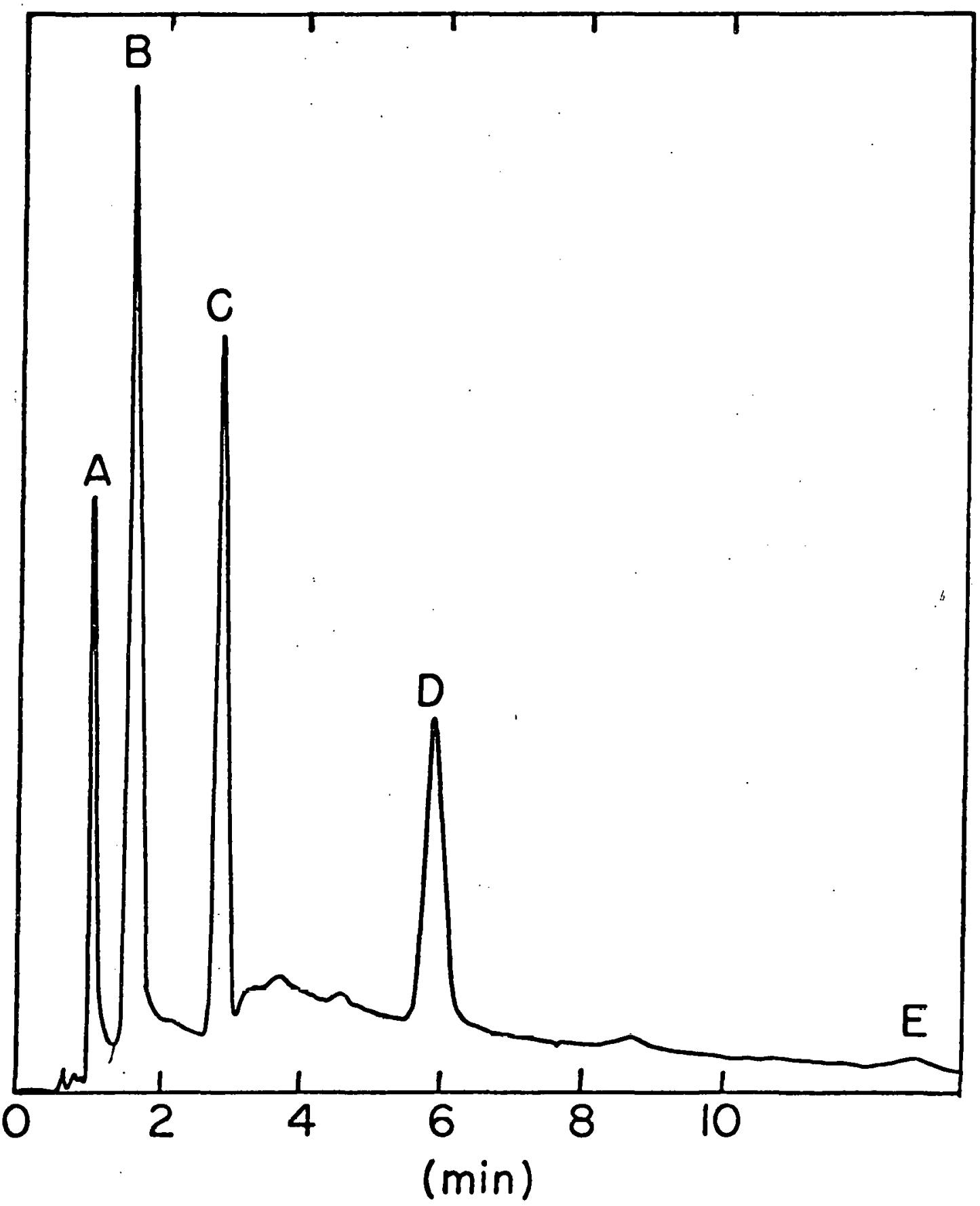

Figure 6. Chromatogram of haloforms from drinking water distributed in Huxley, Iowa. Sample components are: (A) solvent Impurity; (B) chloroform

(2I ppb); (C) bromodichloromethane (7 ppb);

(D) dibromochloromethane (1I ppb); and

(E) bromoform ( $\sim \mathrm{ppb}$ ). 
Storage of water samples

Because the haloforms are only slightly soluble in water and are quite volatile, haloforms in water samples can be lost to the gas phase. A study by the USEPA in 1975 considered this point and noted some losses for water samples stored 20 to 30 days (29). Results in Table 4 show a substantial increase in haloform concentrations when chlorinated-water samples were stored. Because the concentrations of haloforms in water samples may change during storage, concentrations of haloforms in stored samples may not reflect the concentrations of haloforms in the samples at the time the samples were collected.

Addition of a small amount of ascorbic acid to a water sample reduces all chlorine present in a water sample. Data in Tables 4 and 5 show that the concentrations of haloforms In water samples can be retained for long periods of time. Removing residual chlorine from a water sample ensures that no haloforms are produced in the sample during storage. Storage of water samples in bottles without a head space and with ascorbic acid ensures that the haloform concentrations are preserved. Changes in haloform concentrations resulting from volatilization and production are eliminated when proper conditions for storage of water samples are used. 
Table 4. Concentrations of haloforms in laboratory tap water during storage

\begin{tabular}{lcccc}
\hline Compound & $24 \mathrm{hr}$ & $60 \mathrm{hr}$ & $24 \mathrm{hr}$ ascorbic & $60 \mathrm{hr}$ ascorbic \\
\hline & $\%$ recovery & $(0 \mathrm{hr}=100 \%)$ & \\
$\mathrm{CHCl}_{3}$ & 111 & 133 & 95 & 95 \\
$\mathrm{CHBrCl}_{2}$ & 148 & 156 & 96 & 93 \\
$\mathrm{CHBr}_{2} \mathrm{Cl}$ & 160 & 170 & 100 & 90 \\
$\mathrm{CHBr}_{3}$ & Present & Present & Absent & Absent \\
\hline
\end{tabular}

Table 5. Concentrations of haloforms in selected drinking waters during storage with ascorbic acid

\begin{tabular}{lccccc}
\hline \multirow{2}{*}{ Source } & & \multicolumn{4}{c}{$\%$ Recovery $(0 \mathrm{hr}=100 \%)$} \\
\cline { 3 - 6 } Slater, Ia & 2 & 94 & 100 & 100 & 100 \\
& stored & $\mathrm{CHCl}_{3}$ & $\mathrm{CHBrCl}_{2}$ & $\mathrm{CHBr}_{2} \mathrm{Cl}$ & $\mathrm{CHBr}_{3}$ \\
\hline \multirow{2}{*}{ Huxley, Ia } & 2 & 94 & 100 & 100 & 100 \\
& 6 & 92 & 90 & 100 & 75 \\
& 4 & 97 & 90 & 94 & 100 \\
ISU & 6 & 95 & 99 & 94 & 100 \\
& 2 & 100 & 97 & 100 & 100 \\
& 4 & 91 & 92 & 100 & 100 \\
& 4 & & & & \\
\hline
\end{tabular}


A detalled study was performed in which water samples from an Iowa State University tap were analyzed for each of the four haloforms. The samples were carefully stored without head space and in the dark. Results of daily analysis of the water samples are in Flgure 7. The chloroform concentration reached a maximum at three days, then the chloroform concentration began to decrease. The concentrations of the two bromo-chloro compounds increased and gradually leveled off, while the concentration of bromoform increased substantially over the entire storage time. Figure 8 shows that the total-molar concentration of the haloforms inftially increased, then gradually decreased. Water samples from two other central-Iowa cities showed somewhat similar changes; but it should not be concluded that all drinking waters will behave similarly. The increase of total-haloform concentration with time suggests that the water samples contained organic matter that reacted with residual chlorine or bromine to produce additional haloforms. The decrease in chloroform concentration after 3 or 4 days together with the increase in concentration of chloro-bromo compounds and bromoform suggests that an exchange reaction may be taking place in which chloroform is converted to brominated haloforms. 


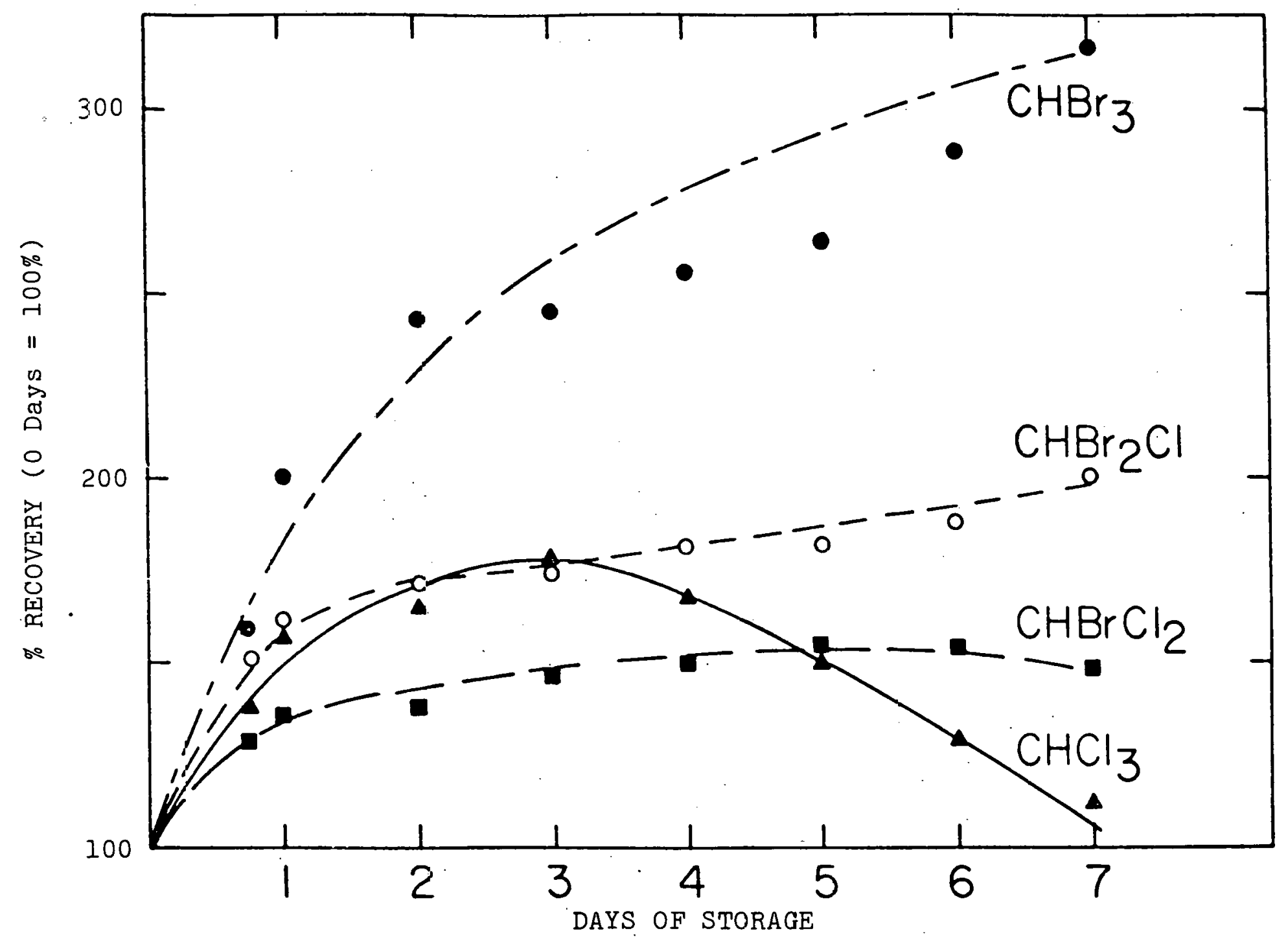

Figure 7. Changes in inaloform concentrations on storaze 


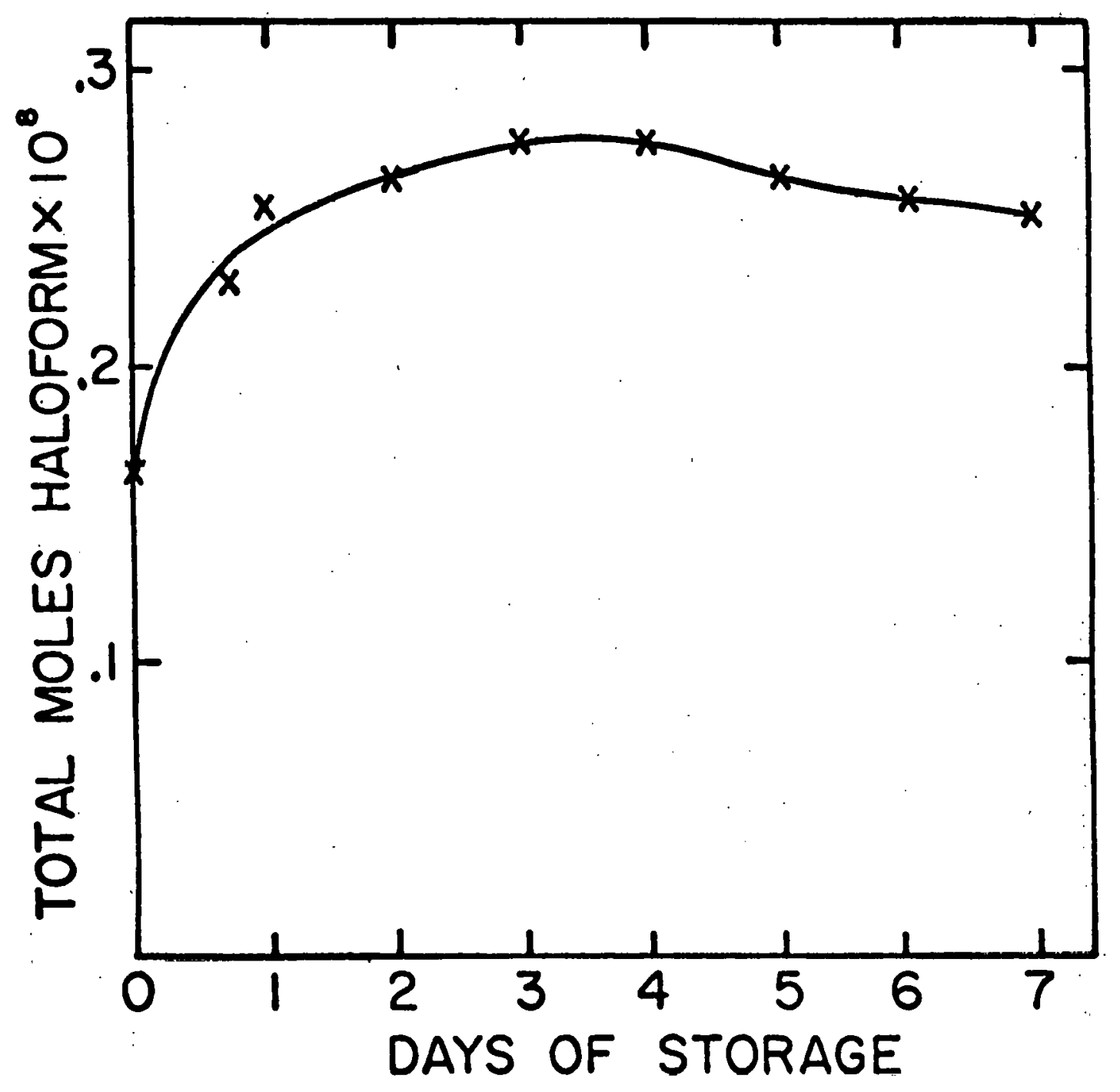

Figure 8. Change in total moles of haloforms per liter on storage 
Experiments on haloform production and exchange reactions Several experiments were performed in which tripledistilled water containing chloride, bromide, and/or humic acid approximating levels found in drinking waters were treated with chlorine or bromine. The results of these experiments are shown in Table 6 . Water containing humic acid and bromide reacted with chlorine to produce all four haloforms. Addition of bromine to water samples containing humic acid and chloride resulted in the production of only bromoform. Since it is more difficult to oxidize chloride than bromide, these results indicate that the oxidized form of the halogen is involved in the haloform production reaction.

Halogen-exchange reactions are indicated by experiments 4 and 8 of Table 6 . Although exchange of chlorine for bromine was observed in the presence of chlorine, experiments 5 and 9 demonstrate that production of brominated haloforms by an exchange reaction does not occur if only bromine is present. Experiment 6 shows that bromide ion alone is not capable of exchanging with the chlorine atoms of chloroform. 
Table 6. Experiments on haloform production and exchange reactions

\begin{tabular}{|c|c|c|c|c|c|c|}
\hline Exp. & No. & Reactions ${ }^{a}$ & $\mathrm{CHCl}_{3}$ & $\mathrm{CHBrCl}_{2}$ & $\mathrm{CHBr}_{2} \mathrm{Cl}$ & $\mathrm{CHBr}_{3}$ \\
\hline 1 & & $\mathrm{HA}, \mathrm{Br}^{-}, \mathrm{Cl}_{2}$ & + & + & + & + \\
\hline 2 & & $\mathrm{HA}, \mathrm{Br}_{2}$ & & & & + \\
\hline 3 & & $\mathrm{HA}, \mathrm{Br}_{2}, \mathrm{Cl}^{-}$ & & & & + \\
\hline 4 & & $\mathrm{CHCl}_{3}, \mathrm{Br}^{-}, \mathrm{Cl}_{2}$ & + & + & + & + \\
\hline 5 & & $\mathrm{CHCl}_{3}, \mathrm{Br}_{2}$ & + & & & \\
\hline 6 & & $\mathrm{CHCl}_{3}, \mathrm{Br}^{-}$ & + & & & \\
\hline 7 & & $\mathrm{CHCl}_{3}, \mathrm{Cl}_{2}$ & $t$ & & & \\
\hline 8 & & $\mathrm{CHBrCl}_{2}, \mathrm{Br}^{-}, \mathrm{Cl}_{2}$ & & + & + & + \\
\hline 9 & & $\mathrm{CHBrCl}_{2}, \mathrm{Br}_{2}$ & & + & & \\
\hline
\end{tabular}

${ }^{a}$ Concentration of reactants: $\mathrm{Cl}_{2}, \mathrm{Br}_{2}$, and $\mathrm{HA}$ (humic acid) - $5 \mathrm{ppm} ; \mathrm{Br}^{-}-2 \mathrm{ppm} ; \mathrm{Cl}^{-}-50 \mathrm{ppm} ; \mathrm{CHCl}_{3}$ and $\mathrm{CHBr}^{\circ} \mathrm{Cl}_{2}-5 \mathrm{ppB}$. Reaction time - 4 days. 
Conclusions

Trace concentrations of haloforms can be quantitatively removed from water and determined by the described method. Addition of a reducing agent, such as ascorbic acid, to water samples stops the production of haloforms, allowing the instantaneous concentrations of haloforms in water samples to be measured accurately. Results obtained from analysis of water samples that have not been properly stored mà be in error.

Because the reactants are present in water distributed by a water utility, water used by consumers may have greater concentrations of haloforms than the water leaving the utility. Daily and seasonal variations of haloform concentrations in a water supply are expected, because of changes in water temperature, humic content, chlorine dose, and chlorine-contact time. Because consumption of haloforms could be harmful to human health, more must be learned about the patterns of concentration changes that occur from the time chlorinated water enters the distribution system until 1t is used by the consumer. The harmful effects of haloforms must be evaluated versus the beneficial effects of chlorination. Chlorination of arinking water has been extremely effective for control of water-borne diseases. Investigations of water treatment practices should provide 
for treatment techniques that produce a disinfected water with lower concentrations of haloforms. 
CAPILLARY-COLUMN SYSTEM FOR GAS CHROMATOGRAPHY

Review of Related Work

The use of wall-coated open tubular (WCOT) columns for gas chromatography was first reported by M. J. E. Golay in 1957 (39). Golay developed the method of preparing smallbore ( 0.01 to 0.03 inch) columns with the inner surface coated with a stationary phase. Although WCOT columns were develuped many ycaro ago, only recently has the use of capillary columns become widespread. The following are reasons for the 3 low acceptance of caplllary-column gas chromatography: poor quality of commerclally available columns, difficulty of preparing WCOT columns, the small sample capacity of capillary columns, and problems related to connection of small columns to inlets and exits of common gas chromatographs (40). Because many of the problems related to capillary-column gas chromatography have been overcome and the high efficiency offered by capillary columns, many laboratorles have turned to caplliary columns to analyze complex mixtures.

Since the work of Golay, many researchers have worked in the area of preparing stable, efficient, and inert capillary columns for gas chromatography. Many researchers have worked in the area of preparing WCOT columns from small-bore metal tubing $(41,42)$. Because 
metal tubing has good mechanical strength and can easily be bent, many researchers felt that metal tubing was 1deal for preparation of capillary columns. However, interactions between sample components and the hot metal surfaces of the column caused peaks for some compounds to be talled. Although small-bore glass tublng has much less mechanical strength then metal tublng, most WCOT columns are presently prepared from glass tubing.

In order to prepare satisfactory WCOT columns from glass tubing, methods of treating the inner surface of the tubing were developed. Hydrochloric acid is usually used to etch the inner surface of glass tubing to increase 1ts surface area $(43,44)$. Because the amount of liquid phase in a WCOT column is small, methods to increase the surface area of the glass tubing have been investigated. Sodium-chloride crystals have been deposited $(45,46)$ and silica whiskers. have been formed $(47,48)$ on the inner surface of the glass tubing to increase the surface areas of giass columns. To improve the capacity of capillary columns, some researchers have produced porous-layer open tubular (PLOT) and supportcoated open tubular (SCOT) columns. The inner surface of a PLOT column is very porous and is coated with a film of stationary phase (49). A SCOT column is produced by coating the walls of a column with a slurry of finely divided packing material from a solution of the stationary phase (50). 
Because the surface areas of SCOT and PLOT columns are greater than WCOT columns, SCOT and PLOT columns have greater sample capacities than WCOT columns. In general, PLOT and SCOT columns have fewer theoretical plates than WCOT columns.

The problems caused by reactivity of glass surfaces and poor adhesion of stationary phases to glass have been approached in numerous ways. Hydroxyl sites on the surfaces of glass columns cause peaks for many compounds to be tailed. Silanization of the glass with trimethylchlorosilane, dimethyldichlorosilane, or hexamethyldisilazane will remove the hydroxyl sites from the surface of glass (22). An added advantage of silanization is that the polar character of the glass surface is reduced, which increases the adhesion of most stationary phases.

The small capacity of a capillary column was considered to be a problem when applying capillary columns to trace analysis. In order to keep the amount of material injected Into a capillary column small enough to avoid overloading the column, splitters were designed to vent most of the sample to the atmosphere. When large split ratios are used, the detection limit with capillary columns is not as low as can be obtained with packed columns. Grob developed a technique that overcomes the problems assoclated with the application of capillary columns to trace analysis. The 
technique is commonly referred to as Grob splitless or splitless injection. Injection of samples onto a capillary column is done through an injection port without venting any of the carrier-gas flow $(51,52)$. After a short interval of time, the inlet is backflushed with a flow of carrier gas to remove the last traces of the injected sample.

Grob showed that by proper selection of the solvent for injection of samples onto a column, the efficiency of a chromatographic system will be greater. with a splitless injection than with a split injection (52). The apparent efflciency of a capillary column may be greater when splitless injection is used, because sample components are concentrated on the column in a plug of solvent. The solvent plug forms over the first few plates of the column. Sample components start to move through the column after the solvent plug is totally volatilized. To eliminate broadening of peaks because of nonplug injection, the injection port is backflushed with carrier gas before the solvent plug evaporates. Although the column capacity is exceeded by the solvent, the sample components are retained in the solvent plug until the overload condition no longer exists. The technique cannot be used if the amount of any sample component will exceed the capacity of the column. Grob has further developed the technique of splitless injection for on-column sample introduction (53). By introducing a sample 
directly onto a column, problems caused by volatilization of the sample are avolded.

The specificity and the sensitivity of detectors used for gas chromatography are different; thus, chromatograms with more than one detector are often obtained for a sample. Rather than perform a separation twice, various types of exit splitters have been developed. The objective of an exit splitter is to simultaneously introduce a fraction of the column effluent to two or more detectors. In order to retain the separation that has been achieved on a capillary column, the void volume of the exit splitter. must be kept to a minimum and the linear-flow rate in all parts of the exit splitter must be greater than in the chromatographic column. Because of the mechanical strength of metal, exit splitters are often fabricated from metal. Oak et al. described an exit splitter fabricated from various lengths of capillarybore, 1/16-in o.d., stainless-steel tubing connected to a colum with a tee (54). By changlng the lengths of tubing used for connecting the column to the detectors, the ratio of the amount of column effluent going to each detector was varled. Etweiler and Nauner-Jahle used an exit splitter fabricated from platinum capillaries to split the effluent from a capillary column to an electron capture detector (ECD) and a flame ionization detector (FID) (55). Secondary pressures of carrier gas were applied to each platinum 
capillary to vary the exit-split ratio. A major disadvantage of using metal for an exit splitter is that the metal surfaces of the exit splitter may cause talling or loss of some compounds eluted from the column.

\section{Experimental}

\section{Apparatus}

Gas chromatograph A Tracor model 550 gas chromatograph equippcd with a dual flame ionization detector, linearized electron capture detector, heated infection ports, and temperature programmer was modified for operation with capillary columns. Figure 9 shows a flow diagram of the system used with the gas chromatograph to allow the use of capillary columns.

Columns WCOT columns made from glass were purchased from $J$ \& W Scientific Company, Inc., Orangevale, California. The columns had an internal diameter of about $0.25 \mathrm{~mm}$, an external diameter between 0.8 and $1.1 \mathrm{~mm}$, and were purchased in 30-m lengths. The columns were guaranteed to have in excess of 50,000 effective theoretical plates $\left(\mathrm{N}_{\mathrm{EFF}}\right)$ as calculated from the equation below.

$$
\begin{aligned}
\mathrm{N}_{\mathrm{EFF}}= & 5.54\left(\frac{\mathrm{t}_{\mathrm{R}}^{\prime}}{\mathrm{PWHH}}\right)^{2} \\
\mathrm{t}_{\mathrm{R}}^{\prime}= & \text { Adjusted Retention Time = (Retention } \\
& \text { Time) - (Retention Time for Non- } \\
& \text { Retained Substance) } \\
\text { PWHH }= & \text { Peak Width at Half Height }
\end{aligned}
$$


The columns were supported in the chromatographic oven by a $1 / 8-$ in stainless-steel rod. Brackets were placed by the injection port and detector ports to secure the rod.

Inlet system The inlet system for the Tracor 550 GC used with capillary columns was similar to the inlet system designed by German and Horning (56). Modifications were made in the inlet system to monitor the head pressure on the capillary column and to allow sample introduction by the splitless-injection technique. Detalls of the inlet system are shown in the top portion of Figure 9. Capillary glass tubing, 6-mm o.d., I-mm 1.d., was used in the injection port to protect the sample from hot-metal surfaces and to reduce the void volume in the inlet. If the capillary column had an external diameter greater than $1 \mathrm{~mm}$, a special plece of glass was used to sleeve the infection port. This sleeve was a $1 \frac{1}{2}-$ in segment of $2-\mathrm{mm} 1 . \alpha ., 6-\mathrm{mm}$ o.d. tubing butted to a $6 \frac{1}{2}-$ in segment of $1-\mathrm{mm}$ i.d., 6-mm o.d. tubing. The capiliary columns were connected to the $2-\mathrm{mm} 1 . \mathrm{d}$. end of this injection-port sleeve. To remove active sites from the surfaces of the glass sleeves, the sleeves were submerged in five-percent solutions of hexamethyldisilazane in toluene overnight.

The tee that was used to connect the infection-port sleeve, the split-exit line, and the caplllary column was fabricated from a 1/16-in to 1/4-1n Swagelok Reducing Union and a 1/16-in to 1/8-1n Swagelok Reducing Union. The 1/16-in 
Figure 9. Cap1llary-column system

\begin{tabular}{|c|c|}
\hline $1,2,3$ & Nupro ${ }^{T M}$ micro-needle valve (stainless-steel) \\
\hline 4,5 & Whitey ${ }^{\mathrm{TM}}$ shut-off valve, toggle type (brass) \\
\hline 6 & Whitey ${ }^{\mathrm{TM}} 3$-way valve (brass) \\
\hline 7 & Rotometer (plastic) \\
\hline 8 & Pressure gauge (brass) \\
\hline 9 & Septa retalner nut (brass) \\
\hline 10 & Connector (brass) \\
\hline 11 & Heated inlet zone (aluminum) \\
\hline 12 & Injection port (stalnless-steel) \\
\hline 13 & Injection-port sleeve (glass) \\
\hline $14,15,16$ & 1/4-in Swagelok nut (brass) \\
\hline 17,18 & $\begin{array}{l}\text { 1/4-1n, } 1 / 8-\text { in, } 1 / 16-1 \text { in Swage lok tee } \\
\quad \text { (stainless-steel) }\end{array}$ \\
\hline 19,20 & 1/16-in Swagelok nut (brass) \\
\hline 21,22 & $1 / 8$-in Swagelok nut (brass) \\
\hline 23 & WCOT capillary column (elass) \\
\hline 24 & Exit splitter body (glass) \\
\hline 25 & 1.5-mm Rod (stainless-steel) \\
\hline 26 & 1/8-in Tubing (stainless-steel) \\
\hline 27 & Heated detector zone (stainless-steel) \\
\hline 28 & Heated column oven (a1r) \\
\hline
\end{tabular}




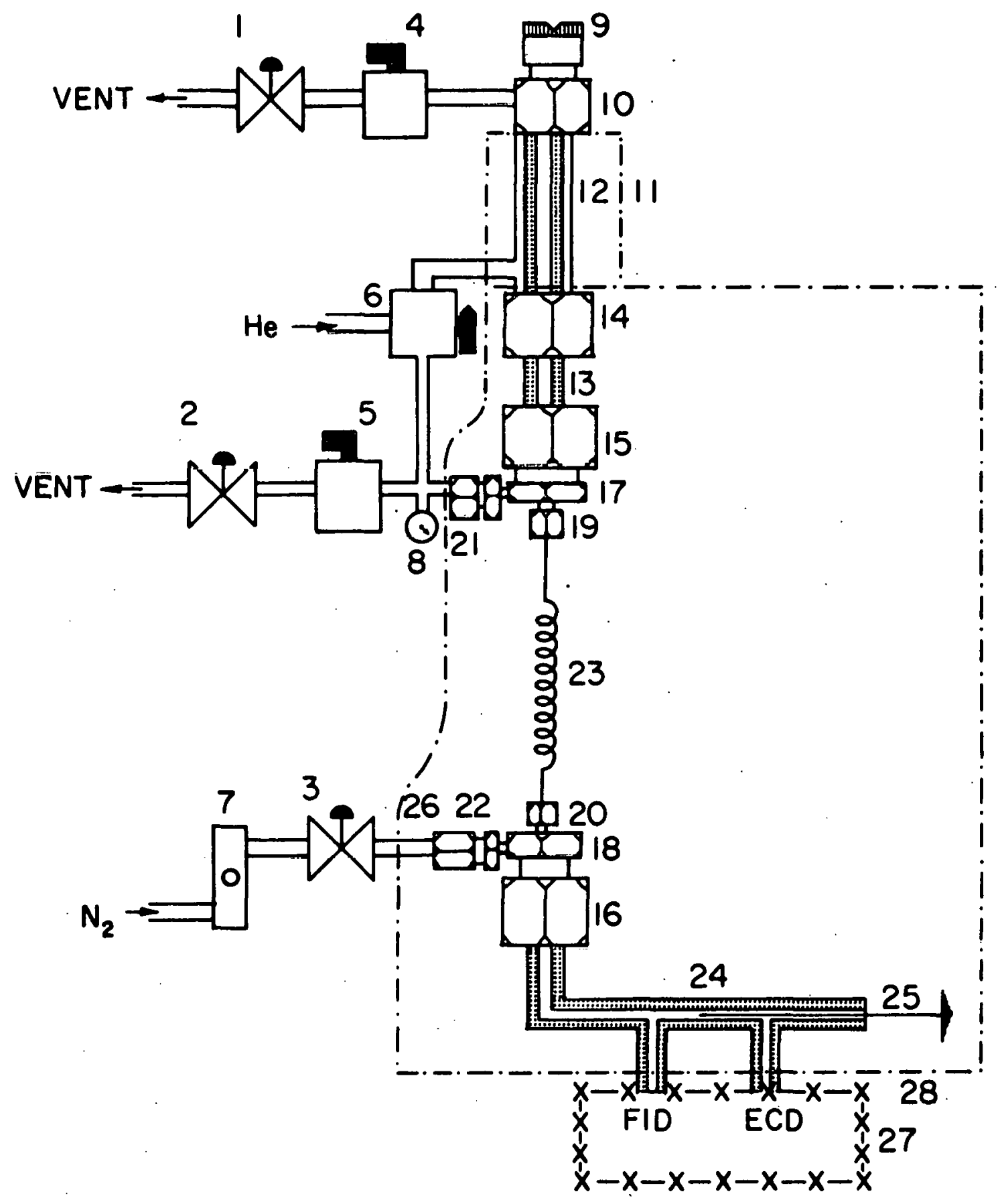


end of the $1 / 16-$ in to $1 / 8-1$ in Swagelok Reducing Union was turned down to a diameter of $1 / 8-i n$, inserted into a hole that was drilled in the side of the $1 / 16-$ in to $1 / 4-$ in Swaglok Reducing Union, and silver soldered into place. The injection-port sleeve was connected to the 1/4-1n Swagelok fitting of the tee, the capillary column was connected to the 1/16-in Swagelok fitting of the tee, and a segment of $1 / 8$-in stainless-steel tubing to carry the split flow was connected to the 1/8-in Swagelok fitting of the tee.

Graphite ferrules were used to seal glass tubing to Swagelok fittings. Brass ferrules were used to seal metal tubing to Swagelok fittings.

Exit interface The exit of the capillary columns was coupled to the detectors of the Tracor 550 GC with a 1/4-in, 1/8-in, 1/16-in Swagelok tee and a 3-in segment of 1-mm capillary glass tubing $(6.5-\mathrm{mm}$ o.d.). The Swagelok tee was fabricated in the same manner as the one used on the inlet systerl. The capillary glass tubing was inserted into the detector port of the $\mathrm{GC}$ and connected to the 1/4-in Swagelok fitting of the tee. Prior to use in the GC, the $1-\mathrm{mm}$ capillary glass tubing was submerged in a five-percent solution of hexamethyldisilazane in toluene overnight to remove hydroxyl sites from the glass surface. The exit Interface was used to connect the caplilary column to either the FID or the ECD. The capillary column was connected to 
the 1/16-in Swagelok f1tting of the tee and nitrogen was added through the 1/8-in Swagelok fitting of the tee.

Vespal ferrules were used to produce seals between the caplliary glass tubing and Swagelok fittings. The capillary column was sealed to the Swagelok tee with a graphite. ferrule. Make-up gas was added through a 1/8-1n tube connected to the Swagelok tee with the ald of brass ferrules. Exit splitter Instead of using the exit interface, a glass exit splitter that allowed the split ratio to be varled was used. The ECD and FID were connected to capillary columns with the exit splitter. A model 41-364a exit splitter from Sclentific Glass Engineering, Inc., North Melbourne, Australia, was modified to provide a low-volume connection to both detectors. The design of the exit splitter is shown in the lower portion of Figure 9. The design of the exit splitter minimizes contact of the sample with metal surfaces. With the Tracor $550 \mathrm{GC}$, the sample contacts metal surfaces in the detectors. The body of the exit splitter was 8-mm o.d., 1.5-mm 1.d. glass tubing. The glass tubing golng to the detectors and capillary column from the exit splitter was 6-mm o.d., 1-mm 1.d. The capillary column was connected to the exit splitter and the make-up gas line using a 1/4-in, 1/8-in, 1/16-in Swagelok tee. A 1.5-mm stainless-steel rod fit into the bore of the exit splitter allowing the split ratio to be varled. Pushing the rod into 
the splitter increased the fraction of the column effluent going to the FID and pulling the rod from the splitter increased the fraction of the column effluent. golng to the ECD.

Glass surfaces of the exit splitter were treated by submerging the glass in a five-percent solution of hexamethyldisilazane in toluene overnight. Seals to the detector ports for the FID and ECD and seals to the 1/4-in, 1/8-in, 1/16-in Swagelok tee were made with graphite ferrules.

Techniques and procedures

Installing the WCOT caplllary columns In order to use capillary columns from $J$ \& W Scientific Company, Inc. with the system for the Tracor $550 \mathrm{GC}$, it was necessary to stralghten the ends of the capillary columns. A 2-1n portion on each end of the columns was made perpendicular to the colls of the column. The straightened ends were connected to the inlet system and the exit interface or exit splitter.

The first step in bending the capillary column was to clean the portion of glass to be stralghtened with a paper tissue that had been thoroughly molstened with methanol. If the glass was not cleaned before bending, the glass became brittle and often broke during installation.

While supporting the column in a horizontal position, a fuel-rich flame from a microburner was used to straighten the lower end of the capillary column. The other end of the 
column was connected to a source of helium. A helium flow through the column was maintained during the bending procedure to remove degradation products from the stationary phase. The last 3-in portion of the column was bent perpendicular to the colls of the column by slowly working the cool flame of the microburner from where the bend was to be started to the end of the column. Gravity caused the section of the capillary column to straighten perpendicular to the coils of the column. The column was turned over and this procedure was repeated on the other end of the capillary column.

To ensure the glass surface of the column was covered by stationary phase, the sections of the column that were heated were recoated. The ends of the capillary column were coated by the dynamic coating method (57). A 0.5 -percent solution of the stationary phase in methylene chloride was repeatediy introduced and withdrawn from the column ends with a syringe. The syringe was connected to the column ends with heatshrinkable Teflon tubing.

The column was connected to the $1 / 16-1$ in Swagelok fittings of the inlet system and the exit interface or exit splitter using graphite ferrules. Graphite ferrules that fit $1 / 16-$ in Swagelok fittings and accept $0.8-\mathrm{mm}$ tubing are avallable from J \& W Sclentific Company, Inc., Orangevale, California. Both the inlet and exit ends of the caplliary columns were inserted 
through the Swagelok tees and about $1 / 2$ in into the glass tubing of the inlet system, exit interface, or exit splitter. By inserting the capillary column into the glass tubing, the sample was protected from hot-metal surfaces. The coaxial Insertion of the capillary column into the injection-port sleeve produced an annular split when the inlet system was used in the split mode.

Operation of the inlet system in the split mode When the inlet system was used in the split mode, valve 6 in Figure 9 was set to provide helium pressure on the septum side of the infection-port sleeve. Valve 4 was closed and valve 5 was opened. By adjusting needle valve 2 , the portion of the carrier gas that was vented before the capillary column was established.

To maximize the efficiency of the capillary-column system, the flow rate of carrier gas through the column was adjusted. By adjusting the helium pressure applied to the column, the maximum number of theoretical plates from the caplllary columns were obtalned. When needle valve 2 was adjusted, the flow rate of carrier gas through the injectionport sleeve changed. The change in flow through the infection-port sleeve caused the pressure drop across the inlet to change. If the efficiency of the capillary-column system was to be maintained when needle valve 2 was adjusted, the pressure regulator on the carrier gas was adjusted to 
re-establish the proper flow of carrier gas through the capillary column.

The minimum split ratio that could be attained, before the column efficiency was reduced, was dependent on the volume of the injection-port sleeve and the flow rate of carrier gas through the capillary column. The efficiency of the capillary column decreased at low split ratios, because the sample was not transferred to the column as a plug. Low flow rates of carrier gas through the injection-port sleeve caused the samples to be slowly introduced to the capillary column. When small split ratios were used, broad peaks for the solvent and early eluted substances were observed. When using an injection-port sleeve of $1-\mathrm{mm}$ 1.d., a split ratio of 1 to 10 was attained before the efficlency of the capillary column was significantly reduced.

The capillary column was inserted about $1 / 2$ in into the injection-port sleeve to keep the sample from contacting hot metal and to minimize fractionation of the sample. If the capillary column is coaxially inserted into a larger tube that carries a mixture of vaporized sample in a carrier gas, the sample split is referred to as an annular split. Bauman and Gill showed that by vaporizing a sample in a carrier-gas stream and by using an annular splitter, fractionation of a sample was minimized (58). Using other splitter designs, a 
smaller fraction of high-boiling components are transferred to the capillary column than of low-boiling components. Operation of the inlet system in the splitiess mode To inject samples by the splitless technique, valve 6 in Figure 9 was positioned to provide carrier-gas pressure on the septum side of the injection-port sleeve. Valves 4 and 5 were both in the closed position. After allowing time for the gas lines of the inlet to reach an equilibrium pressure, a microliter syringe was used to introduce liquid samples through the septum into the injection-port sleeve. At a predetermined time, usually 30 seconds for this work, valve 6 was actuated to provide carrier-gas pressure on the column side of the injection-port sleeve. After actuating valve 6 , valve 4 was opened to backflush the injection-port sleeve. Needle valve 1 was adjusted to obtain the desired flow of gas through the inlet.

The time interval for splitless operation that maximizes the efficiency of a capillary-column system is a function of many variables, including: volume of the injection-port sleeve, flow rate of carrier gas through the capillary column, number of theoretical plates in the capillary column, and solvent effects (52). Because it is usually impossible to avoid broadening for all peaks, the time interval used for splitless operation is generally a compromise that gives satisfactory results. With the system used in this work, 
the time interval used for splitless operation usually was 30 sec.

Optimization of exit-interface parameters To retain the separation that has been obtained on a capillary column, mixing of the column effluent before entering the detector must be avoided. Mixing of the effluent was minimized by keeping the volume between the column exit and the detector to a minimum and keeping the linear-flow rate in the transfer lines much greater than the linear-flow rate in the capillary column. A 3-in segment of 1-mm i.d." capillary glass tubing was used to connect the caplllary column to the detectors. The 1-mm capillary glass tubing was used instead of standard 1/4-in glass tubing to minimize the volume of the exit interface. Make-up gas was added to the column effluent to increase the flow rate of gas through the exit interface. Capillary columns of a $0.25-\mathrm{mm}$ i.d. were usually operated at flow rates of about $25 \mathrm{~cm} / \mathrm{sec}$. A. linear-flow rate of $25 \mathrm{~cm} / \mathrm{sec}$ through the capillary column implies a volumetricflow rate of $0.73 \mathrm{ml} / \mathrm{min}$. Assuming a linear-flow rate in the capillary tubing of three times the rate in the capillary column is sufficlent to prevent mixing of substances eluted from the column, a linear-flow rate of $75 \mathrm{~cm} / \mathrm{sec}$ or a volumetric-flow rate of $35 \mathrm{ml} / \mathrm{min}$ of make-up gas must be added to the column effluent prior to the exit interface to prevent broadening of eluted components. Typically, make-up 
gas was added at a rate of $50 \mathrm{ml} / \mathrm{mln}$ in this work. If volumetric-flow rate of make-up gas is too large, the sensitivities of the FID and the ECD will be reduced.

Optimization of exit-splitter parameters As with the exit interface, the two critical factors in regard to peak broadening are void volume and linear-flow rate. Since the void volume of the exit splitter was constant, the linearflow rate of gas in the exit splitter was the factor used to limit broadening. If it is assumed that a linear-flow rate in all parts of the exit splitter must be greater than $75 \mathrm{~cm} / \mathrm{sec}$ to prevent broadening, make-up gas must be added to the column effluent at a volumetric-flow rate of $140 \mathrm{ml} / \mathrm{mIn}$ when an exit-split ratio of 1 to 31 s used. Because the sensitivities of both the ECD and the FID are reduced by high rates of gas flow, exit-split ratios of greater than 1 to 5 were not practical with this exit splitter.

Result.s and Discussion

Figure 10 demonstrates the resolution that was obtained using capillary columns with the modified Tracor 550 GC. The effective number of theoretical plates for the capillarycolumn system, as calculated from the peak marked with an asterisk, was 44,476. The chromatogram in Figure 10 is of a mixture of polychlorinated biphenyls in Arochlor 1254. A 


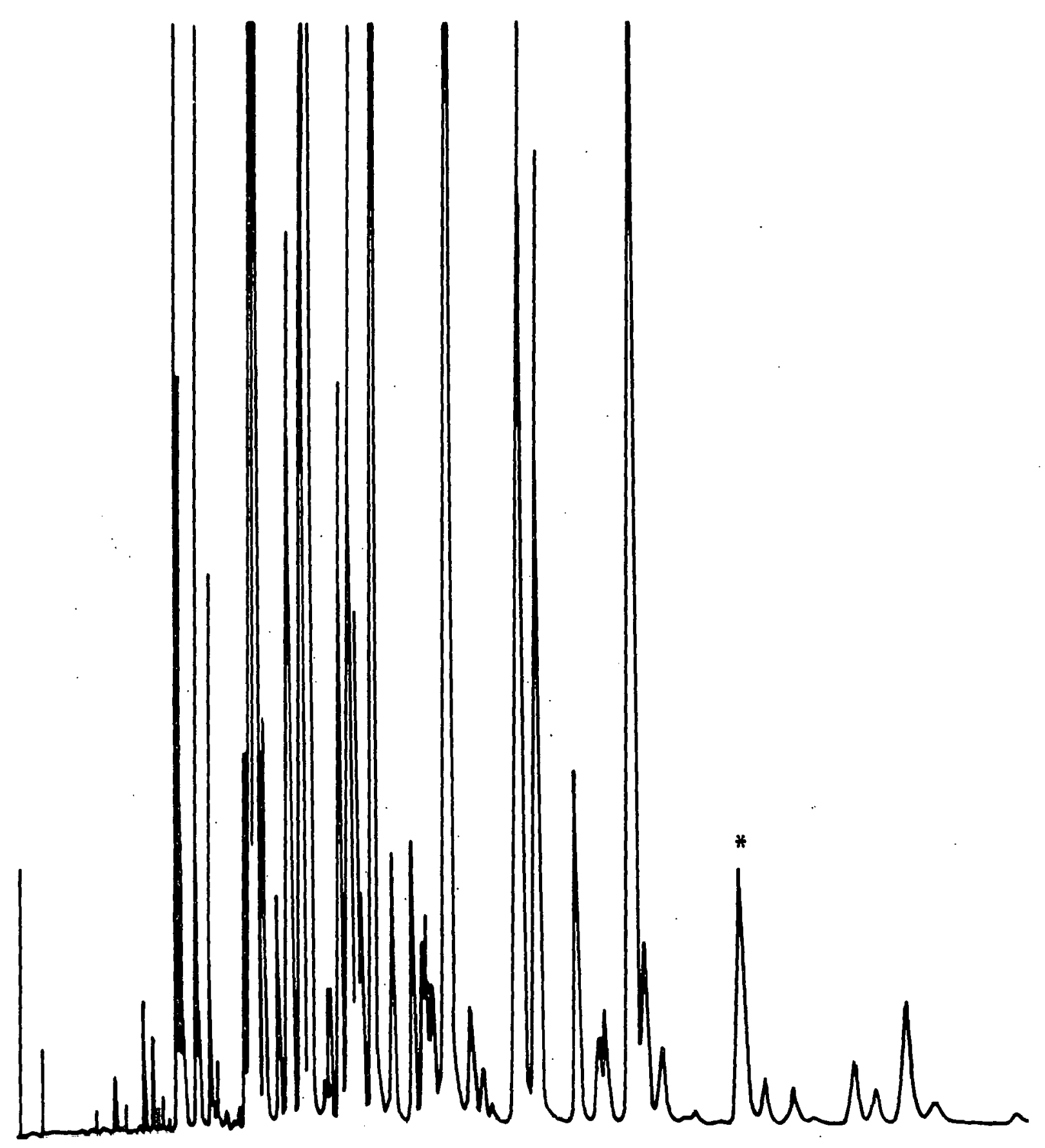

Figure 10. Separation of Arochlor 1254. Conditions of separation: Column - WCOT, $S E-30$ stationary phase, $30 \mathrm{~m} \times 0.25 \mathrm{~mm}$ 1.d.; Temperature $-170^{\circ} \mathrm{C}$ isothermal for $80 \mathrm{~min}$; Carrier gas $-28 \mathrm{~cm} / \mathrm{sec}$ of helium; Sample introduction $-1 \mu 1$, split ratio = helium; Sample 1n - ECD, attenuation = 32; Make-up 1:100; Detection of nitrogen; Sample - $200 \mathrm{ng}$ of Arochlor. 1254 in pentane. 
large split ratio was used to reduce the amount of each compound golng to the ECD. By using the large split ratio, the responses for the polychlorinated biphenyls were within the linear range of the ECD.

The flexibility and sensitivity provided by temperature programming, splitless injection, and exit splitting is demonstrated in Figure 11. The chromatograms of the mixture demonstrate the ability of this system to provide good chromatograms with two detectors from a single chromatographic separation. Large peaks for 2,4-hexanedione, 2-(.2-butoxyethoxy)ethyl acetate, and 1-chloro-3-nitrobenzene were observed with the ECD. All compounds in the mixture were detected by the FID. By using the splitless infection technique, one nanogram of most organic compounds can be detected by the FID with this system. The detection limit for some polychlorinated compounds is one picogram when the ECD is used with capillary columns.

Reproducibility of peak heights with the capillarycolumn system is a function of many variables: backflush rate, carrier-gas pressure, sample size, splitless time, etc. By introducing the sample with a microliter syringe in a reproducible manner that minimized changes of the carrier-gas pressure, peak heights were reproduced within 2 percent. If injection technique was not duplicated, large differences in peak helghts were observed. If the splitless time was too 
Figure 11. Separation of model compounds

$$
\begin{aligned}
& \text { Conditions of separation: } \\
& \text { Column - WCOT, SP1000 stationary phase, } \\
& 25 \mathrm{~m} \mathrm{x} 0.25 \mathrm{~mm} \text { 1.d. } \\
& \text { Temperature - Isothermal at } 80^{\circ} \mathrm{C} \text { for } 4 \mathrm{~min} \text {, } \\
& \text { increased temperature at } \\
& 3^{\circ} \mathrm{C} / \mathrm{min} \text {. Maximum temperature } \\
& \text { of } 220^{\circ} \mathrm{C} \\
& \text { Carrier Gas }-28 \mathrm{~cm} / \mathrm{sec} \text { of helium } \\
& \text { Sample Introduction - } 2 \mu 1 \text {, splitless } \\
& \text { for } 30 \mathrm{sec} \\
& \text { Detection - Top: ECD, attenuation }=2 \\
& \text { Bottom: FID, attenuation }=10 \\
& \text { Make-up Gas - } 105 \mathrm{ml} / \mathrm{min} \text { of nitrogen } \\
& \text { Backflush Gas - } 15 \mathrm{ml} / \mathrm{min} \text { of helium } \\
& \text { ECD Purge Gas - } 70 \mathrm{ml} / \mathrm{min} \text { of nitrogen } \\
& \text { Exil-Spl1t Ratio (ECD:FID) - } 1: 2 \\
& \text { Sample Components }-8 \times 10^{-9} \mathrm{~g} / \mu \mathrm{I} \text { each in } \\
& \text { methylente chloride } \\
& \text { Peak Number } \\
& \text { Compound } \\
& 1 \\
& \text { 2,5-Hexanedione } \\
& 2 \\
& 3 \\
& 4 \\
& \text { 1-Chloro-3-nitrobenzene } \\
& 5 \\
& \text { Butyl phosphate } \\
& 6 \\
& \text { Hexadecane } \\
& \text { 2-(2-Butoxye thoxy) ethy I } \\
& \text { acetate } \\
& 4 \\
& \text { 2,6-Dime thy lphenol }
\end{aligned}
$$


THIS PAGE

WAS INTENTIONALLY

LEFT BLANK 

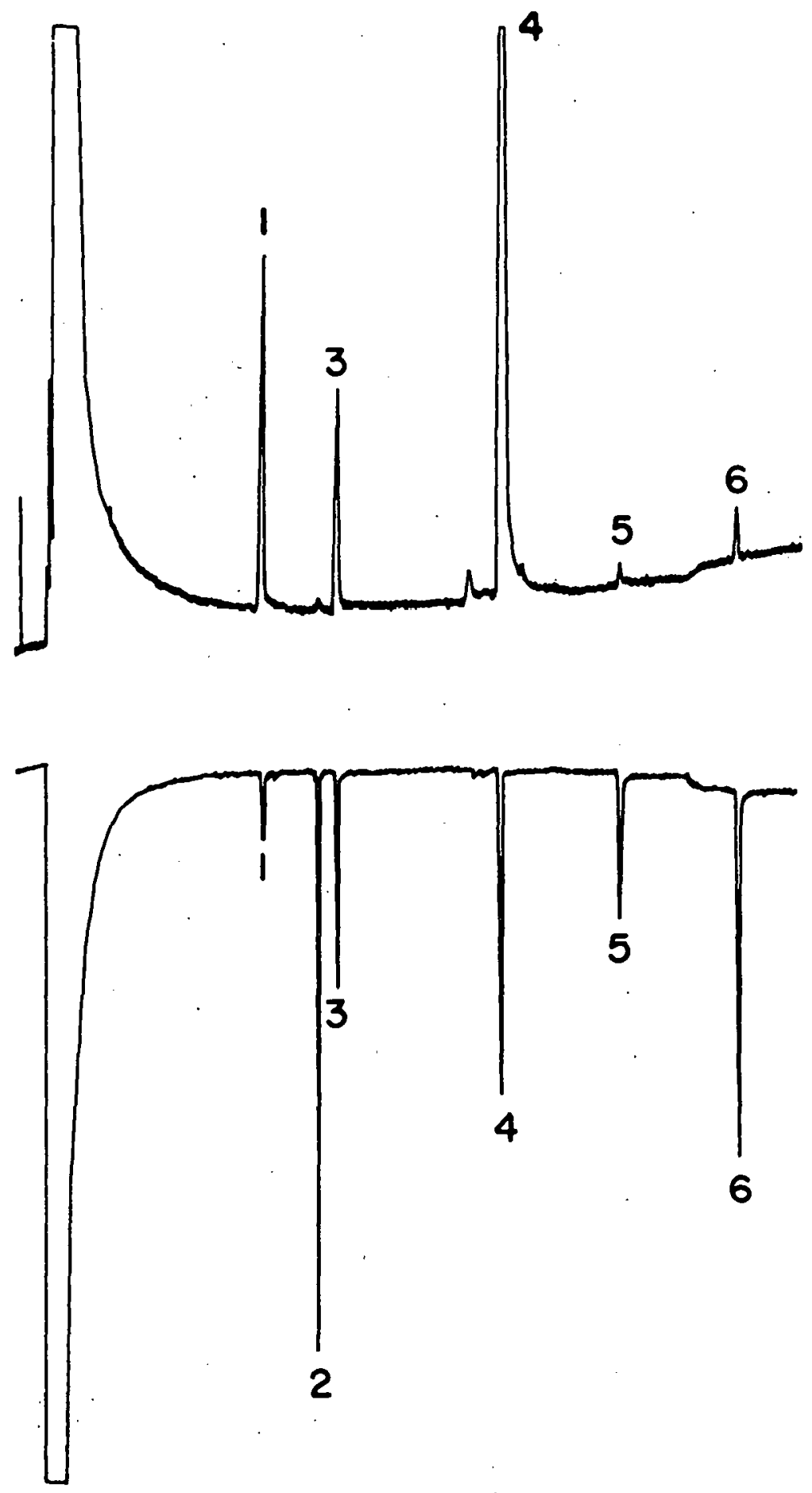
short, it was difficult to reproduce the amount of sample introduced to the column. A backflush flow great enough to quickly remove remaining sample from the inlet was necessary to obtain plug injection. A flow of $10-20 \mathrm{ml} / \mathrm{min}$ through the injection-port sleeve was sufficient to quickly purge the inlet. By trial and error, operating parameters were selected that maximized the reproducibility of the system with various capillary columns.

Retention times were reproducible with this capillarycolumn system. Table 7 shows the variations in retention times that were observed during three days. The average of the relative standard deviations observed for the retention times of the compounds in Table 7 was 2 percent. Large variations in retention times for early eluted compounds were the result of the inability of the Tracor 550 GC to preclsely reproduce temperatures below $100^{\circ} \mathrm{C}$. When an initial temperature of greater than $100^{\circ} \mathrm{C}$ was used, reproducibility of retention times was much better than the 2 percent variation observed for compounds in Table 7 .

Conclusions

The ability of the capillary-column system with dual detection to provide retention times and relative-response factors makes the system ideal for screening samples. Specific organic compounds in samples could be determined 
Table 7. Reproducibility of retention times with capillarycolumn gas chromatography.

\begin{tabular}{|c|c|c|c|c|}
\hline Compound & $\begin{array}{l}\text { Average } \\
\text { Retention } \\
\text { Timea } \\
\text { (minutes) }\end{array}$ & $\begin{array}{l}\text { Number } \\
\text { of } \\
\text { Determi- } \\
\text { nations. }\end{array}$ & $\begin{array}{l}\text { Standard } \\
\text { Deviation }\end{array}$ & $\begin{array}{l}\text { Percent } \\
\text { Standard } \\
\text { Deviation }\end{array}$ \\
\hline Octane & 2.8 & 6 & 0.1 & 4.2 \\
\hline Nonane & 5.6 & 6 & 0.3 & 5.0 \\
\hline Decane & 9.5 & 8 & 0.6 & 5.9 \\
\hline Nitrobenzene & 11.4 & 5 & 0.4 & 3.9 \\
\hline Undecane & 13.1 & 8 & 0.6 & 4.8 \\
\hline $\begin{array}{l}1,2,4-\operatorname{Trichloro-} \\
\text { benzene }\end{array}$ & 14.7 & 5 & 0.4 & 3.9 \\
\hline Benzethiophene & 15.5 & 5 & 0.4 & 2.6 \\
\hline Benzothiozole & 16.2 & 3 & 0.4 & 2.2 \\
\hline Dodecane & 16.4 & 8 & 0.5 & 2.9 \\
\hline Tridecane & 19.4 & 8 & 0.4 & 2.0 \\
\hline Acenaphthalene & 23.8 & 7 & 0.08 & 0.3 \\
\hline Hexadecane & 27.6 & 10 & 0.2 & 0.7 \\
\hline Heptadecane & 29.9 & 5 & 0.07 & 0.2 \\
\hline Octadecane & 32.2 & 5 & 0.05 & 0.2 \\
\hline Nonadecarie & 34.4 & 5 & 0.08 & 0.2 \\
\hline Eicoane & 36.6 & 5 & 0.05 & 0.1 \\
\hline Fluoranthrene & 37.2 & 7 & 0.07 & 0.2 \\
\hline Docosane & 40.5 & 5 & 0.08 & 0.2 \\
\hline Tetracosane & 44.1 & 5 & 0.00 & 0.0 \\
\hline $\begin{array}{l}\text { Diethylhexy } \\
\text { Phthalate }\end{array}$ & 46.2 & 8 & 0.2 & 0.4 \\
\hline
\end{tabular}

${ }^{a}$ Chromatographic conditions:

Column - 30-m x 0.25-mm i.d. glass wCOT capillary column, SE-30 stationary phase

Temperature - Isothermal at $50^{\circ} \mathrm{C}$ for $4 \mathrm{~min}$, then increased temperature at $5^{\circ} \mathrm{C}$ per min. Maximum temperature of $260^{\circ} \mathrm{C}$ was held for $10 \mathrm{~min}$.

Carrier Gas: Helium flow of $90 \mathrm{~cm} / \mathrm{sec}$ 
and quantified using this gas-chromatographic system. Because two types of information are obtalned using this system, the identities of compounds can be confirmed while obtaining information for quantitative calculations. Reproduciblilty of peak heights and retention times are highly dependent on parameters of operation. Variations in sample-introduction technique and column-oven temperature cause large variations in the chromatograms obtained. 
FRACTIONATION OF ORGANIC COMPOUNDS IN WATER EXTRACTS ON FLORISIL

Review of Related Work

Organic compounds in drinking waters

In recent years much interest in the organic materials present in drinking waters has developed. Although the concentrations of total-organic carbon (TOC) in drinking waters are usually less than $1 \mathrm{ppm}(1 \mathrm{mg} / 1$ ), the effect of chronic, low-level doses of some organic compounds is a matter of concern to many people.

Because the concentrations of organic compounds in drinking waters are low, it is difficult to ldentify and quantify the organic compounds. Beyond quantitative analysis, it is even more difficult to determine the potential health hazards of the trace levels of organic compounds present in drinking waters. Recently, techniques have been developed for concentrating and determining some of the organic compounds present in drinking waters at the sub-part-per-billion level.

Various techniques for determining trace levels of organic pollutants in water have been developed. Although only a small portion of the TOC present in most drinking waters can be determined by gas chromatography, most analytical methods depend on gas chromatography to separate the organic compounds. Gas chromatography has been the 
predominant technique for separating organic compounds found in waters because of the high resolution it offers and the sensitivity attainable when it is interfaced to a mass spectrometer. Gas chromatography/mass spectrometry (GC/MS) provides retention information and mass spectra that can be used to elucidate the structures of organic compounds. To obtain mass spectra for identifying organic compounds, approximately $10 \mathrm{ng}$ of a compound must be introduced to a GC/MS. Application of GC/MS to the analysis of trace organic compounds in drinking waters requires that samples be concentrated prior to analysis. Many techniques have been implemented for concentrating the organic compounds present in drinking waters. Among the most prominent methods of concentrating organic compounds present in water are: solvent extraction $(59,60,61)$, gas-phase extraction (33), purge and trap $(17,61)$, carbon sorption $(62,63)$, reverse osmosis $(64)$, and resin sorption $(5,6,7,65)$.

Resin sorption using Amberlite XAD-2 appears to be the most efficient analytical technique for concentrating organic compounds found in potable waters. Carbon sorption may be as effective in removing organic compounds from water; however, removal or desorption of organic compounds from activated carbon generally is incomplete (66).

Organic compounds sorbed on XAD-2 can be removed by thermal desorption or solvent elution. Chang described a method to thermally desorb organic compounds from a XAD-2 
column onto a column of Tenax GC (16). Ryan and Fritz further investigated the use of thermal desorption of XAD-2 for the analysis of water for organic pollutants (67). By sorbing the organic pollutants onto a Tenax-GC column, water was removed from the sample before introducing the organic compounds to the analytical column of the gas chromatograph. Organic compounds sorbed on columns of XAD-2 can be desorbed by solvent elution (5). By passing a small volume of diethyl ether through a resin bed, the organic compounds sorbed from a large volume of water are eluted. The concentration of the organic compounds in the diethyl-ether solution can be increased by distilling the diethyl-ether solution to a smaller volume. A small portion of the diethyl-ether solution $(2 \mu 1)$ is then injected into a gas chromatograph. Although greater sensitivity can be obtained for a given volume of water by thermal desorption, solvent elution yields a sample that can be treated and analyzed in many ways.

The task of 1dentifying organic compounds extracted f'rom waters is often extremely difficult. Infrared (IR) spectroscopy, proton magnetic resonance (PMR) spectroscopy, and mass spectrometry (MS) are useful in determining the structures of organic compounds. The spectroscopic techniques provide information about compounds' structures, but it is necessary to separate the compounds of a mixture before spectroscopic 
analysis. Of these techniques, MS is the only technique that has enough sensitivity to obtain information about the trace organic pollutants present in drinking waters.

Some techniques that have been used to separate mixtures of organic compounds are: solvent extraction, liquid chromatography, and gas chromatography. Because numerous compounds are present in extracts of many waters, a high-resolution technique must be used to separate compounds in water extracts. Gas chromatography has been the most popular technique for separating organic compounds from waters because of the resolution obtained with gas chromatography. The resolution of gas chromatography can be increased further by the use of wall-coated open tubular (WCOT) capillary columns; however, the chromatogram in Figure 12 indicates the inability of capillary columns to completely resolve all the components in complex mixtures.

Gas chromatography coupled with mass spectrometry (GC/MS) provides retention information and mass spectra that can be used to determine the identities of organic compounds. The information provided by GC/MS is sufficient to determine the identities of most compounds. The 1dentities of some compounds are diffieult to determinc from the mass spectra and retention time on a gas chromatographic column. If GC does not completely resolve the compounds in a sample, mass spectra obtained by GC/MS for some peaks w1ll be of mlxtures. 
Wula 
When compounds are introduced to a mass spectrometer as mixtures, it is extremely difficult and time-consuming to determine the identities of the compounds from the mass spectra.

Because analysis by GC/MS is not sufficient to determine the identities of all the organic compounds present in extracts of drinking waters, additional techniques must be used to identify some of the organic pollutants in drinking waters. A separation prior to GC/MS would help determine the Identities of some compounds in samples. By dividing the compounds of a sample into fractions according to molecular properties of the compounds, information about the components is obtained. Because fewer components would be present in each fraction, fewer problems with incomplete resolution will be encountered during GC. Because fractionating a sample increases the resolution obtained for the analysis, identification of some components is easier than if the complex mixture is analyzed directiy.

In addition to reducing the complexity of samples, a fractionation technique would provide additional information about the components of the sample. The information provided by the fractionation would ald in the interpretation of the data obtained by GC/MS. Information provided by a fractionation could be used to confirm the identities of compounds not well-characterized by MS. 
Because WCOT capillary columns are susceptible to contamination, a fractionation could be used to remove contaminants from samples prior to introduction to the column. Only a small amount of stationary phase is present in a WCOT column; thus, the thin film of stationary phase in a capillary column can be destroyed by a small amount of a contaminant. High molecular-we1ght compounds that do not chromatograph build up on the column or are thermally decomposed by the heat of the gas-chromatographic oven. Water and oxygen are harmful to the thin film of stationary phase because they may cause hydrolysis of the stationary phase or the activation of the glass surface. When analyzing concentrates from water samples by capillary-column gas chromatography, a fractionation that removes nonchromatographable contaminants would increase the useful life of a WCOT capillary column.

Evaluation of fractionation techniques

Fractionating extracts of some drinking waters would help in the analysis for organic pollutants. Some properties that are desired of a fractionation scheme for water extracts are listed below.

Quantitative recovery Complete recovery of all organic compounds in the water extracts is the ideal. situation. When the analysis of the sample is to be 
performed by gas chromatography, recovery of compounds that cannot be analyzed by gas chromatography is not necessary. Informative Because it is difficult to determine the identities of some organic compounds in water extracts, information about compounds in the sample provided by the fractionation would be useful as an aid in determining their structures.

Noncontaminative The amount of organic material concentrated from a water sample is generally quite small. To maintain sample integrity, the fractionation technique must not introduce any substance that would interfere with the analysis.

Semipreparative Although most organic compounds are present in drinking waters at very dilute concentrations, the technique should have the capacity to handle any compounds that may be present in high concentrations.

Sample clean-up To aid in the analysis, the technique should provide fractions that are free of compounds that may interfere with the analysis.

Rapid Implementation of a fractionation technique on a routine basis as an aid to an analysis would require that the technique itself not be time-consuming. If the total analysis time of the water extracts is to be minimized, the time involved in analyzing the fractions must be considered. 
Inexpensive Whether or not the cost of a fractionation technique is important may be debatable; however, a technique that is low in cost and produces the desired results would be preferred to more expensive techniques.

A number of fractionation techniques have been developed and applied to separating a variety of complex mixtures. Some fractionation techniques for complex mixtures are reviewed in the following paragraphs. Advantages and Iimitations in regard to fractionating water extracts are discussed.

Stedman and coworkers developed a technique for fractionating clgarette-smoke condensates based upon solvent extraction (68). Table 8 shows the extraction steps that were performed in the separation scheme. Using six-liter separatory funnels, 720-g quantities of clgarette-smoke condensates were separated into eleven fractions. The scale of this separation scheme was large to allow for the preparation of suffiolent amounts of material for mutagenic testing with mice (69). The weights of the fractions indicated that 90.8 percent of the condensates were recovered. Variations in the amount recovered in each fraction were especially pronounced for the smaller fractions. The resolutions of the fractionation scheme is low; thus, small differences in the amount of a component remaining in a phase causes large differences in the amounts found in the smaller 


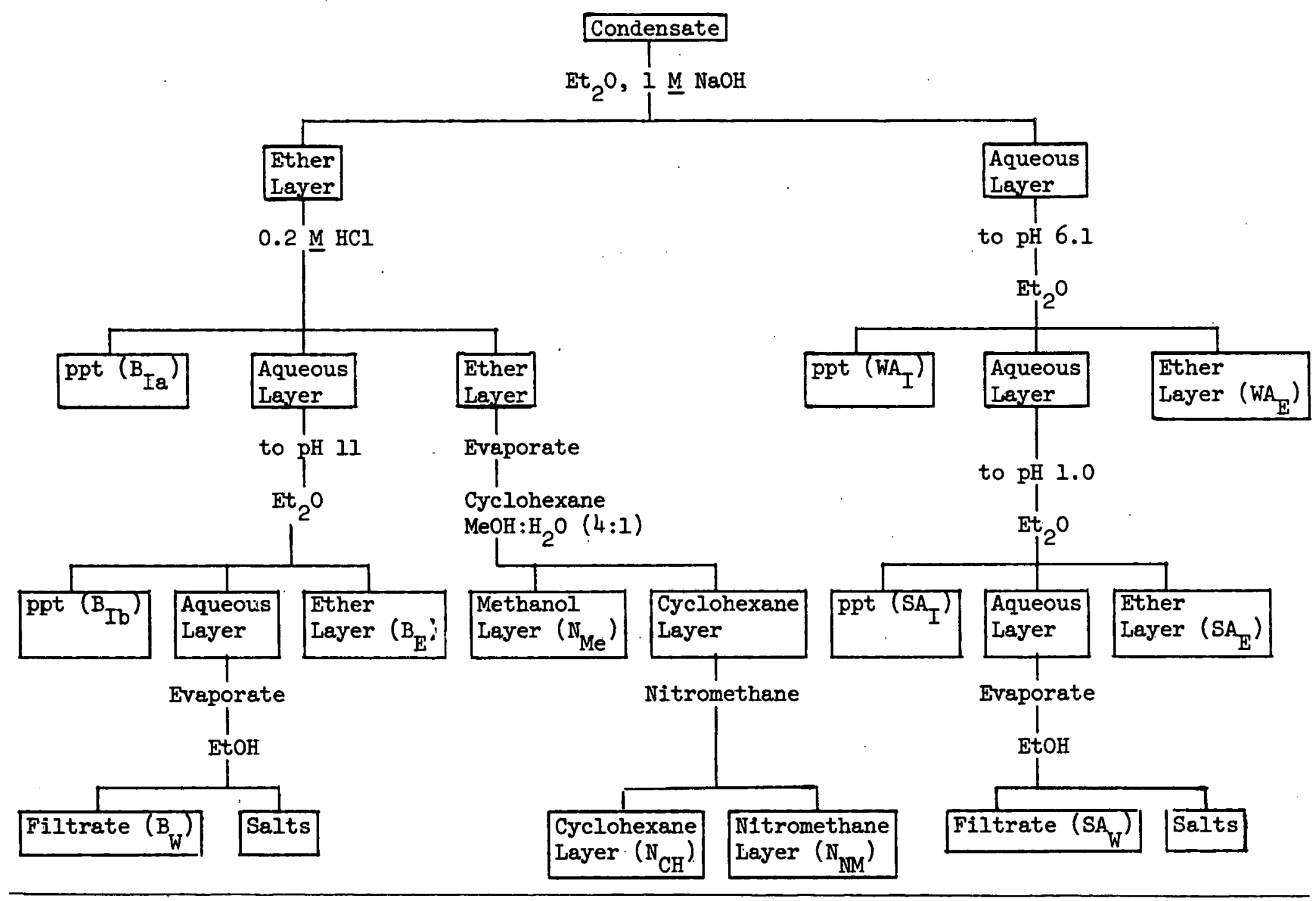


fractions. For preparative fractionations, the amount of solvent used and the handling of the sample does not pose any significant problems. In addition to scaling down the scheme for trace analysis, steps to assure the purity of solvents and glassware would be necessary to avold contamination of the sample. Studies have been performed that indicate low recoverles of trace organic compounds may occur because of sorption onto glass surfaces (6). The types of compounds in fractions $B_{I a}, B_{I b}, W A_{I}, W A_{E}, S A_{I}, S A_{E}, S A_{W}$, and $B_{E}$ would not be sufficiently volatile nor chemicaliy inert to analyze by gas chromatography.

The separation scheme by Stedman and coworkers has been expanded by other workers. Novotny et al. scaled the scheme down and used it as part of a scheme to prepare samples of clgarette-smoke condensates for analysis of polycyclic aromatic hydrocarbons $(70,71)$. The polycyclic aromatic hydrocarbons were contained in the $\mathrm{N}_{\mathrm{NM}}$ fraction of Table 8 . The $\mathrm{N}_{\mathrm{NM}}$ fraction was evaporated to dryness, dissolved in isopropanol, and $1.5 \mathrm{~g}$ of the extract introduced to a $115-\mathrm{cm} \times 1.5-\mathrm{cm}$ column packed with Sephadex LH-20. Organic compounds were eluted from the Sephadex column by pumping isopropanol at a rate of $6 \mathrm{ml} / \mathrm{hr}$. The size of each fraction collected and a representative compound for each fraction are listed in Table 9. These fractions were analyzed by gas chromatography with capillary columns. If the 
Table 9. Fractions collected from Sephadex LH-20 column by Novotny and coworkers

\begin{tabular}{clc}
\hline $\begin{array}{l}\text { Fraction } \\
\text { Number }\end{array}$ & Representative Compound & Collection Volume (mI) \\
\hline I & \multicolumn{1}{c}{ Naphthalene } & $0-240$ \\
II & Anthracene & $241-345$ \\
III & Fluoranthrene & $346-415$ \\
IV & Chrysene & $416-470$ \\
V & Denzo[a]pyrene & $471-585$ \\
VI & Dibenz[a,h]anthracene & $506-740$ \\
VII & --- & $741-860$ \\
VIII to XIV & & $861-4360$ \\
& &
\end{tabular}

capillary-column chromatogram was too complex, the fraction was further separated by liquid chromatography on a 50-cm $\times 2.6-\mathrm{mm}$ reverse-phase column. The reverse-phase column was packed with OPN/Porisil $C$ and hexane was used as the eluent. The procedure was shown to be an effective, but time-consuming, way of obtaining samples containing polycyclic aromatic hydrocarbons with specific numbers of rings. Many more steps would be required to analyze for compounds other than aromatic hydrocarbons.

Rubin et al. also investigated the further fractionation of the $\mathrm{N}_{\mathrm{NM}}$ fraction from Stedman's scheme (72). Organis. 
compounds were eluted from Florisil columns, $30 \mathrm{~cm} \mathrm{x} 2.6 \mathrm{~cm}$, with ten bed volumes of the following solvents: hexane, hexane:benzene $(4: 1)$, benzene:ether $(4: 1)$, and methanol. Polycyclic aromatic hydrocarbons were observed to elute in the hexane and the hexane:benzene fractions. Samples of cigarette-smoke condensates and synthetic olls were fractionated then examined for mutagenic activity by a microbacterial technique developed by Ames (73). This is a rapid technique that provided sufficient material for mutagenic testing. Compounds from cigarette-smoke condensates were separated more rapidly on the Florisil columns than by Novotny using Sephadex LH-20. Results of the fractionation indicate that not all aliphatic hydrocarbons are resolved from the aromatic hydrocarbons. Elution behavior of compounds other than hydrocarbons was not investigated.

Many methods of fractionation by adsorption chromatography have been developed for complex mixtures of organic compounds. A commonly used fractionation scheme was developed by Mills for samples to be analyzed for pesticides (74). Samples were separated on 22-mm 1.d. columns containing $20 \mathrm{~g}$ of $60 / 100$-mesh Florisil that had been activated at $130^{\circ} \mathrm{C}$. Organic compounds were eluted from the Florisil columns by the following solvents: $6 \%$ diethyl ether in petroleum ether, $15 \%$ diethyl ether in petroleum ether, and 50\% diethyl ether in petroleum ether. Two-hundred milliliters of each solvent 
were passed through the columns by gravity flow and collected as independent fractions. The pesticides eluted in each fraction are listed in Table 10. Nonpolar compounds were

Table 10. Pesticides grouped according to the fraction the compounds eluted from Florisil

\begin{tabular}{llc}
\hline Fraction $I^{a}$ & Fraction II $^{\mathrm{b}}$ & Fraction III \\
\hline Aldrin & Dieldrin & Malathion \\
o,o'-DDT & Endrin & \\
o,p'-DDT & Methyl \\
p,p'-DDT & Parathion \\
Heptachlor & Ethyl \\
E-BHC & Parathion \\
Lindane & \\
\hline
\end{tabular}

\footnotetext{
${ }^{2} 6 \%$ diethyl ether in petroleum ether.

$b_{15 \%}$ alelhyl elher in petruleurn ether.

$c_{50 \%}$ diethyl ether in petroleum ether.
}

eluted by the first solvent and the polar compounds were divided between the second and third fractions. Milis developed the technique to confirm the identities of pesticides present in the samples and to remove substances, such as lipids, that may interfere with the gas-chromatographic 
determination of the pesticides. Reproducibility of elution was obtained by adjusting the amount of Florisil used in the columns according to the activity of the Florisil (75). With the solvent system used by Mills, not all compounds that could be analyzed by gas chromatography were eluted from the Florisil. Because the fractionation is rapid, inexpensive, and effective, the technique is a part of most standard methods for the analysis of samples for pesticides. With slight modifications, the Florisil fractionation technique has been applied to the analysis of grapefruit for aromatic compounds (76), and the analysis of animal and vegetable oils for hydrocarbons (77), sterolds (78), and alcohols (79).

Another adsorption-chromatography scheme was developed by Jones et al. for fractlonating organic compounds present in process streams $(80)$. Organic compounds were eluted from a $25-\mathrm{cm} \times 1.0-\mathrm{cm}$ column packed with 200-mesh silica gel that had been activated at $200^{\circ} \mathrm{C}$. Fractions were collected from the column by eluting with $25 \mathrm{ml}$ of eight solvents. The solvents used and the types of compounds eluted by each solvent are listed in Table 11. The volumes of the fractions were reduced by distillation. The two techniques employed to analyze the fractions were weighing the residue and infrared spectroscopy. The scale of the scheme was large enough that a sensitive analytical balance could be used to determine the welghts of the fractions. Although the complexity of 
Table 11. Fractions collected from the Jones scheme

\begin{tabular}{|c|c|c|}
\hline $\begin{array}{l}\text { Fraction } \\
\text { Number }\end{array}$ & Solvent & Compounds Eluted \\
\hline I & Petroleum Ether & Aliphatic Hydrocarbons \\
\hline II & $\begin{array}{l}\text { 20\% Methylene Chloride } \\
\text { in Petroleum Ether }\end{array}$ & $\begin{array}{l}\text { Aromatic Hydrocarbons, } \\
\text { Halides }\end{array}$ \\
\hline III & $\begin{array}{l}\text { 50\% Methylene Chloride } \\
\text { in Petroleum Ether }\end{array}$ & $\begin{array}{l}\text { Esters, Ethers, Epoxides, } \\
\text { Nitro Compounds }\end{array}$ \\
\hline IV & Methylene Chloride & $\begin{array}{l}\text { Esters, Ketones, } \\
\text { Aldehydes, Phenols }\end{array}$ \\
\hline $\mathrm{V}$ & $\begin{array}{l}\text { 5\% Methanol in } \\
\text { Methylene Chloride }\end{array}$ & $\begin{array}{l}\text { Esters, Phenols, } \\
\text { Alcohols, Amines }\end{array}$ \\
\hline VI & $\begin{array}{l}\text { 20\% Methanol in } \\
\text { Methylene Chloride }\end{array}$ & $\begin{array}{l}\text { Amides, Sulfonates, } \\
\text { Carboxylic Acids, } \\
\text { Acid Salts }\end{array}$ \\
\hline VII & $\begin{array}{l}50 \% \text { Methanol in } \\
\text { Methylene Chloride }\end{array}$ & $\begin{array}{c}\text { Sulfonates, Sulfoxides, } \\
\text { Sulfonic Acids }\end{array}$ \\
\hline VIII & Methanol & Sulfonic Acids \\
\hline
\end{tabular}

samples was reduced, analysis of fractions by infrared spectroscopy was not suitable for extracts of most process streams. The information gained by the fractionation was empirical; thus, the elution behavior of all compounds of interest must be determined. Reproducibility of the technique was not explored, but other studies indicate that retention behaviors of compounds on activated silica gel are difficult to reproduce (81). 
Snyder and Buell combined the separating abilities of alumina, silica gel, carbon, and ion-exchange resins to develop a technique to fractionate petroleum $(82,83)$. The scheme is outlined in Table 12. The technique had the flexibility of deciding sample size, column size, and eluent volumes that best suited the needs of the analysis. The sorbents required for the fractionation scheme were: Amberlyst A-29 anion-exchange resin, Alcoa F-20 alumina, Amberlyst $\mathrm{XN}-1005$ cation-exchange resin, Darco G-60 charcoal mixed with Celite 545, and Davison Code 62 silica gel. Each adsorbent was prepared in a manner that tailored its adsorptive properties. Although many fractions were obtained by this fractionation scheme, complete resolution was not obtained with the three to five milliliters of solvent per gram of adsorbent used to collect the fractions. By employing the additional steps of chromatography on charcoal and alumina, many components of these were determined by high-resolution mass spectrometry. The scheme may be unsatisfactory for fractionating trace levels of organic compounds, because the sample may be contaminated by impurities present in most commerical ion-exchange resins (84). The difficulty in assuring the purity of all of these sorbents and solvents makes this technique undesirable for trace analysis. 
Table 12. Fractionation scheme developed by Snyder and Buell

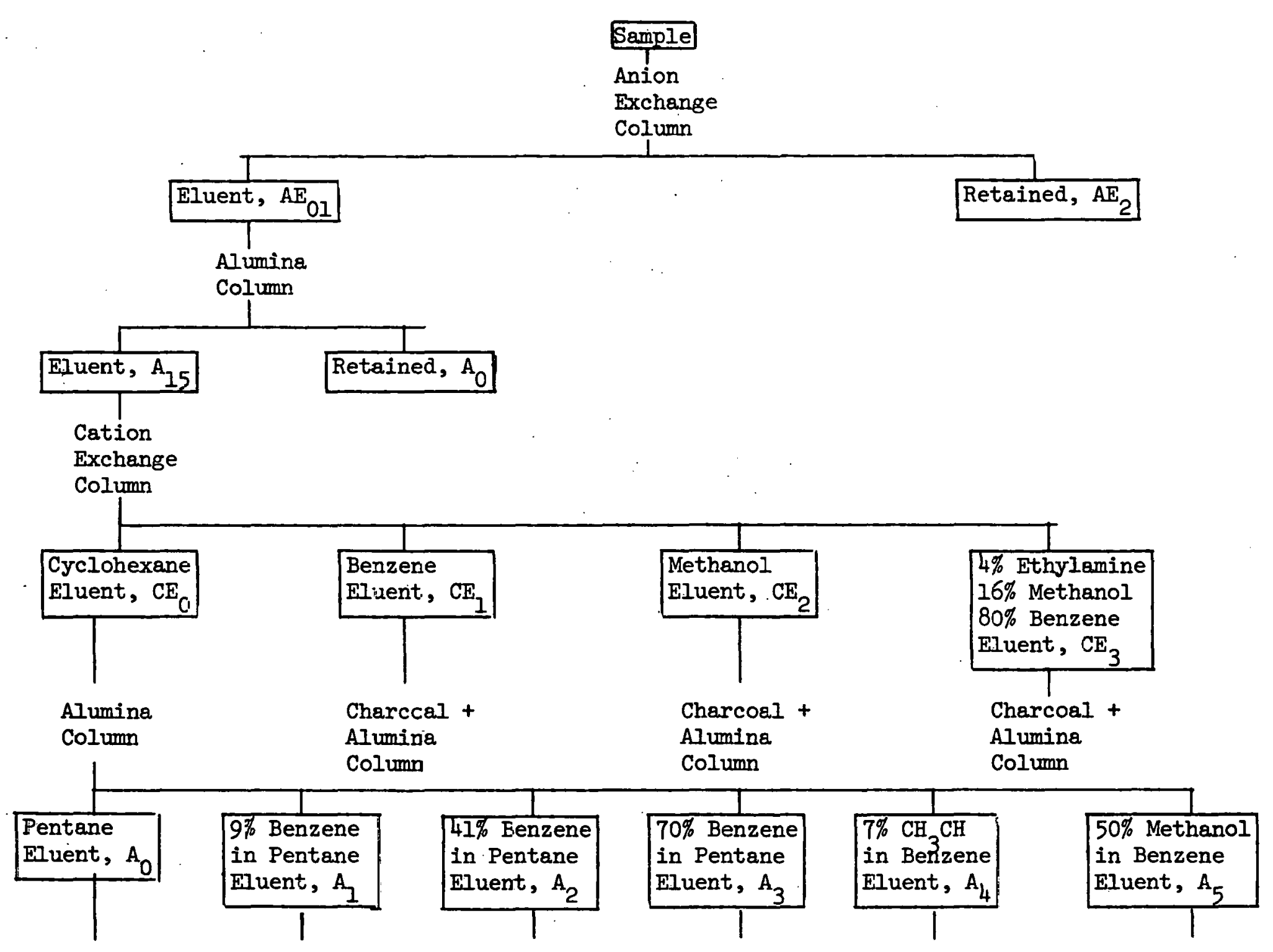




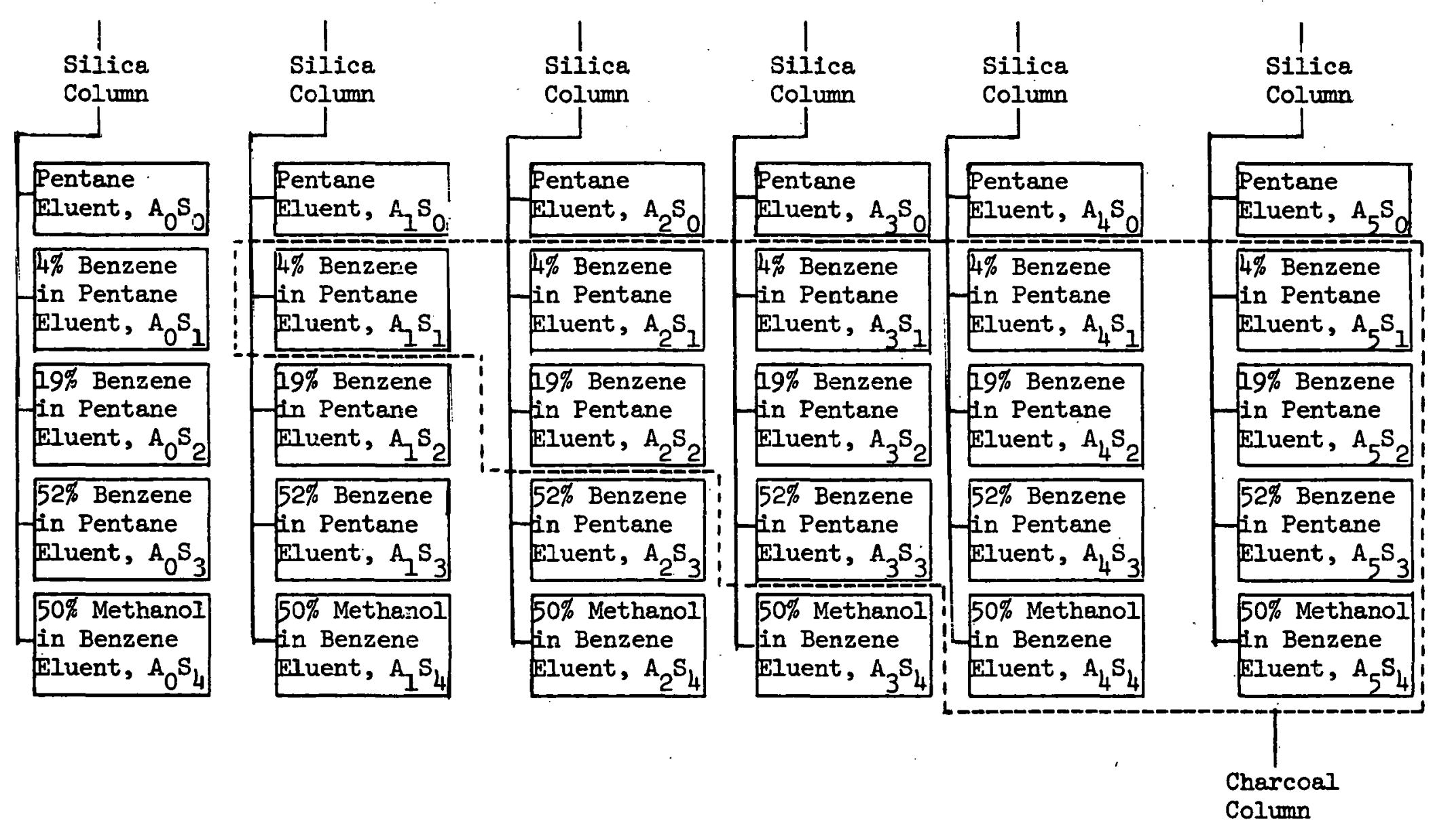


Gel-permeation chromatography is another technique that has been used to fractionate mixtures. Gjessing and Lee eluted humic material from Sephadex G columns with water (85). The fractionation provided information about the molecular-weight distribution of macro-molecules present in natural waters. Low molecular-welght compounds were not separated by this technique.

A. R. Jones et al. used three solvents to elute organic compounds in crude olls from three $1-\mathrm{m} \times 5-\mathrm{cm}$ columns packed with Sephadex LH-20 (86). The samples of crude oils were scparated according to the scheme in Table 13. Because of the effects different solvents have on the elution behavior of compounds from Sephadex LH-20, three types of separations were performed on the Sephadex LH-20 columns. The first separation was the result of the gel being a support for a methanol/water mixture that retalns hydrophilic compounds (87). To elute hydrophillic compounds from the first Sephadex LH-20 column, it was necessary to use methanol or acetone and swell the gel again in $85 \%$ methanol/water before reusing the column. Elution of Sephadex LH-20 with tetrahydrofuran (THF) produced separations as a result of molecular exclusion and hydrogen bonding (88). Nonpolar compounds were separated according to the principles of gelpermeation chromatography, while compounds that hydrogen bonded with the gel were retained longer than the nonpolar 
Table 13. Fractionation scheme for crude oils by A. R. Jones et al.

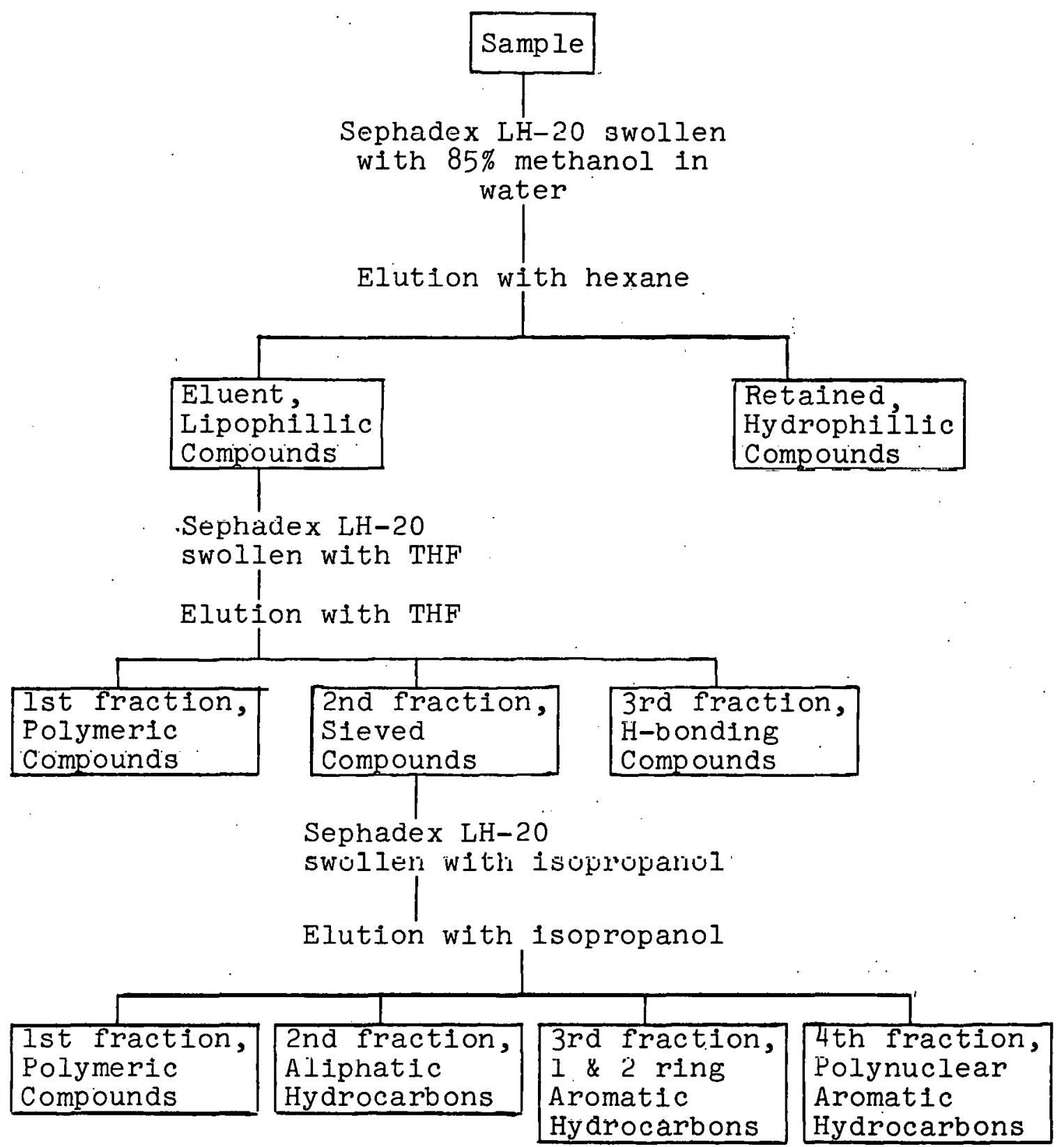


compounds. The third separation occurred by the mechanisms of size exclusion and $\pi$-bonding to the gel (89). Aliphatic hydrocarbons eluted from the column according to molecular sizes. Aromatic hydrocarbons were retained on the third column by $\pi$-bonding and eluted in order to increasing aromaticity. Sample sizes from $10-300 . \mathrm{g}$ were separated on the columns. The scale of the scheme was preparative to allow biological testing of the fractions. Elution of the columns was performed by pumping solvents at a flow rate of approximately $500 \mathrm{ml} / \mathrm{hr}$. The volumes collected for each fraction ranged from $250 \mathrm{ml}$ to $6 \mathrm{l}$. The resolution between fractions was not great; hence, some compounds were present in more than one fraction. Because the compounds of interest were hydrocarbons, the elution behavior of other compounds was not studied. Studies have shown that little losses of polar and reactive compounds occurs when samples are chromatographed on Sephadex LH-20 (70).

Giger and Schaffner used columns packed with Sephadex LH-20 and silica gel to fractionate environmental samples prior to analysis by capillary-column gas chromatography (90). Extracts were separated on a $50-\mathrm{cm} \times 1.6-\mathrm{cm}$ column packed with Sephadex LH-20. Organic compounds were eluted from the column with $50 \%$ benzene in methanol. The first 50-ml fraction contained compounds that could not $\pi$-bond to the Sephadex LH-20. Compounds that $\pi$-bonded to the Sephadex 
LH-20 were collected in the second 50-ml fraction. After reducing the volumes of the two fractions that were obtained by GPC, the fractions were added to $13-\mathrm{cm} \times 1-\mathrm{cm}$ columns packed with Kieselgel 40 silica gel. A fraction eluted with $25 \mathrm{ml}$ of pentane and a fraction eluted with $25 \mathrm{ml}$ of methylene chloride were collected from the silica gel columns. The volumes of the fractions were reduced, then the fractions were analyzed by gas chromatography. Although only four fractions were obtained from this scheme, good information was provided about the components of each fraction. Chromatography on the Sephadex LH-20 separated the samples into nonaromatic and aromatic fractions, while chromatography on silica gel separated the samples into polar and nonpolar fractions. Using these solvents, incomplete elution of sample components and cross contamination of samples on Sephadex LH-20 column occurred.

P. W. Jones et al. developed a scheme for fractionating extracts of process streams using gel-permeation chromatography (GPC) and high-performance liquid chromatography (HPLC) ( 80$)$. The combination of these chromatographic techniques allows for the sample to be separated into fractions determined by both molecular weight and molecular polarity. Table 14 shows the scheme suggested by Jones et al. In the description of the technique, details were not given in regard to column packings and fraction sizes. Important 
Table 14. Fractionation scheme for process stream developed by $P$. W. Jones et al.

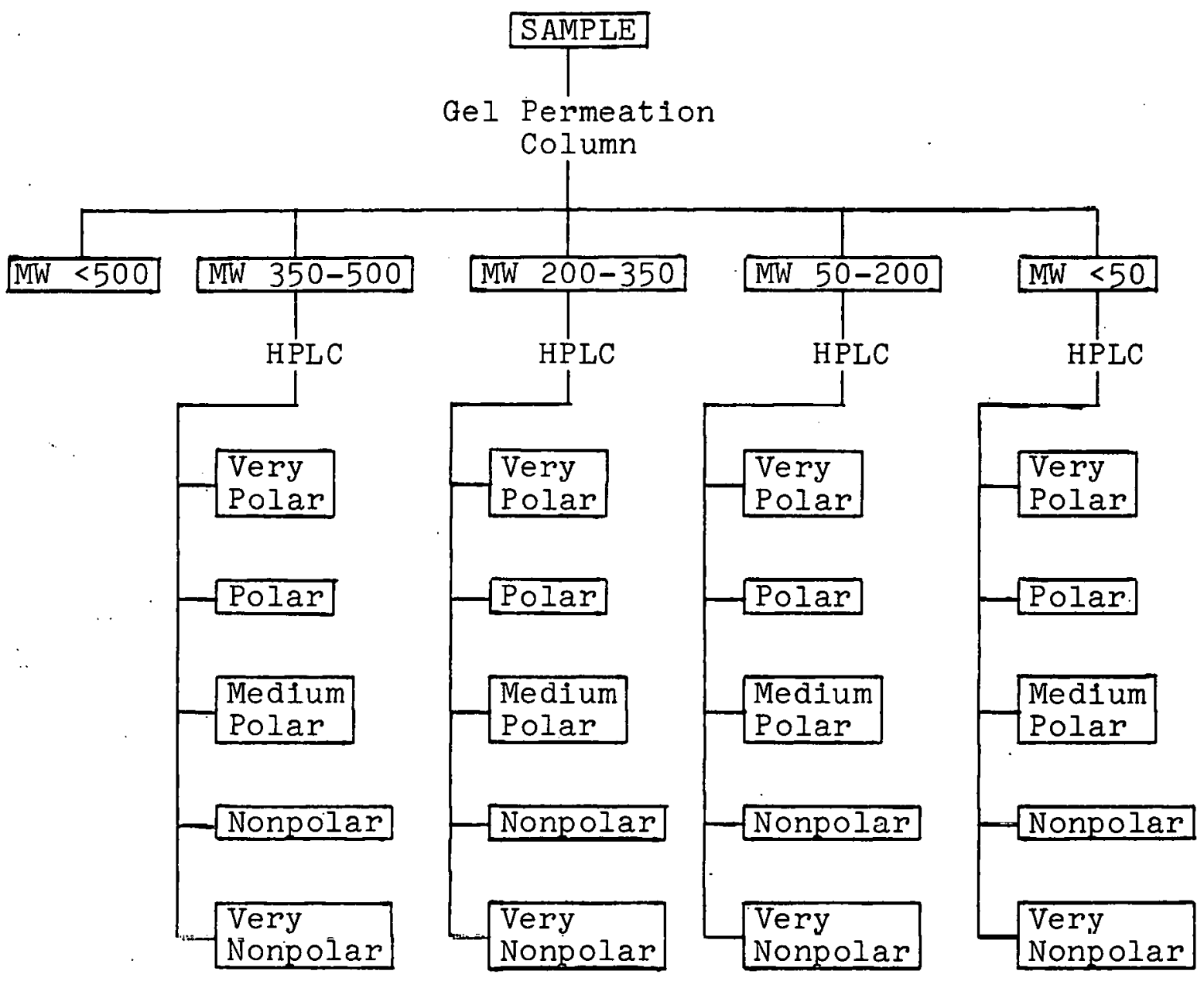


factors such as recovery, reproducibility, and sample contamination would have to be examined to determine the applicability of the scheme to the analysis of samples on a routine basis. The combination of GPC and HPLC seems to be an effective way of obtaining much information about the components of samples. By separating samples by GPC before introducing the samples to a HPLC column, contamination of the reverse-phase packing should be minimized and the useful life of the expensive column extended. The instrumental costs and the preparation time required to perform both GPC and HPLC separations on samples are apparent disadvantages of the scheme.

A major disadvantage in using most of the described fractionation schemes for analysis of water extracts is that much time would be required to analyze all of the fractions. Chromatograms on high-performance capillary columns for gas chromatography may take as long as two hours to obtain. Although more information can be derived about sample components by fractionation schemes ylelding many fractions, the time required to analyze the fractions must be considered.

Selection of fractionation technique for water extracts After evaluating some fractionation schemes, it appears that no fractionation scheme can completely satisfy the properties listed for water extracts. To obtain a balance between analysis time and the information obtained, a 
gravity-flow chromatography technique was selected. Three fractions collected from small columns packed with an absorbent will provide information about the sample components without adding unnecessarily to the analysis time of water extracts.

Silica gel, alumina, and Florisil are the three most common adsorbents for adsorption chromatography. Various grades and activities of silica gel and alumina have been prepared. Snyder has shown the adsorption characteristics of these adsorbents can be tailored to fit various needs by deactivation with water $(81,91,92,93)$. Although the properties of silica gel, alumina, and Florisil are very similar, a number of advantages exist for the use of Florisil to fractionate water extracts.

Florisil is commonly used to fractionate and clean-up complex mixtures $(74,94)$. The success of the fractionation scheme for pesticide analysis indicates the usefulness of Florisil fractionations for organic compounds. Florisil fractionation of pesticides has been useful for providing information about the pesticides present in samples and for the removal of components that interfere with the gaschromatographic determination of the pesticides. The simple technique developed by Mills for measuring the activity of Florisil (75) makes elution behaviors of compounds reproducible for columns packed with Florisil. For these 
reasons, Florisil was the adsorbent selected for fractionating water extracts.

Mutagenic testing

Mutagens have been determined in extracts of drinking waters (95). Mutagens can be detected in samples by a test developed by B. N. Ames et al. $(73,96)$. Mutations of various strains of Salmonella typhimurium indicate the presence of mutagens in a water sample. The mutagenic activities of compounds, as determined by the Ames Test, have been correlated to the carcinogenic potential of the compounds $(97,98)$. The strains of Salmonella used by Ames were histidine auxotrophs, which means they were unable to produce histidine. The histidine auxotrophs could not reproduce without having histidine present in their environment. Some substances caused mutations in these strains of Salmonella which made the bacteria able to produce histidine. The histidine produclng bacteria, histidine prototrophs, could grow and reproduce. By culturing these strains of bacteria with some nutrients and a finite amount of histidine, the population of the culture was limited by the amount of histidine present. If mutagens were introduced to the culture, the population was proportional to the number of mutations from histidine auxotrophs to histidine prototrophs caused by the mutagens. The mutagenic 
activities of numerous compounds $(97,98)$, cigarette-smoke condensates $(73,99)$, and shale oll (100) have been evaluated using the Ames Test.

\section{Experimental}

\section{Apparatus and reagents}

Gas chromatography A Tracor model 550 gas chromatograph equipped with an automatic linear temperature programmer, a flame ionization detector (FID), and a linearized electron capture detector (ECD) was used for this work. Modifications as previously described were implemented to operate the chromatograph with WCOT capillary columns and simultaneous detection with both detectors. Chromatograms were recorded with a Fisher Recordall series 5000 strip chart recorder.

Gravity-flow columns Glass columns of $8-\mathrm{mm}$ o.d., 6-mm 1.d. were fabricated. At one end of a $14-\mathrm{cm}$ segment of 8-mm glass tubing, a $1.5-\mathrm{cm}$ segment of 4-mm glass tubing was attached. An $8-\mathrm{cm}$ segment of $22-\mathrm{mm}$ glass tubing was attached to the remaining end of the $8-\mathrm{mm}$ glass tubing. The 22-mm glass tubing functioned as a reservoir for solvents.

Solution concentrators A solution concentrator fitted with a Snyder column was used to reduce the volumes of solutions by evaporative distillation. A diagram of a solution concentratior and Snyder column is shown in Figure 13 . 


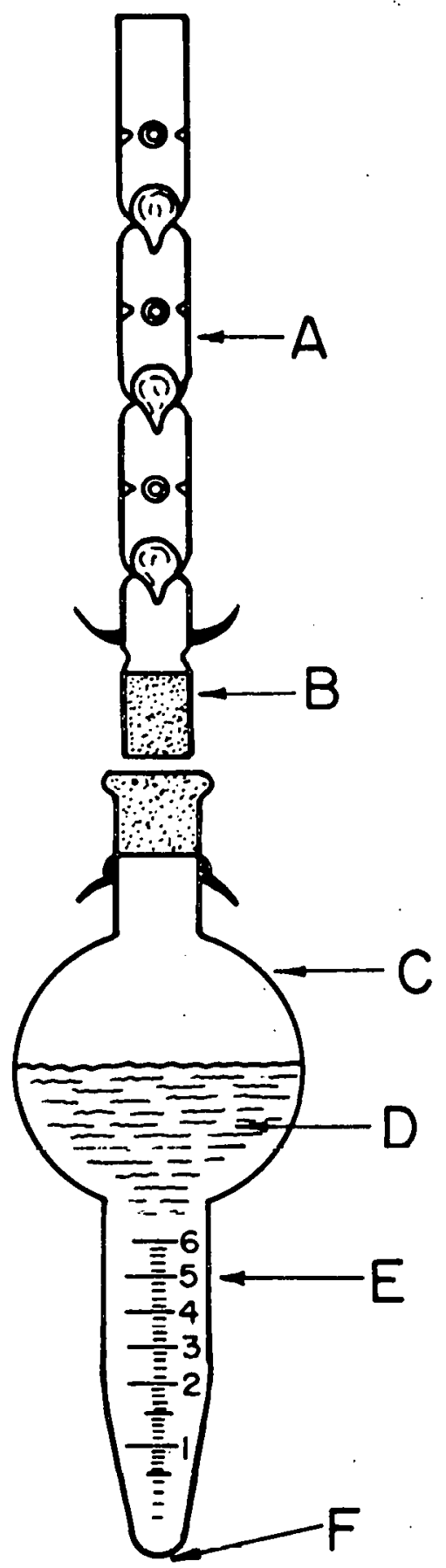

Figure 13. Solution concentrator: (A) Snyder distillation column; (B) $14 / 20$ standard taper; (C) $50 \mathrm{ml}$ flask; (D) solution; (E) graduated and calibrated taper; (F) boiling chip 
The concentrators were fabricated after the design described by Junk et al. to minimize the loss of compounds during concentration (6). Longer sections from calibrated centrifuge tubes were used than previously described to allow measurement of sample volumes in the range of $0.5-5.0 \mathrm{ml}$. Florisil Two batches of pesticide grade Florisil (a product of Floridin, Pittsburgh, Pennsylvania) were obtained from Fisher Scientific Company, Falr Lawn, New Jersey. Florisil was stored in a drying oven at $130^{\circ} \mathrm{C}$ for at least 24 hrs prior to use in the gravity-flow column or measuring its activity.

Amberlite $X A D-2$ resin Amberlite $X A D-2$ resin, a macroporous styrene-divynylbenzene copolymer, was obtained from Rohm and Haas, Philadelphia, Pennsylvania. Soxhlet extraction was used to clean the resin before sampling waters (6).

Solvents Diethyl ether for water extracts was obtained from Fisher Scientific Company, Fair Lawn, New Jersey. The diethyl ether was redistilled to remove the sodium diethyldithiocarbamate present as a free-radical inhibitor.

Petroleum ether $\left(30-60^{\circ} \mathrm{C} \mathrm{bp}\right)$, methylene chloride, and acetonitrile used in solutions to elute organic compounds from Florisil columns were distilled-in-glass grade obtained from Burdick and Jackson Laboratories, Inc., Muskegon, Michigan. 
Hydrofluoric acid, 48\% in water, was obtained from Fisher Scientific Company, Fair Lawn, New Jersey.

Techniques and procedures

Determination of Florisil activity The activity of Florisil used in this work was measured by the procedure developed by Mills (75). Two grams of Florisil and $20 \mathrm{ml}$ of hexane containing $400 \mathrm{mg}$ of lauric acid were stirred for 15 min. After allowing the Florisil to settle from the hexane solution, $10 \mathrm{ml}$ of the hexane solution above the Florisil were pipetted into a beaker containing $50 \mathrm{ml}$ of ethanol that had been neutralized to a phenolphthalein endpoint. The lauric acid remalning in the $10 \mathrm{ml}$ of hexane was titrated with $0.05 \mathrm{~N}$ aqueous sodium hydroxide solution. By dividing the amount of lauric acid sorbed on the Florisil by the weight of Florisil used, a value for the activity of the Florisil was obtained.

Fractionation procedure

Preparation of Florisil columns A quantity of Florisil was weighed out to give a total activity of $125 \mathrm{mg}$ lauric acid as measured by the procedure developed by Mills. If a batch of Florisil had an activity of $100 \mathrm{mg}$ lauric acid per gram, $1.25 \mathrm{~g}$ of Floris1l was welghed out to prepare a column.

A plug of Pyrex glass wool, approximately $1 \mathrm{~cm}$ thick, was placed at the bottom of a gravity-flow column. The 
correct amount of Florisil was added to the column and was made to settle by gently rapping the column. Another $1-\mathrm{cm}$ plug of Pyrex glass wool was placed on the top of the Florisil bed.

Prior to addition of a sample to the column; $15 \mathrm{ml}$ of petroleum ether was added to the column and the effluent from the column was discarded.

\section{Elution of compounds from Florisil columns}

Compounds were eluted from the Florisil columns in three fractions according to the following steps:

1. When the level of petroleum ether used to prepare the column reached the top of the glass-wool plug, the sample was pipetted onto the column.

2. A concentrator was placed under the column and coliection of the first fraction started.

3. When the level of liquid in the column again reached the glass-wool plug, $25 \mathrm{ml}$ of a $2 \%$ (volume/volume) solution of methylene chloride in petroleum ether was added to the column.

4. When the level of liquid approached the glass-wool plug, $25 \mathrm{ml}$ of a $50 \%$ (volume/volume) solution of methylene chloride in petroleum ether was added to the column.

5. Immediately after addition of the $60 \%$ solution, an empty solvent concentrator was placed under the column to collect the second fraction. 
6. As the level of the solution in the column again reached the glass-wool plug, $25 \mathrm{ml}$ of a petroleum ether solution contalning 60\% (volume/volume) methylene chloride plus $2 \%$ (volume/volume) acetonitrile was added to the column.

7. After addition of the $60 \%$ plus $2 \%$ solution, an empty solution concentrator was placed under the column to collect the third fraction.

\section{Fraction concentration After collecting the}

fractions from the Florisil columns, the volume of each fraction was reduced to the volume of the initial sample. After adding a couple of boiling chips to each solution concentrator, the solutions were heated to a boil. When the desired volumes were achieved, the solution concentrators were removed from the heat and allowed to cool. Fractions were removed from the solution concentrators and stored in glass vials with Teflon-faced septa under refrigeration.

Dissolution and extraction of Florisil with hydrofluoric acid To test for compounds that were not eluted, Florisil was dissolved and extracted by a method similar to that used by Kukreja and Bove (101). The steps of the dissolution and extraction procedure are as follows:

1. The glass-wool plug was removed from the top of the Florisil bed.

2. By rapping the side of the column, the top inch of Florisil was emptied from the column into a 50-ml glass beaker. 
3. Slowly $25 \mathrm{ml}$ of hydrofluoric acid was added to the beaker, then stirred periodically during the next five minutes.

4. The contents of the beaker and $25 \mathrm{ml}$ of petroleum ether were added to a separatory funnel. The contents of the separatory funnel were shaken, being careful to vent off gas pressure that bullds up.

5. After two layers formed, the lower layer was removed into the 50-ml beaker.

6. The upper layer was removed into a solution concentrator.

7. Steps 4, 5, and 6 were repeated and the upper layer was added to the same solution concentrator.

8. The volume of the petroleum ether solution was reduced as described above.

Model compound recoveries Solutions containing between $1 \times 10^{-8}$ and $1 \times 10^{-6} \mathrm{~g} / \mu 1$ of model compounds were made up in petroleum ether. The petroleum-ether solutions were introduced to Floris1l columns and fractionated according to the described procedure. After decreasing the volume of each fraction, gas chromatograms of each fraction and the initial sample were obtained. To evaluate the total recovery efficiency of the fractionation scheme, the fractions from the Florisil column were combined before concentration. 
Preparation of water extracts Extracts of water in diethyl ether were obtained by passing water through beds of XAD-2, eluting compounds from the XAD-2 with diethyl ether, and concentrating the volume of the effluent to a small volume (6). Prior to introduction to Florisil columns, the diethyl-ether solutions were placed in solution concentrators with approximately twenty times the volume of petroleum ether. A couple of boiling chips were added to each solution concentrator, a Snyder column placed on the concentrators, and the volumes of the solutions reduced to that of the initial solutions by boiling. The petroleum-ether solutions were then ready to be fractionated on columns packed with Florisil. If a precipitate formed, the precipitate was allowed to settle before removing the solution to be fractionated.

Mutagenicity testing The potential health hazards of waters were estimated by testing the extracts for mutagens by the procedure described by Ames, McCann, and Yamasaki (102). Work performed at Iowa State University indicates that organic compounds concentrated from some drinking waters were mutagenic $(95,103)$. Samples in volatile solvents were added to 500 lil. of dimethyl sulfoxide (DMSO). The volatile solvents were allowed to evaporate; concentrating the organic compounds into the DMSO. Mutagenic activities of the DMSO solutions were determined by adding $10 \mu 1$ of the DMSO solutions to petri 
dishes of agar seeded with Salmonella according to the procedure described by Ames, McCann, and Yamasaki (102). Salmonella typhimurium strains TA98, TA100, TA1535, TA1537, and TA1538 were used for testing the samples. Positive or mutagenic activities were recorded if the number of colonies on the test plates were at least twice the number of colonies on solvent control plates. Marginal positives were recorded if only small increases in the numbers of colonies were observed.

Results and Discussion

Development of analytical technique

The usefulness of fractionating water extracts on Florisil columns was evaluated. Various parameters that affect the separation on Florisil were examined.

Selection of solvent system The widely used technique for fractionating pesticide samples on Florisil by eluting with solutions of petroleum ether and diethyl ether (74) was applied to fractionation of mixtures of model compounds. The data in Table 15 indicate the poor resolution obtained by eluting small columns that were packed with Florisil with mixtures of diethyl ether and petroleum ether. Because compounds eluted faster from the smaller columns, the fraction of each compound in the mobile phase was significant. The reproducibility of the fractionation with these solvents would 
Table 15. Percentage of model compounds in fractions eluted from Florisil with dietryl ether in petroleum ether

\begin{tabular}{|c|c|c|c|c|c|c|c|c|c|c|c|c|}
\hline \multirow[t]{2}{*}{$\begin{array}{l}\text { Compound } \\
\text { Column }\end{array}$} & \multicolumn{2}{|c|}{ Tridecane } & \multicolumn{2}{|c|}{$1-0 c \tan 01$} & \multicolumn{2}{|c|}{$\begin{array}{c}\text { 2-Indeca- } \\
\text { none }\end{array}$} & \multicolumn{2}{|c|}{$\begin{array}{l}\text { 1-Chloro- } \\
\text { dodecane }\end{array}$} & \multicolumn{2}{|c|}{ Naphthalene } & \multirow{2}{*}{$\begin{array}{c}\text { Benzyl } \\
\text { A }\end{array}$} & \multirow{2}{*}{$\begin{array}{c}\text { Alcohol } \\
\text { B }\end{array}$} \\
\hline & $A^{a}$ & $\mathrm{~B}^{\mathrm{b}}$ & A & B & A & $B$ & A & B & A & $\mathrm{B}$ & & \\
\hline \multicolumn{13}{|l|}{ Fraction ${ }^{c}$} \\
\hline $0 \%$ & 83 & 100 & 0 & 0 & D & 0 & 22 & 100 & 0 & 9 & 0 & 0 \\
\hline $10 \%$ & 17 & 0 & 0 & 0 & 0 & 57 & 78 & 0 & 97 & 91 & 0 & 0 \\
\hline $25 \%$ & 0 & 0 & 0 & 100 & 0 & 43 & 0 & 0 & 3 & 0 & 0 & 63 \\
\hline $50 \%$ & 0 & 0 & 0 & 0 & 83 & 0 & 0 & 0 & 0 & 0 & 0 & 37 \\
\hline $100 \%$ & 0 & 0 & 100 & 0 & 17 & 0 & 0 & 0 & 0 & 0 & 100 & 0 \\
\hline
\end{tabular}

${ }^{2}$ Column bed $2.2 \times 10 \mathrm{~cm}$.

${ }^{\mathrm{b}}$ Column bed $1.5 \times 10 \mathrm{~cm}$.

${ }^{c} 100 \mathrm{ml}$ of eluent per fraction, percentage indicates the amount of diethy ether in the eluent used to collest the fraction. 
be dependent on the reproducibility of fraction volumes. To ensure reproducibility of elution behavior, the number of bed volumes of each eluent would have to be reproduced. Rather than accurately reproduce the amount of eluent used, it would be preferable to use eluents that greatly changed the distribution coefficients of compounds. If a compound is to be present in a fraction, the solvent used to collect the fraction should cause the compound to have a very small distribution coefficient. With solvents not used to elute the compound from the column, the distribution coefficient should be very large.

Distribution coefficients (D) for some model compounds between Florisil and various solvents are shown in Table 16. Approximate values for distribution coefficients were obtained by collecting fractions from Florisil columns. Small fractions from gravity-flow columns were collected, then the fractions were analyzed by gas chromatography. By measuring the peak heights for compounds in each fraction, the retention volume $\left(V_{R}\right)$ for each compound was approximated. After measuring the vold volume of the column $\left(V_{V}\right)$, the distribution coefficient was calculated from the equation below. The great differences in distribution coefficients

$$
D=\frac{V_{R}-V_{V}}{V_{V}}
$$


Table 16. Distribution coefficients (D) for some model compounds between Filorisil and various solvents

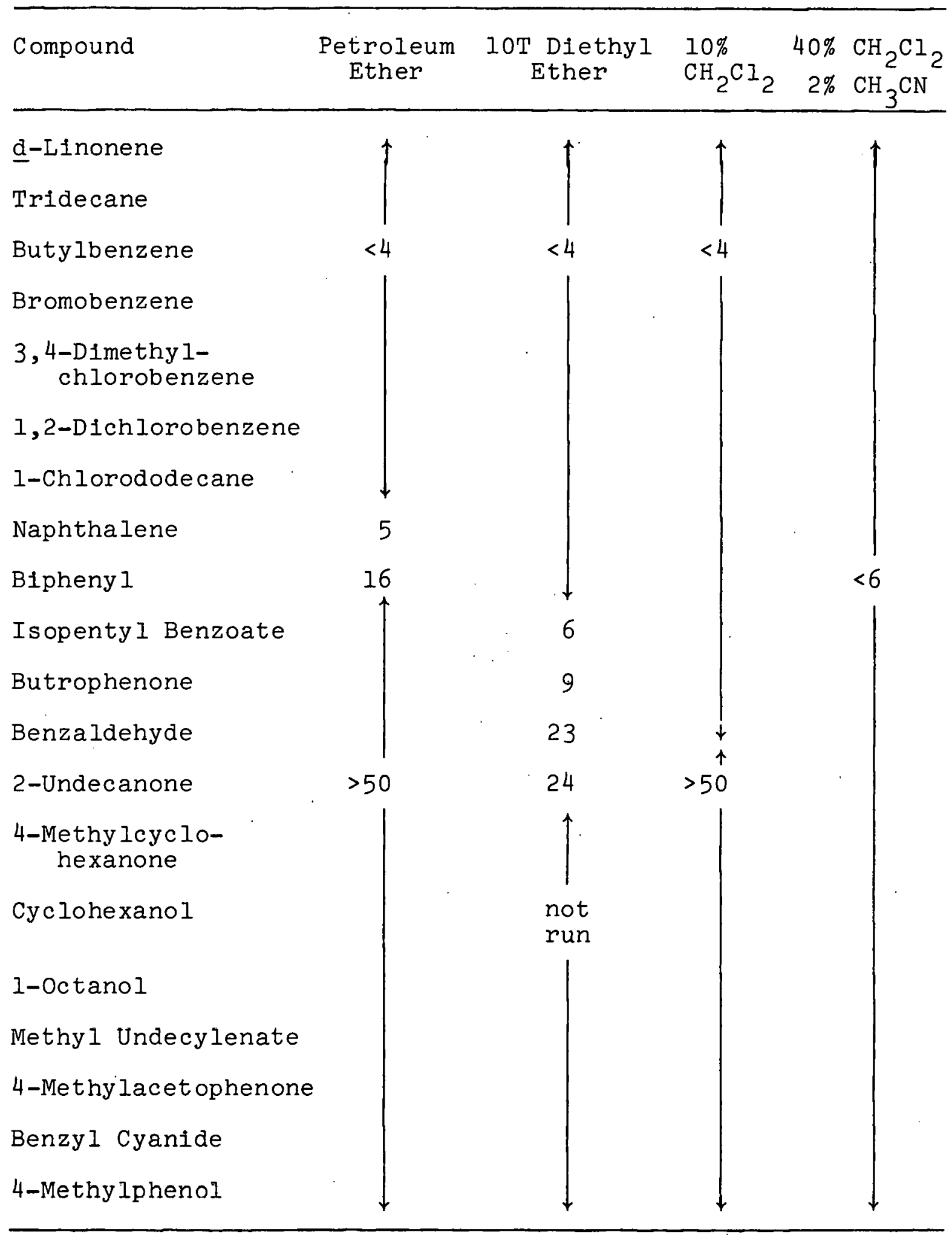


obtained with $10 \%$ methylene chloride in petroleum ether vs $40 \%$ methylene chloride plus $2 \%$ acetonitrile in petroleum ether indicate that elution with these solvents would minimize the variation of elution behaviors of compounds. The effects of sample volume, Florisil activity, fraction size, eluent composition, etc. on the elution behaviors of compounds would be minimized if the distribution coefficients of compounds are greatly different with the solvents used for elution of the column.

Snyder has measured the eluent strengths $\left(\varepsilon^{\circ}\right)$ of many solvents for different sorbents $(91,93,104)$. The eluent strength of a solvent is a measure of the ability of a solvent to elute strongly sorbed compounds. A list of the eluent strengths of some solvents as determined by Snyder for Florisil is in Table 17. The eluent strength of a solvent of

Table 17. Elution strengths $\left(\varepsilon^{\circ}\right)$ of some solvents for Florisil

\begin{tabular}{ll}
\hline Solvent & $\varepsilon^{\circ}$ \\
\hline Pentane & 0.00 \\
Carbon Tetrachloride & 0.07 \\
Benzene & 0.28 \\
Chloroform & 0.31 \\
Methylene Chioride & 0.37 \\
Diethyl Ether & 0.49 \\
\hline
\end{tabular}


mixed composition can be calculated by summing the fraction of eluent strength provided by each component of the mixture.

Additional solvents containing petroleum ether, diethyl ether, methylene chloride, acetonitrile, methanol, benzene, and acetone were evaluated for eluting organic compounds from Florisil. Results showed that even small amounts of acetone or acetonitrile in a solvent greatly increased the elution strength of a solvent. From these experiments, the three solvents that caused the distribution coefficients for compounds to change greatly were selected for elution of the Florisil columns. In order of their addition to the Florisil, the solvents that were selected for elution of the Florisil columns were: $2 \%$ methylene chloride in petroleum ether, $60 \%$ methylene chloride in petroleum ether, and $60 \%$. methylene chloride plus $2 \%$ acetonitrile in petroleum ether. The Florisil columns were eluted with $25 \mathrm{ml}$ of each of the solvents.

Fifferts of water in samples The dictribution coefficients of compounds onto Florisil from organic solutions vary with the water content of the Florisil (93). Water is strongly adsorbed onto the surface of Florisil, altering the activity of the Florisil. Approximate distribution coefficients obtained by collecting fractions from 6-mm x 10-cm. gravity-flow columns are listed in Table 18. The data in Table 18 indicate that water present in a sample. has only small affects on the elution behaviors of model 
Table 18. Variation in distribution coefficients (D) on Florisil with water presenta

\begin{tabular}{|c|c|c|c|c|c|c|}
\hline \multirow[b]{2}{*}{ Compound } & \multirow[b]{2}{*}{$\mu \mathrm{I} \mathrm{H}_{2} \mathrm{O}$} & \multicolumn{2}{|l|}{ D } & \multirow[b]{2}{*}{$\mu 1 \mathrm{H}_{2} \mathrm{O}$} & \multirow[b]{2}{*}{500} & \multirow[b]{2}{*}{$\mu \mathrm{IH} \mathrm{H}_{2} \mathrm{O}$} \\
\hline & & $50 \mu \mathrm{I} \mathrm{H}_{2} \mathrm{O}$ & 200 & & & \\
\hline Bromobenzene & 0.85 & 1.1 & & 2.0 & & 1.1 \\
\hline Butylbenzene & 4.6 & 3.4 & & 3.9 & & 2.5 \\
\hline Naphthalene & 4.4 & $3 \cdot 3$ & & 2.9 & & 2.5 \\
\hline Dodecane & 2.3 & 2.2 & & 2.0 & & 1.1 \\
\hline 1-Tetradecane & 0.7 & 0.8 & & $0: 8$ & & $2 \cdot 3$ \\
\hline 1-Chlorodecane & 4.4 & 3.5 & & 3.0 & & 1.7 \\
\hline Hexadecane & 6.4 & 4.5 & & 6.4 & & 6.8 \\
\hline
\end{tabular}

compounds. Because the solubility of water in hexane is approximately $1.38 \times 10^{-4} \mathrm{~g} / \mathrm{ml}(105)$; the amount of water introduced to a column of Florisil by adding. samples in petroleum ether should have negligible effects on the retention behavior of compounds in the sample.

Effects of Florisil activity The effectiveness of adjusting the amount of Florisil used in a column, based upon the activity of the Florisil, was evaluated. A technique developed by Mills was used to measure the activity of 
Florisil (75). Distribution coefficients $\left(D=\frac{t_{R}-t_{V}}{t_{V}}\right)$ calculated from retention times $\left(t_{R}\right)$ on Florisil columns of 6-mm 1.d. are listed in Table 19. A Chromatronix Cheminert metering pump and a Chromatronix Model 220 UV detector were used to determine the retention times of model compounds. The time for a nonretained substance to reach the detector $\left(t_{\mathrm{V}}\right)$ was determined by introducing hexane to the column. By dividing the activity of the Florisil bed by a compound's distribution coefficient, the activity of Florisil per distribution coefficient unit (activity/D) was obtained. The ratios of activity per distribution coefficient unit for the low-activity Florisil versus the high-activity Florisil are shown in the last column of Table 19. Because these ratios are near unity, the retention behavior of compounds can be reproduced by adjusting the amount of Florisil packed into the column. If the total activity of Florisil in a column is equal to the total activity of Florisil in another column, the elution behaviors of compounds on the two columns will be the same.

Elution behaviors of model compounds Elution behaviors of organic compounds were determined by fractionating samples of model compounds on Florisil columns. The compounds in each fraction were determined by gas chromatography. Chromatograms for a sample of model compounds and fractions from the sample are in Figure 14. Except for 
Table 19. Retention behavicr of compounds on different activities of Florisil

\begin{tabular}{|c|c|c|c|c|c|c|}
\hline \multirow[b]{2}{*}{ Compound } & \multirow[b]{2}{*}{ Solvent } & \multicolumn{2}{|c|}{$\begin{array}{l}\text { Low-Activity } \\
\text { Florisila }\end{array}$} & \multicolumn{2}{|c|}{$\begin{array}{l}\text { High-Activity } \\
\text { Florisil }\end{array}$} & \multirow{2}{*}{$\begin{array}{c}\text { Ratio } \\
\text { D/Activity }\end{array}$} \\
\hline & & $\underline{D}^{C}$ & Activity/D $\mathbb{D}^{\mathbb{\alpha}}$ & $\underline{\mathrm{D}}$ & Activity/D & \\
\hline Benzene & pet. ether & 0.90 & 210 & 2.0 & 188 & 1.12 \\
\hline Bromobenzene & pet. ether & 0.60 & 315 & 1.0 & 375 & 0.84 \\
\hline Naphthalene & $\begin{array}{l}\text { pet. ether } \\
2 \% \mathrm{CH}_{2} \mathrm{Cl}_{2}\end{array}$ & $\begin{array}{l}2.9 \\
1.4\end{array}$ & $\begin{array}{r}65 \\
135\end{array}$ & $\begin{array}{l}8.2 \\
2.8\end{array}$ & $\begin{array}{r}46 \\
134\end{array}$ & $\begin{array}{l}1.41 \\
1.01\end{array}$ \\
\hline N1trobenzene & $60 \% \mathrm{CH}_{2} \mathrm{Cl}_{2}$ & 1.6 & 118 & 3.2 & 117 & 1.01 \\
\hline$\frac{3-\text { tert- }}{\text { Butylphencl }}$ & $60 \% \mathrm{CH}_{2} \mathrm{Cl}_{2}$ & 1.8 & 105 & 4.2 & 89 & 1.18 \\
\hline Benzyl Alcohcl & $60 \% \mathrm{CH}_{2} \mathrm{Cl}_{2}$ & 2.4 & 78 & 7.6 & 49 & 1.60 \\
\hline
\end{tabular}

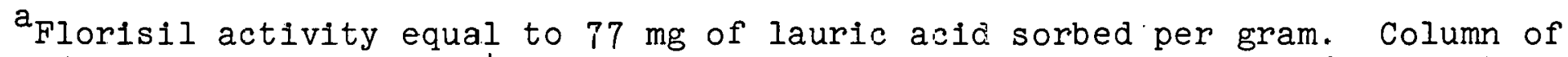
$6 \mathrm{~mm} 1 . \mathrm{d}$. was packed with $2.45 \mathrm{~g}$ of Florisil to make total activity of the column equal to $189 \mathrm{mg}$ of lauric acid.

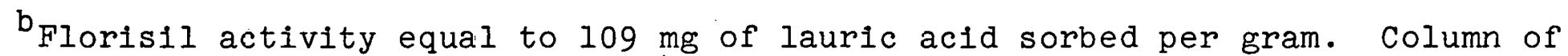
$6 \mathrm{~mm}$ i.d. Was packed with $3.44 \mathrm{~g}$ of Fiorisil to make total activity of the column equal to $375 \mathrm{mg}$ of lauric acid.

${ }^{c}$ Distribution coefficient.

dactivity of Florisil bed divided by the distribution coefficient.

${ }_{\text {Activity per } D}$ unit for the low-activity Florisil divided by the activity per $D$ unit for the high-activity Florisil. 
Figure 14. Chromatograms from a mixture and fractions from the mixture: (a) separation of model compounds in a mixture; (b) separation of compounds in first fraction; (c) separation of compounds in second fraction; (d) separation of compounds in third fraction. Chromatographic conditions:

Column - WCOT, Carbowax 20M stationary phase, $28 \mathrm{~m} \mathrm{x} 0.25 \mathrm{~mm}$ i.d.

Temperature - Isothermal at $80^{\circ} \mathrm{C}$ for $4 \mathrm{~min}$, then increased temperature at $4^{\circ} \mathrm{C} / \mathrm{min}$. Maximum temperature of $200^{\circ} \mathrm{C}$ held for $4 \mathrm{~min}$

Carrier gas - $30 \mathrm{~cm} / \mathrm{sec}$ of helium

Sample introduction $-2 \mu \mathrm{I}, 30 \mathrm{sec}$ spitless

Make-up gas - $100 \mathrm{ml} / \mathrm{min}$ of nitrogen

Backflush gas - $20 \mathrm{ml} / \mathrm{min}$ of helium

ECD purge gas - $65 \mathrm{ml} / \mathrm{min}$ of nitrogen

Detection - Top: $E C D$, attenuation $=8$

Bottom: FID, attenuation $=8$

Exit-split ratio (ECD:FID) - 2:5

Sample components - $6 \times 10^{-9} \mathrm{~g} / \mu \mathrm{l}$ each

Peak Number $\quad$ Compound

2-Ethylhexyl acetate

1,2-D1chlorobenzene

1-Octanol

Benzyl nitrile

1,2,4-Trichlorobenzene

Nitrobenzene

Benzothiophene

n-Butyrophenone

Benzyl alcohol

I-Me thy Inaph tha lene

11

Isopentyl benzoate

12

Acenaphthalene

13

Tributy 1 phosphate 

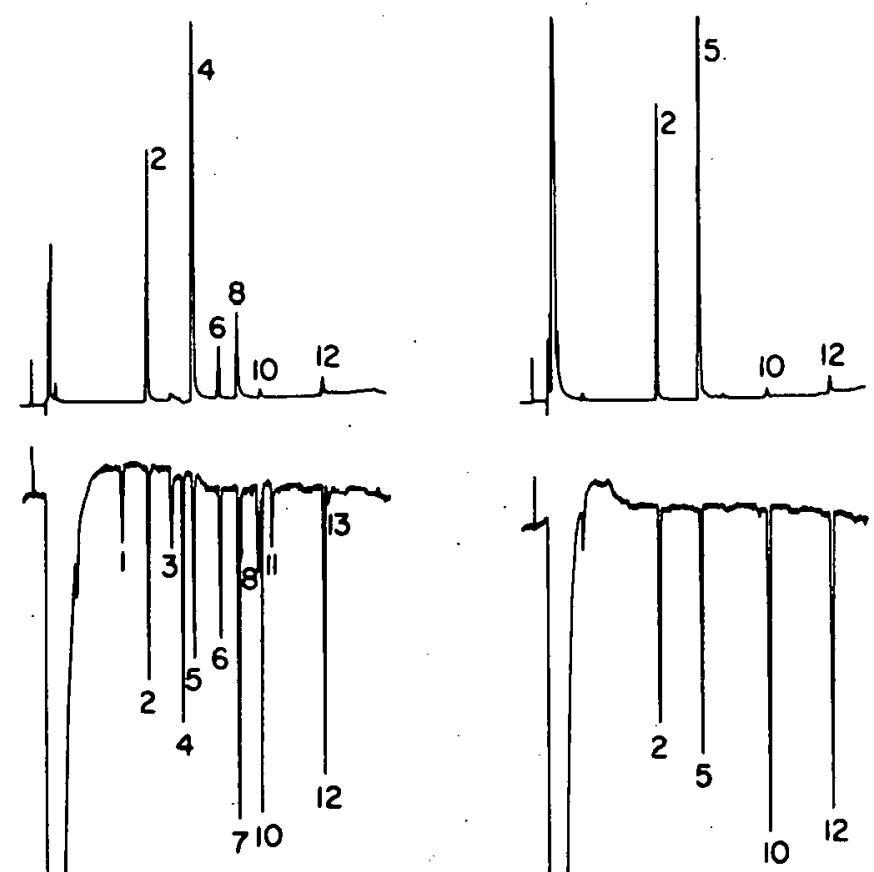

(a)
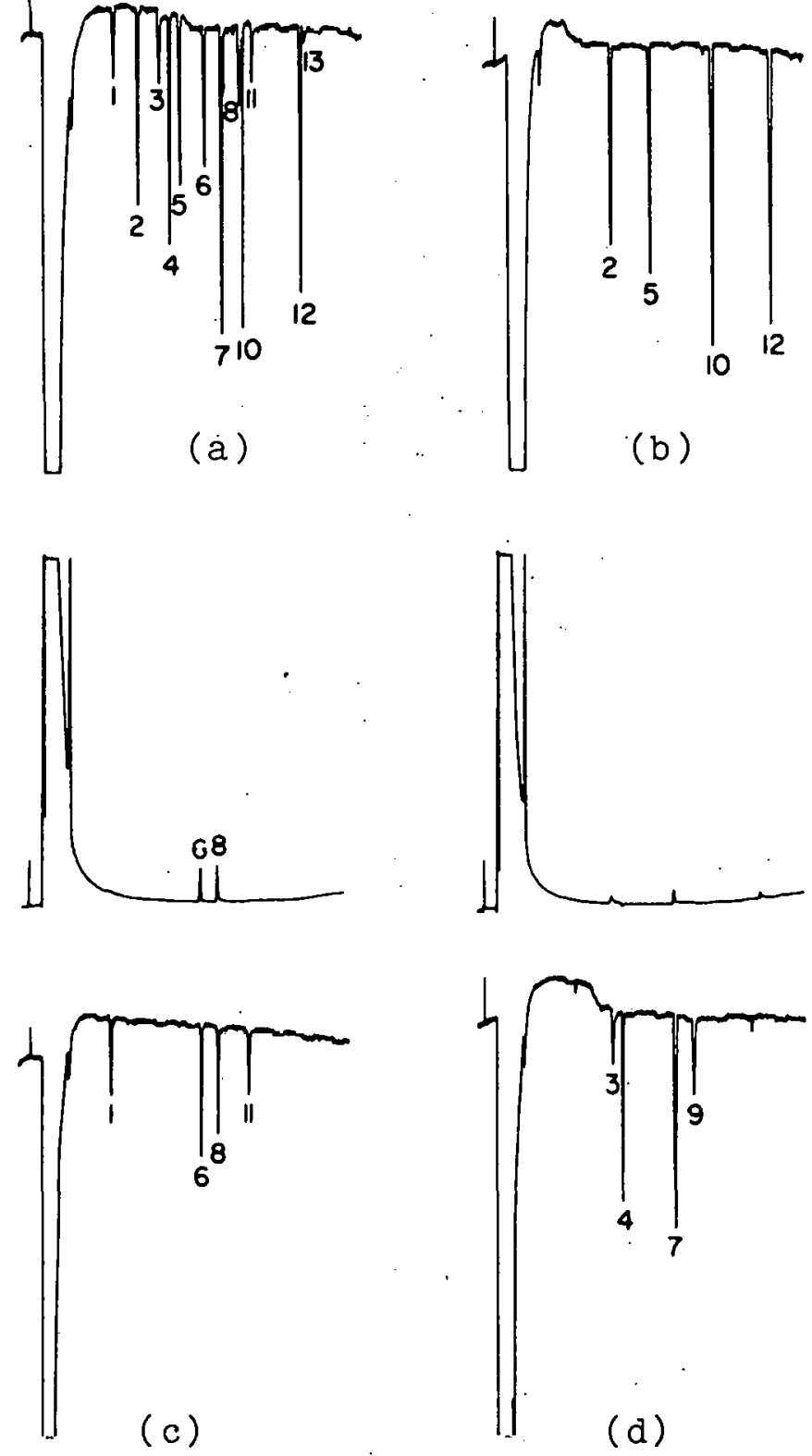
tributyl phosphate, all of the organic compounds in the mixture were present in one of the fractions. Table 20 lists compounds according to the fraction they were eluted from Florisil. Of all the organic compounds introduced to the Florisil columns, tributyl phosphate was the only compound not eluted by the solvents. Of the compounds listed in Table 20, only a few compounds were present in more than one fraction. Interpretation of chromatograms obtained from samples fractionated by this technique was simplified by the reproducibility and the resolution obtained.

For clarlty, the fractions collected from the Florisil columns will be referred to in an abbreviated form. 'The fraction eluted from Florisil with $2 \%$ methylene chloride in petroleum ether will be referred to as the first fraction. The fractions eluted with $60 \%$ methylene chloride in petroleum ether and $60 \%$ methylene chloride plus $2 \%$ acetonitrile in petroleum ether will be referred to as the second fraction and third fraction, respectively.

The first fraction contained hydrocarbons and halogenated hydrocarbons. The eluent strength of the first solvent was low; thus, only nonpolar compounds that were weakly retained by Florisil were eluted from the column with the first solvent.

The boundary between the second and third fractions was not as well defined as the boundary between the first and 
second fractions. Compounds having the following functional groups were eluted in the second fraction: nitro, carbonyl, or ester. Compounds found in the third fraction were alcohols, nitriles, and esters of dibasic acids. Elution behaviors of some classes of compounds were not well established by the data in Table 20. For example, some phenols, amines, and polyfunctional compounds were eluted in the second fraction, while other phenols, amines, and polyfunctional compounds were eluted in the third fraction. Recovery Recoveries of compounds from samples were determined by measuring peak heights from chromatograms for samples before and after passing the samples through Florisil columns. Recoveries of model compounds and gaschromatographable components from water samples were determined. Although large deviations were caused by volume measurements and peak height measurements, recoveries of most compounds from the Florisil columns were 80-120\%. The complexity of chromatograms obtained from water extracts made accurate measurements of recoveries difficult.

It was discovered that small amounts of some polar compounds were not eluted from the Florisil columns. Approximately $10 \mu \mathrm{g}$ of tributy 1 phosphate was present in a water extract. The tributyl phosphate in the water extract was not present in any of the fractions collected from the Florisil column, but the tributyl phosphate was recovered by 
Table 20. Model compounds grouped according to the fraction the compounds eliuted from Filorisil

\begin{tabular}{|c|c|c|}
\hline First Fraction & Second Fraction & Third Fraction \\
\hline Hexadecane & Nitrobenzene & 2,5-Hexanedione \\
\hline Octadecane & $\begin{array}{l}\text { 1-Chloro-3- } \\
\text { nitrobenzene }\end{array}$ & $\begin{array}{l}\text { 4-Methy lcyclo- } \\
\text { hexanone }\end{array}$ \\
\hline 1-Chlorodecane & 1-Nitronaphthalene & Methyl undecylenate \\
\hline 1-Bromododecane & & $\begin{array}{c}\text { 2-(2-Butoxyethoxy)- } \\
\text { ethyl acetate }\end{array}$ \\
\hline I-Iodooctane & Phenylacetonitrile & Diethyl phthalate \\
\hline Bromo form. & 2-Undecanone & Dibutyl phthalate \\
\hline 4-MethyIdecane & Cyclohexanone $\mathrm{b}^{\mathrm{b}}$ & Diethyl malonate \\
\hline 1-Tetradecene & $\begin{array}{l}\text { n-Butyrophenone } \\
\text { 4-Methyl ace tophenone }\end{array}$ & $e^{\frac{1-O c t a n o l}{b}}$ \\
\hline d-I-imonene & Benzaldehyde & Benzyl alcohol \\
\hline Pinene & Dibutoxybenzene & 2,4-Dichlorophenol \\
\hline Biphenyl & $\begin{array}{l}\text { 2-Ethylhexyl acetate } \\
\text { Isopentyl benzoate }\end{array}$ & $\mathrm{N}, \mathrm{N}$-Dimethylaniline \\
\hline Naphthalene & Phenol ${ }^{b}$ & 2,4--Dime thy laniline \\
\hline $\begin{array}{l}\text { Acenaphthalene } \\
\text { Butylbenzene }\end{array}$ & 3-tert-Butylphenol & N-Ethylaniline \\
\hline $\begin{array}{l}\text { I-Methy lnaphthalene } \\
\text { Bromobenzene }\end{array}$ & 2,6-Dime thylphenol & Benzyl nitrile \\
\hline $\underline{\alpha-C h l o r o n a p h t h a l e n e}$ & 1-Naphthy lamine & Benzothiophene \\
\hline $\begin{array}{l}\text { 1,2-Dichlorobenzene } \\
\text { 1,2,4-Trichlorobenzene } \\
\text { 3,4-Dinethylchlorobent }\end{array}$ & $\begin{array}{l}\text { Dibenzy lamine } \\
\text { ne } \\
\text { nzene }\end{array}$ & \\
\hline \multicolumn{3}{|c|}{ Polychlorinated biphenyls } \\
\hline \multicolumn{3}{|c|}{ 4-Iodotoluene } \\
\hline \multicolumn{3}{|c|}{$\begin{array}{l}{ }^{a} \text { Some of this compound was found in the previous } \\
\text { fraction. }\end{array}$} \\
\hline $\begin{array}{l}{ }^{b} \text { Some of this con } \\
\text { raction. }\end{array}$ & ompound was found in & the foll \\
\hline
\end{tabular}


dissolving the Florisil in hydrofluoric actd. When $1 \mathrm{mg}$ of tributyl phosphate was introduced to a Florisil column, greater than $90 \%$ of the tributyl phosphate was eluted in the third fraction. The greater retention of tributyl phosphate at low concentrations indicates that some heterogeneity of Florisil exists. Recoveries obtained for tributyl phosphate indicate that recoveries of other phosphorus and polar compounds may be incomplete.

\section{Analytical determinations}

Gas-chromatographic analysis Extracts of drinking waters from fifteen utilities were fractionated on Florisil columns. Water samples were obtained from fourteen clties that participated in an American Water Works Association (AWWA) sponsored water quality survey (106) and Ames, Iowa. Sampling was performed in the fall of 1976. The amount of water sampled from each city was approximately 400 liters. The organic compounds from 100-1. water samples were sorbed on 6-in $\times 5 / 8$-in brass columns packed with Amberlite XAD-2. The organic compounds were eluted from the XAD-2 with $100 \mathrm{ml}$ of diethyl ether. The diethyl-ether solutions from each city were combined and reduced to a volume of $5 \mathrm{ml}$ by evaporative distillation. Half of the volume from the diethyl-ether solutions were taken for fractionation on Florisil columns. 
The identities of the fourteen cities participating in the AWWA sponsored survey are to remain confidential. For this survey, It was agreed that results of this survey would remain confidential, unless the utilities themselves wished to release information obtained from this survey. In the following discussion, the water sources will be referred to as Cities \#1-14.

Chromatograms obtained from two water extracts and fractions from those extracts are in Figures $15-24$. The identities and concentrations of most of the components of these samples have not been determined, but the chromatograms demonstrate the separations that are possible by fractionating water extracts on small columns packed with Florisil.

Chromatograms of the organic compounds concentrated from City \#l's water are in Figures $15-20$. Chromatographic conditions for the separations in Figures $15-20$ are given in Table 21. By comparing the chromatograms in Figure 17 to those in Figure 15, it can be concluded that the majority of compounds that give a large response on the electron capture detector (ECD) are nonpolar. Large peaks are observed for bromodichloromethane and dibromochloromethane using the ECD. The haloforms present in the water are probably formed during the treatment procedure by the action of chlorine on humic matter and bromide present in the water $(27,28)$. Because halogenated hydrocarbons are the only nonpolar compounds 
that give a large relative response on the ECD versus the FID, the chromatograms in Figure 17 indicate that only a small portion of the gas-chromatographable material in this water was haloforms.

Figure 16 demonstrates that only a small portion of the gas-chromatographable material was precipitated when changing the solvent from diethyl ether to petroleum ether. The total amount of precipitate formed for the extract from City \#l was $7 \mathrm{mg}$. The precipitate was dissolved in a volume of methanol that equaled the volume of the extract. A number of compounds were present in the second and third fractions from city \#1.

The chromatograms in Figure 18 and Figure 19 contain peaks for a number of polar compounds that were extracted from the water of City \#1. It is apparent by inspecting the chromatograms that it would be easier to determine a polar compound in this sample after fractionating than before fractionating the sample.

Tributyl phosphate present in the water extract from City \#1 was not eluted from the Florisil column by any of the solvents. Figure 20 demonstrates that tributyl phosphate was recovered from the Florisil column by dissolving the Florisil in hydrofluoric acid, then extracting the hydrofluoric-acid solution with petroleum ether. As previously discussed, small amounts of tributyl phosphate were not eluted from the Florisil with the solvents used. 
Table 21. Chromatographic conditions for Figures $15-20$

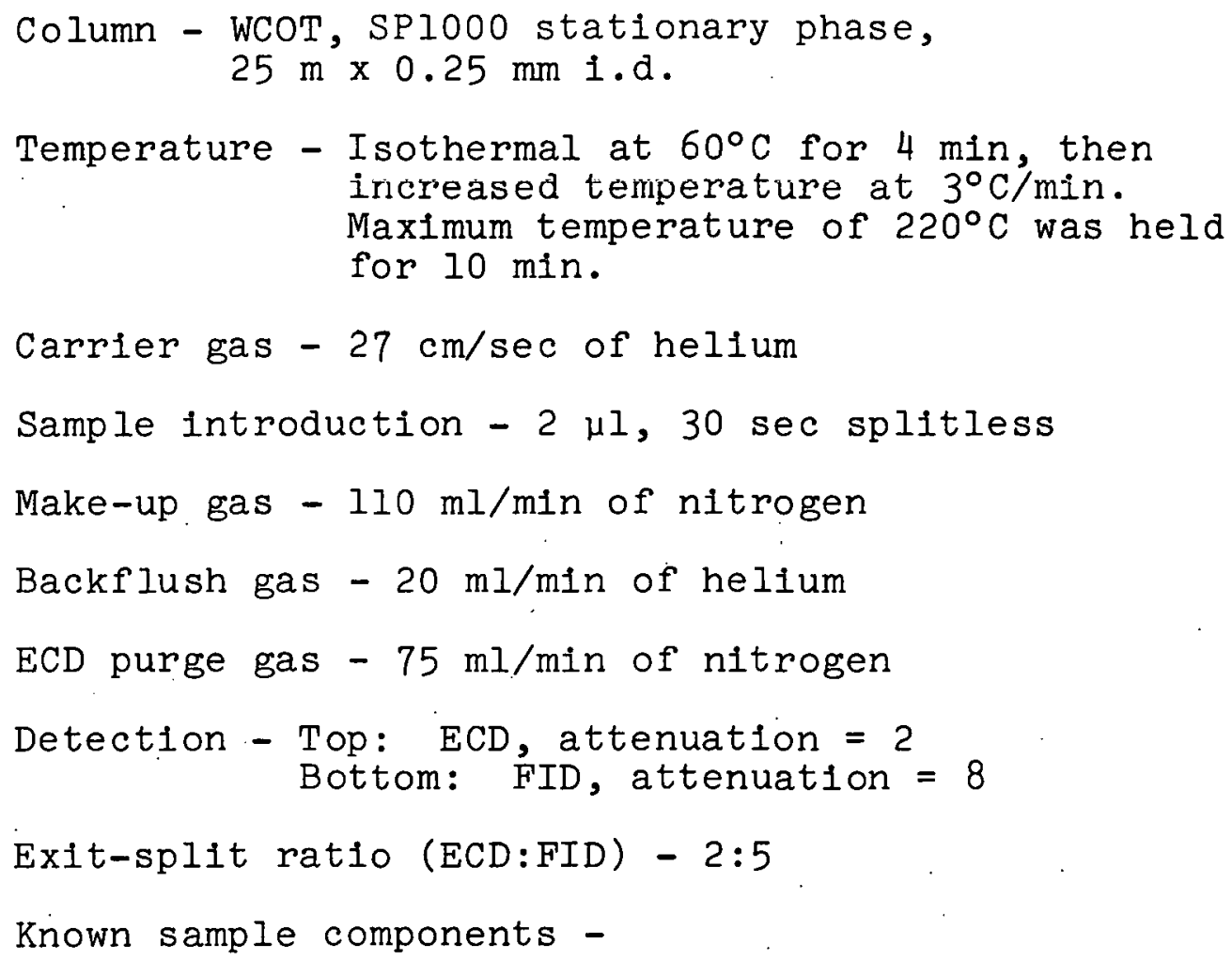



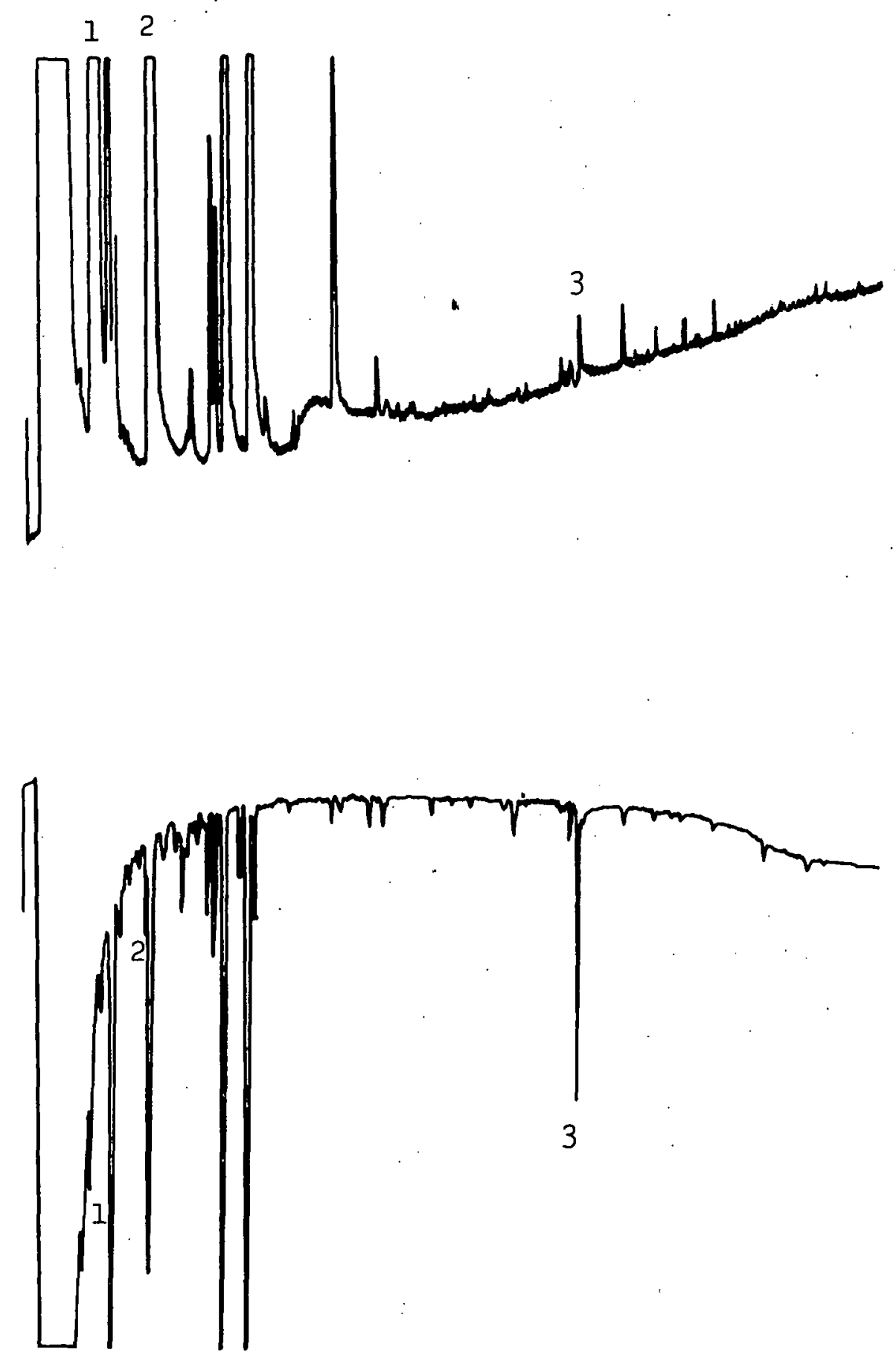

Figure 15. Separation of compounds extracted from City \#I's water supply 
126
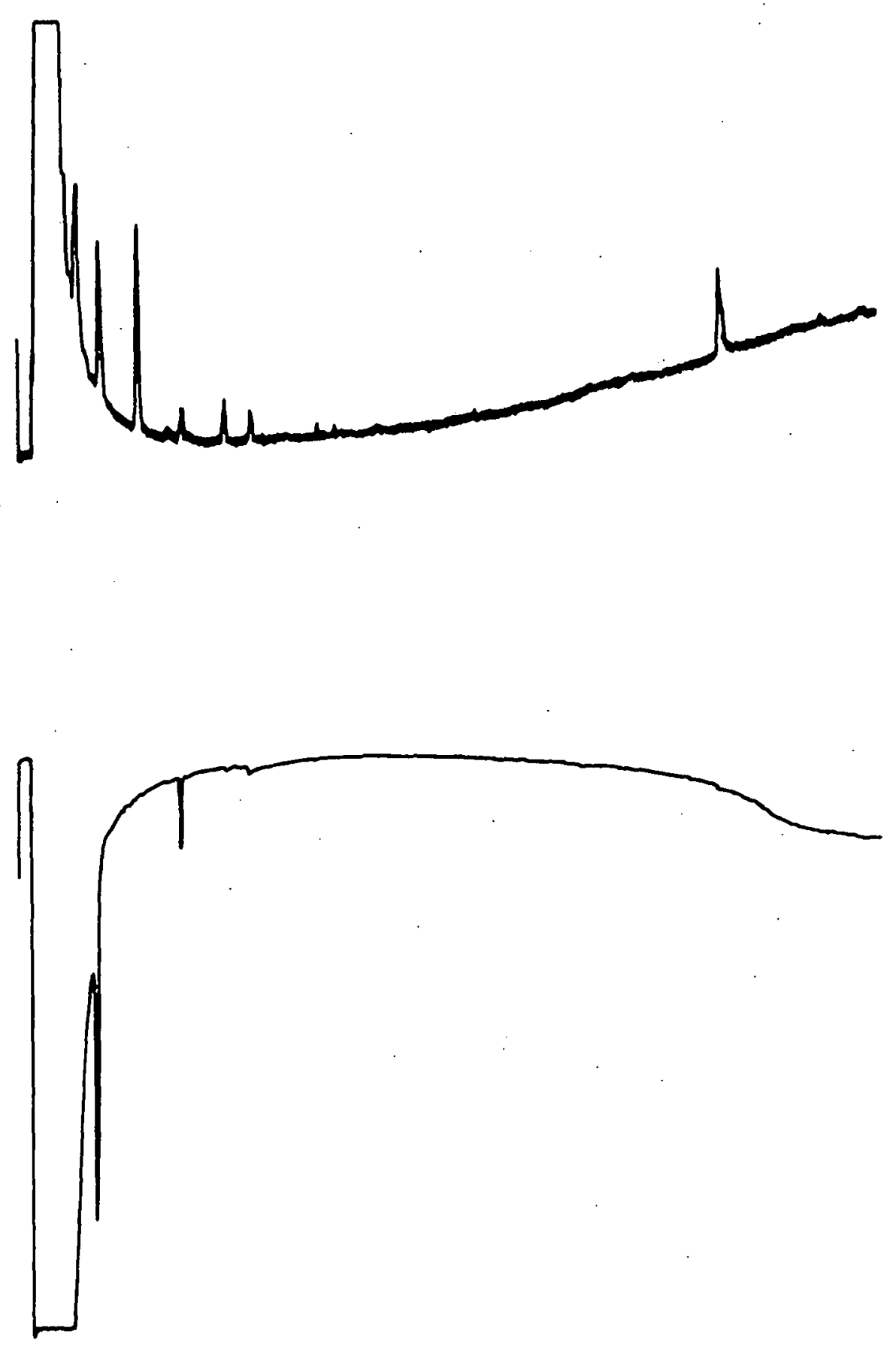

Figure 16. Separation of compounds from City \#1's water supply chat were not soluble in petroleum ether 
12
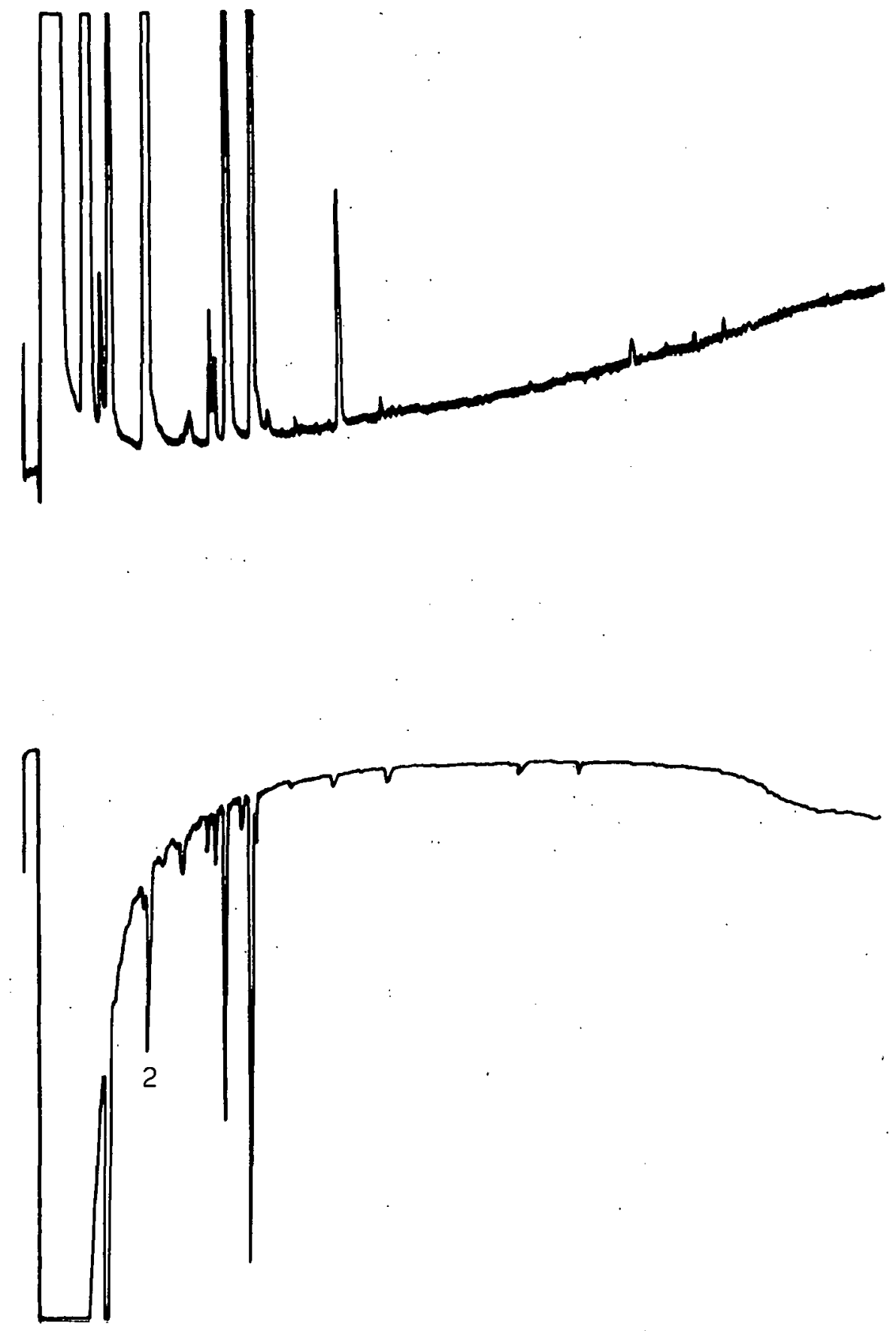

F1gure 17. Separation of compounds from City \#I's water supply that were eluted in the first fraction from the Florisil column 

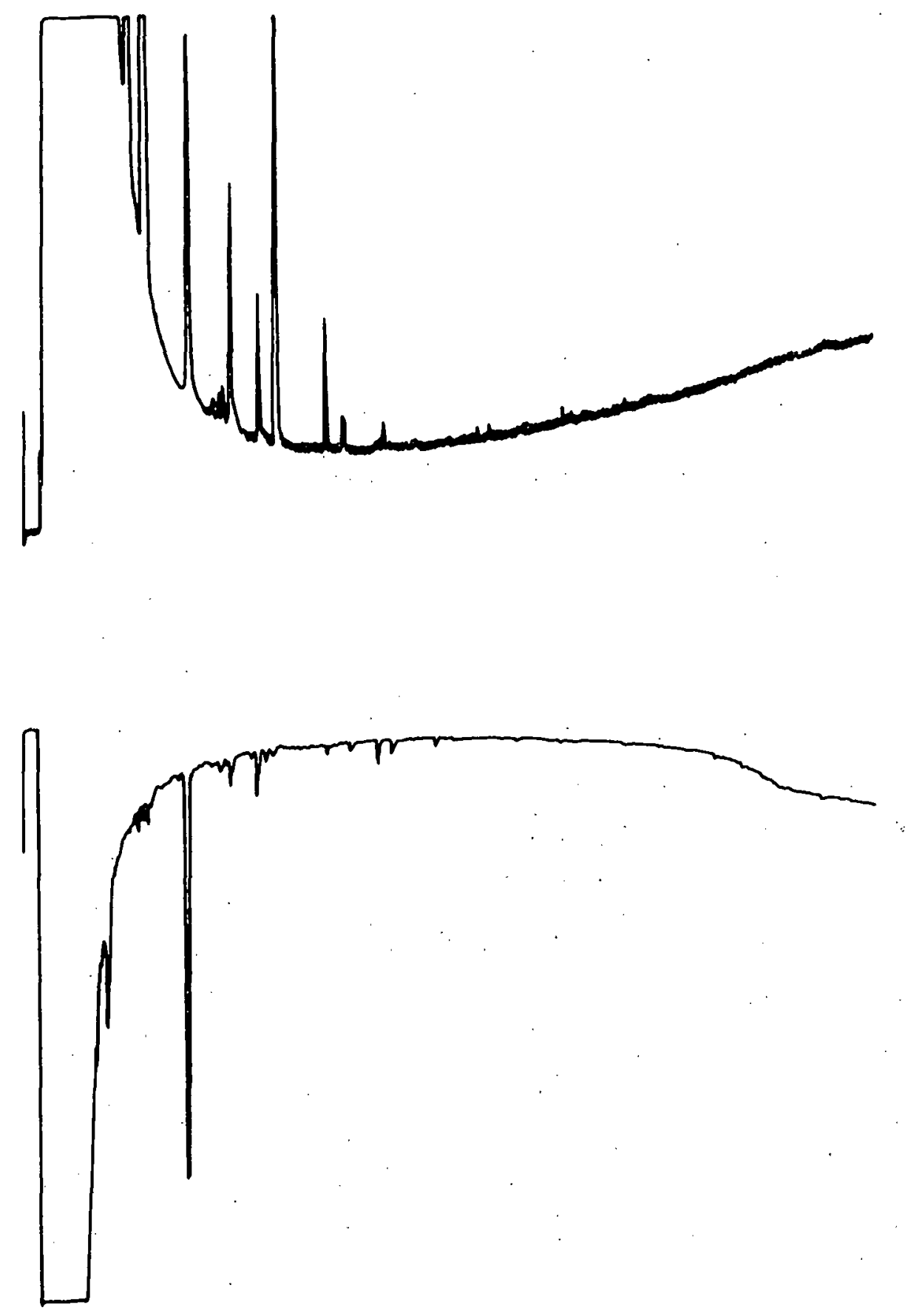

Figure 18. Separation of compounds from City \#l's water supply that were eluted in the second fraction from the Florisil column 

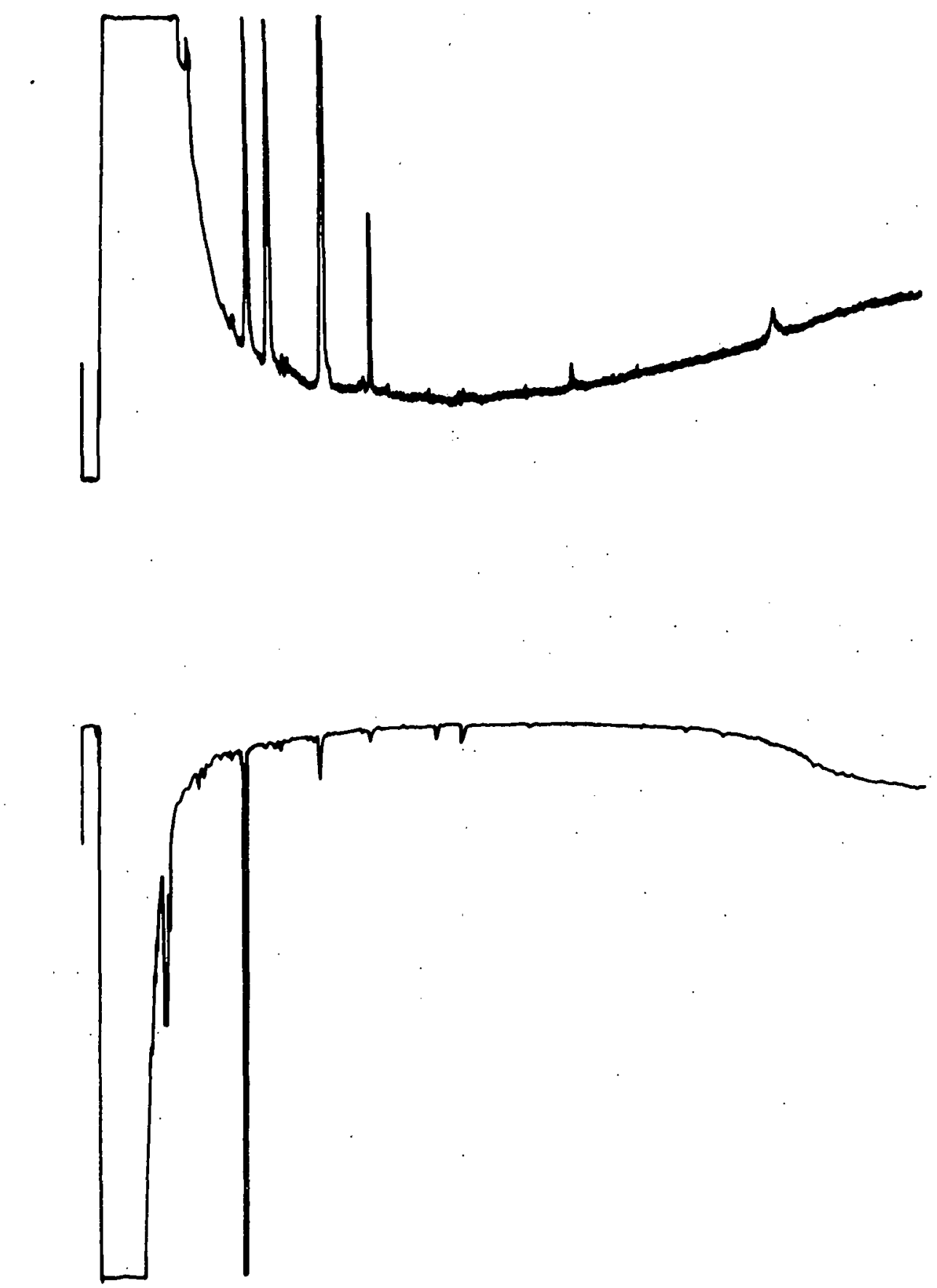

Figure 19. 'Separation of compounds from City \#l's. water supply that were eluted in the third fraction from the Florisil column 
130
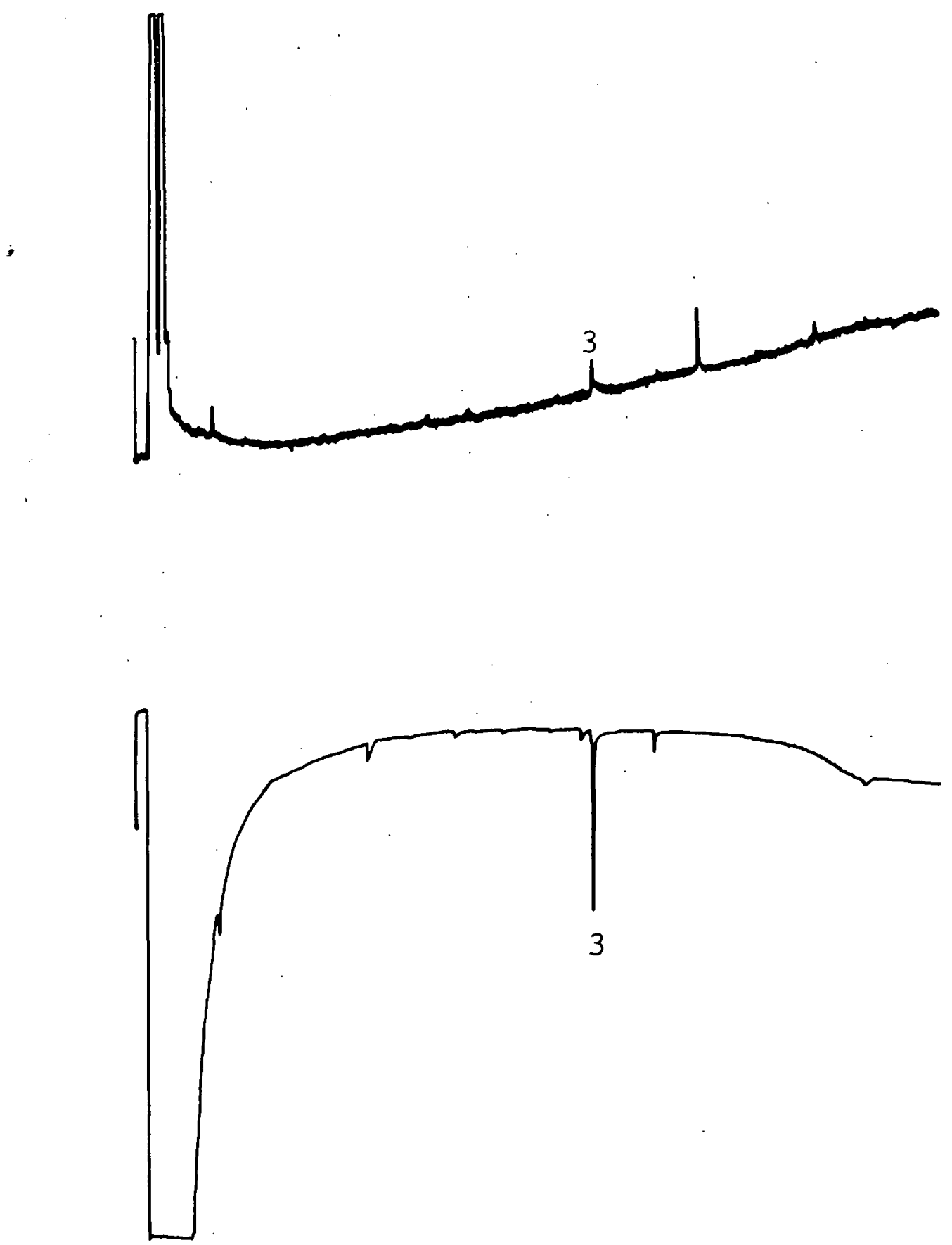

Figure 20. Separation of compounds from City \#I's water supply that were recovered from Florisil by dissolution in hydrofluoric acid 
Figures $21-24$ are chromatograms of organic compounds concentrated from the water distributed in City \#13. Table 22 lists the chromatographic conditions used to obtain the chromatograms in Figures 21 - 24. Presence of halogenated hydrocarbons in this water sample is indicated by the large responses obtained.with the ECD in Figure 22. The presence of halogenated hydrocarbons in the first fraction is indicated by larger peaks using the ECD than FID in Figure 22. Assuming the sensitivity of the FID is about the same for all organic compounds, the bottom chromatogram in Figure 23 indicates that the majority of gas-chromatographable compounds from this extract were eluted in the second fraction. Because the majorlty of gas-chromatographable compounds were present in the second fraction, the majority of the gas-chromatographable compounds in the extract from City \#13 were polar. The lack of response with the FID for the first fraction indicates that little nonpolar material was present in the extract of water from Gity \#13. Chromatograms in F1gure 24 show that only a small amount of the gas-chromatographable material from this water extract was eluted in the third fraction. Figures 23 and 24 indicate that a number of the polar compounds in the extract have a large cross-section for low-energy electrons; thus, peaks were observed using the ECD. 
Table 22. Chromatographic conditions for Figures $21-24$

Column - WCOT, Carbowax 20M stationary phase, $30 \mathrm{~m} \times 0.25 \mathrm{~mm}$ i.d.

Temperature - Isothermal at $50^{\circ} \mathrm{C}$ for $4 \mathrm{~min}$, then increased temperature at $3^{\circ} \mathrm{C} / \mathrm{mln}$. Maximum temperature of $200^{\circ} \mathrm{C}$ was held for $6 \mathrm{~min}$.

Carrier gas $-27 \mathrm{~cm} / \mathrm{sec}$ of hellum

Sample introduction - $2 \mu 1,30$ sec splitless

Make-up gas - $110 \mathrm{ml} / \mathrm{min}$ of nitrogen

Backflush gas - $20 \mathrm{ml} / \mathrm{min}$ of helium

ECD purge gas - $60 \mathrm{ml} / \mathrm{min}$ of nitrogen

Detection - Top: ECD, attenuation $=4$ Bottom: FID, attenuation $=10$

Exit-split ratio (ECD:FID) - $1: 2$ 

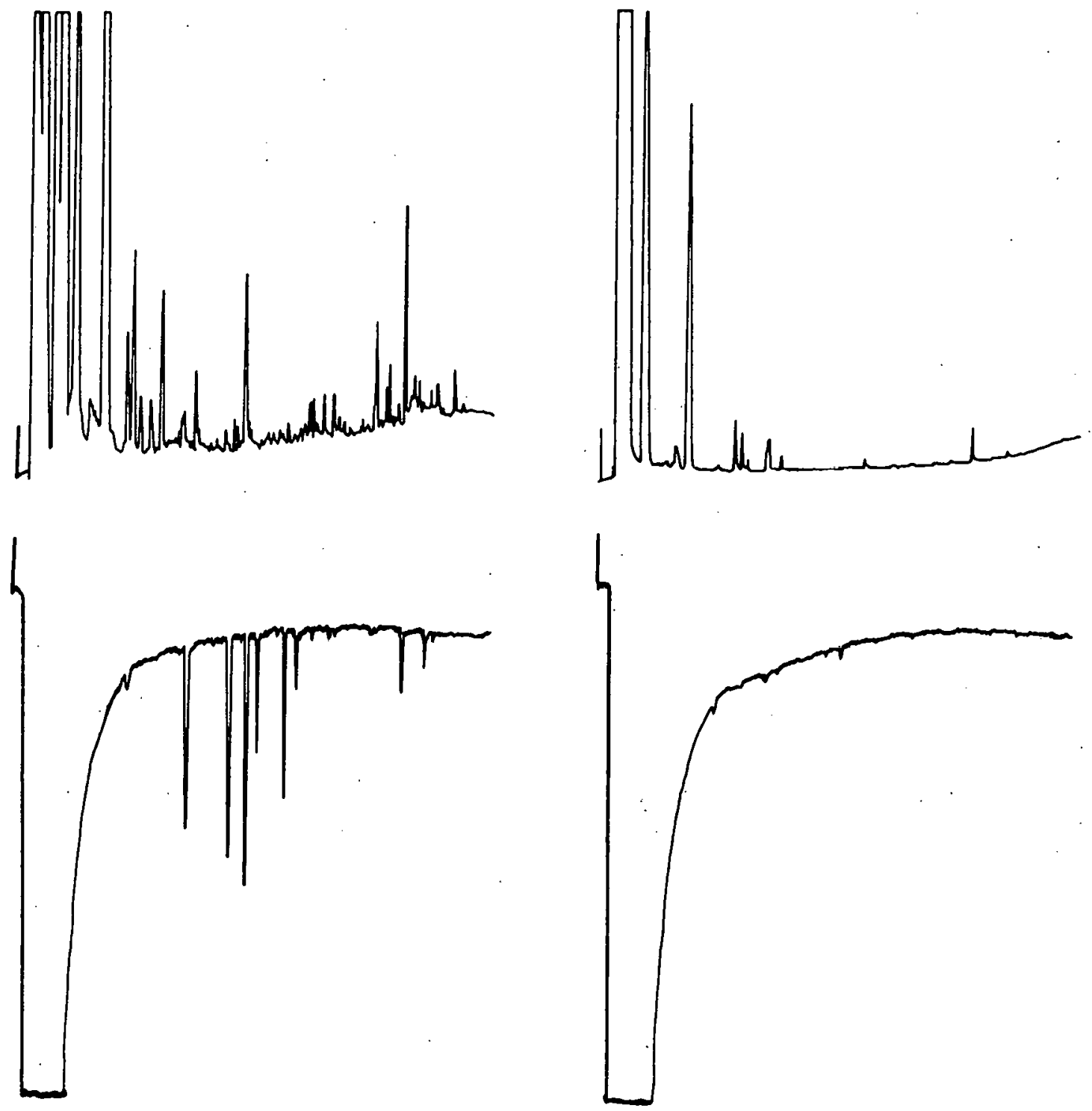

Figure 21.

Figure 22.

Figure 21. Separation of compounds extracted from City \#13's water supply

Figure 22. Separation of compounds from City \#13's water supply that were eluted from Florisil in the first fraction 


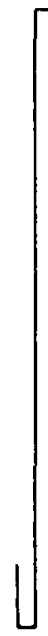
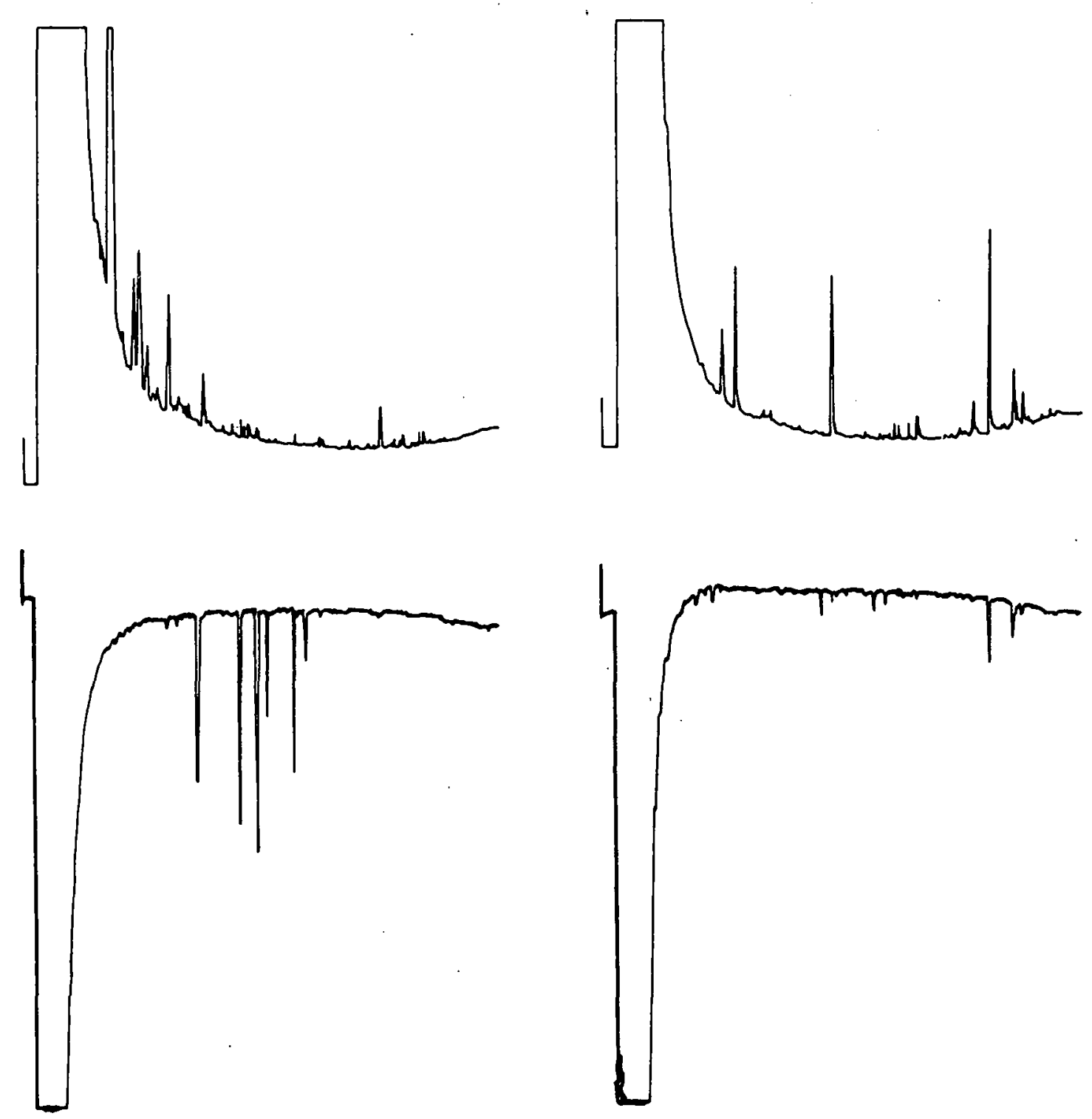

Figure 23.

Figure 24.

Figure 23. Separation of compounds from City \#13's water supply that were eluted from Florisil in the second fraction

Figure 24. Separation of compounds from C1ty \#13's water supply that were eluted from Florisil in the third fractior 
The results of fractionating extracts from the various cities were significantly different. For some of the water extracts, compounds were present in each of the three fractions from the Florisil columns. The gas-chromatographable compounds from some of the water extracts were completely eluted from florisil in one of the fractions. Although the fractionation on Florisil was ineffective for separating the organic compounds from some of the water extracts, the fractionation provided information about the compounds in the samples. In some cases, the organic compounds from water extracts gave little or no response on the FID or ECD. Very little material was detected by the ECD or FID for water extracts from Cities $\# 2$ and 4 . Because the amounts of gas-chromatographable matter in these extracts were low, the fractionation on Florisil was of little utility.

For most of the cities, the majority of organic compounds detected by gas chromatography in the water extracts were nonpolar. The vast majority of the peaks in the water extracts from City \#10 and Ames, Iowa, were for nonpolar compounds. The chromatograms of the first fractions from these cities looked the same as the chromatograms of the water extracts. Only a few, small peaks were observed in chromatograms of the second and third fractions from these cities. Previous research has shown that most of the gaschromatographable compounds in the drinking water of Ames, 
Iowa, were aromatic hydrocarbons (5). Because aromatic hydrocarbons were nonpolar, most of the gas-chromatographable compounds in a water extract from Ames, Iowa, were eluted from the Florisil column in the first fraction. Most of the compounds that gave responses on the FID from Cities \# 5, 6, 7, 8, 11,12 , and 14 were present in the first fraction. Unlike City \#10 and Ames, Iowa, significant amounts of the gas-chromatographable compounds were eluted in the second and third fractions. The compounds that gave a response on the ECD from Cities \#8 and 12 were eluted in the first fraction, while the compounds that gave large FID responses were eluted in the second fractions. This information indicates that halogenated hydrocarbons and some polar compounds were present in the water from Cities \#8 and 12. In the case of City \#14, most of the compounds that eluted quickly from the gas-chromatographic column were present in the first fraction. Peaks for the compounds that eluted later from the gas-chromatographic column were present in the second fraction. Because a nonpolar column was used for the gas chromatography of samples from City \#14, the information from the fractionation indicates that most of the volatile compounds in the water from City \#14 were nonpolar, while most of the polar compounds in the water were less volatile.

The organic compounds that could be determined by gas chromatography from City \#3 were polar. Only a few, small 
peaks were observed in the first and second fractions from City \#3. The vast majority of gas-chromatographable matter In the sample from City \#3 was present in the third fraction. Because only small responses were observed with the ECD for compounds extracted from the water of city \#3, apparently few halogenated compounds were present in this water.

The gas-chromatographable compounds in the water extract from City \#9 were divided into three approximately equal portions by fractionating on Florisil. Numerous peaks were present in each of the fractions from City \#9. Because of the complexity of the chromatograms for the water extract from City \#9, the fractionation was useful for simplifying the chromatograms of the organic compounds. The fractionation of this water extract indicates that many types of compounds were present in the water distributed in City \#9. Some of the organic compounds present in water extracts were not present in any of the fractions because some of the compounds were not soluhte in petroleum ether. When the solvents for the water extracts were changed from diethyl ether to petroleum ether, precipitates formed in many of the water extracts. Elemental analysis of the precipitate from City \#l showed the composition of the precipitate to be as follows: $65 \%$ carbon, $7.7 \%$ hydrogen, and $1.5 \%$ nitrogen. Although the composition of the precipitate was organic, the chromatograms in Figure 16 indicate that very little 
gas-chromatographable matter was present in the precipitate. Attempts to gain information about the petroleum-ether insoluble matter by proton magnetic resonance (PMR) and infrared (IR) spectroscopy were unsuccessful. Using onepercent solutions of the precipitate, only short and broad peaks were obtained by PMR and IR spectroscopy. This information indicates that the precipitate was composed of high molecular-weight, polar compounds that are commonly referred to as humic matter.

Many water utilities have a problem with a musty or earthy odor in the water (107). Most of the water extracts from the cities participating in the AWWA survey had an earthy odor. After fractionating the water extracts, the earthy odor was only present or was the strongest in the second fraction. Geosmin and 2-methylisoborneol are two cyclic alcohols that impart an earthy odor to drinking waters $(108,109)$. Chromatograms of some fractions that had an earthy odor had no peaks or only a few small peaks. Because the sensitivities for geosmin and 2-methylisoborneol with the FID are approximately $1 \times 10^{-8} \mathrm{~g}$, the amounts of geosmin or 2-methylisoborneol in the extract were very small or some other compounds were responsible for the odor.

Mutagenic testing Table 23 presents the results of mutagenic testing on raw and finished water extracts from various sources. Results in Table 23 indicate that the 
mutagenic activity of a mixture of compounds is not the sum of the mutagenic activities of the compounds present in the mixture. Pelroy and Peterson reported the mutagenic activity of a mixture may be inhibited or enhanced by some compounds $(100)$.

Results of mutagenic testing indicate that mutagenic activities of the organic compounds in drinking water may be increased by the treatment processes. In seven of the fourteen cities participating in the AWWA survey, the mutagenic activity of an extract from the finished water was greater than an extract from the raw water.

Data in Table 23 indicate the mutagenic activities of water extracts were not related to the mutagenic activities of any one fraction from the florisil columns. Because chloroform is a mutagen (26), concern has developed over the fact that most drinking waters are treated with chlorine. Because the mutagenic activities of the water extracts were not correlated with mutagenic activities of the first fractions, the mutagenic activities of the water extracts was not the result of halogenated hydrocarbons present in the waters.

Although little gas-chromatographable material was present in the water extract from C1ty \#2, mutagenic activity was detected in the water extract from City \#2. The compounds that caused the mutagenic activity from 
Table 23. Mutagenic activities of selected water extracts

\begin{tabular}{|c|c|c|c|c|c|c|}
\hline \multicolumn{2}{|c|}{ Source } & \multirow{2}{*}{$\frac{\text { Total }}{+}$} & \multirow{2}{*}{$\begin{array}{l}\text { First } \\
\text { Fraction } \\
- \\
-\end{array}$} & \multirow{2}{*}{$\begin{array}{l}\begin{array}{l}\text { Second } \\
\text { Fraction }\end{array} \\
- \\
-\end{array}$} & \multirow{2}{*}{$\begin{array}{l}\text { Third } \\
\text { Fraction } \\
+\end{array}$} & \multirow{2}{*}{$\begin{array}{c}\begin{array}{c}\text { Precip- } \\
\text { itate }\end{array} \\
\bar{?}\end{array}$} \\
\hline City & $\begin{array}{l}\# 1, \text { Finished } \\
\text { Raw }\end{array}$ & & & & & \\
\hline City. & $\begin{array}{l}\# 2, \begin{array}{l}\text { Finished } \\
\text { Raw }\end{array} \\
\text { a }\end{array}$ & $\begin{array}{l}+ \\
+\end{array}$ & $\begin{array}{l}? \\
-\end{array}$ & $\bar{?}$ & $\begin{array}{l}? \\
-\end{array}$ & - \\
\hline City & $\begin{array}{l}\text { \#3, Finished } \\
\text { Raw }\end{array}$ & $\begin{array}{l}+ \\
-\end{array}$ & $\stackrel{?}{-}$ & $\bar{?}$ & $\stackrel{?}{-}$ & - \\
\hline City & $\begin{array}{l}\text { \#4, Finished } \\
\text { Raw }\end{array}$ & $\begin{array}{l}+ \\
-\end{array}$ & - & - & - & - \\
\hline City & $\begin{array}{l}\text { \#5, Finished } \\
\text { Raw }\end{array}$ & $\stackrel{?}{-}$ & - & $\stackrel{?}{-}$ & - & - \\
\hline City & $\begin{array}{l}\text { \#6, Finished } \\
\text { Raw }\end{array}$ & $\begin{array}{l}? \\
?\end{array}$ & - & - & - & - \\
\hline City & $\begin{array}{l}\text { \#7, Finished } \\
\text { Raw }\end{array}$ & $\begin{array}{l}+ \\
?\end{array}$ & $\bar{?}$ & - & $\bar{?}$ & - \\
\hline City & $\begin{array}{l}\text { \#8, Finished } \\
\text { Raw }\end{array}$ & - & - & $\stackrel{?}{-}$ & - & - \\
\hline City & $\begin{array}{l}\text { \#9, Finished } \\
\text { Raw }\end{array}$ & - & - & - & - & - \\
\hline City & \#10, $\underset{\text { Raw }}{\text { Finished }}$ & $\begin{array}{l}+ \\
-\end{array}$ & - & - & - & - \\
\hline City & $\begin{array}{l}\text { \#11, Finished } \\
\text { Raw }\end{array}$ & $\begin{array}{l}+ \\
?\end{array}$ & $?$ & $?$ & - & $?$ \\
\hline City & $\begin{array}{l}\# 12, \text { Finished } \\
\text { Raw }\end{array}$ & $\begin{array}{l}+ \\
+\end{array}$ & - & - & $\begin{array}{l}+ \\
-\end{array}$ & - \\
\hline oity & $\begin{array}{l}\text { \#1.3, Finished } \\
\text { Raw }\end{array}$ & $\begin{array}{l}+ \\
+\end{array}$ & $\begin{array}{l}+ \\
+\end{array}$ & $\begin{array}{l}+ \\
+\end{array}$ & - & $\bar{?}$ \\
\hline City & $\begin{array}{l}\text { \#14, } \\
\text { Rawished }\end{array}$ & - & - & $\overline{-}$ & $\bar{?}$ & - \\
\hline Ames, & , IA, Finished & - & - & - & - & - \\
\hline & 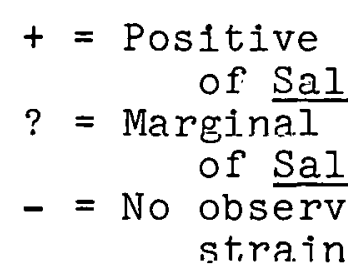 & $\begin{array}{l}\text { mutage } \\
\text { lmonel] } \\
\text { mutage } \\
\text { lmonel } \\
\text { ved mut } \\
\text { ns of }\end{array}$ & $\begin{array}{l}\text { nic activ } \\
\text { a. } \\
\text { nic activ } \\
\text { a. } \\
\text { agenic ac } \\
\text { almonella }\end{array}$ & $\begin{array}{l}\text { ty by at } \\
\text { ivity with }\end{array}$ & $\begin{array}{l}\text { east one } \\
\text { any of } t\end{array}$ & $\begin{array}{l}\text { strain } \\
\text { the }\end{array}$ \\
\hline
\end{tabular}


this water extract were probably not eluted from the gaschromatographic column. Because only a small portion of the organic matter from water can be detected by gas chromatography, techniques such as liquid chromatography are needed to determine the mutagens present in the water extract.

\section{Conclusions}

The usefulness of Florisil fractionation as an ald to the analysis of water for trace organic compounds has. been demonstrated by this work. Although the information obtained by the fractionation is not enough to determine the 1dentities of compounds, the information provided by the fractionation and clean-up is useful when combined with other analytical techniques.

Application of the technique of fractionation is limited to cases where recovery of polar, high molecularwelght compounds, such as humle matter, is not important. Low solubility of humic matter in petroleum either and strong adsorption of humic matter on Florisil result in little humic matter being recovered in fractions from Florisil.

The combination of mutagenic testing and fractionation has demonstrated that compound identification and quantification is not necessarily the best approach to evaluating 
the toxilogical effects of drinking waters. Even if the identities, concentrations, and potential health hazards of all components present in a mixture are known, the potential health hazard of the mixture is not known directly from this information. Because the mutagenic activities of compounds in a mixture are not accumulative, methods other than identification of compounds present in waters must be applied to determine the potential health effects of the organic compounds injested with drinking water. 
SUGGESTIONS FOR FUTURE WORK

The potential of capillary-column gas chromatography with two different types of detectors for determination and verification of compound identities is great. If the outputs from a flame ionization detector and an electron capture detector or a photo Ionization detector were connected to a microprocessor, retention times on capillary columns and relative response factors of sample components on two detectors could be obtalned from a single chromatographic separation. By fractionating samples on Florisil columns prior to analysis on capillary columns with dual detection, enough information could be obtained to verify the presence of preselected compounds and determine their. concentrations.

Further characterization of the organic compounds present in drinking waters could be accomplished by ident1fying compounds present in fractions by GC/MS. After determining the compounds that are present in fractions from water extracts, specific compounds could be determined in samples by fractionating the samples and analyzing the fractions by capillary-column gas chromatography with dual detection. This technique of analysis would be more rapid and sensitive, provide about the same quality of information for compound verification, and be much less expensive than capillary-column GC/MS. 
Although the fractionation was developed to aid in the analysis of organic compounds present in drinking waters, it is applicable to other types of analysis. Air pollutants and waste-water effluents are areas which organic compounds in complex mixtures are analyzed by gas chromatography and in which fractionation and capillarycolumn chromatography with dual detection could be useful. 
1. C.C. Johnson, Transcript: Safe Drinking Water, Series No. 92-24, U. S. Government Printing Office, Washington, D.C., 1971, p. 58 .

2. J. H. Lehr, Transcript: Safe Drinking Water, Series No. 92-24, U. S. Government Printing Office, Washington, D.C., 1971, p. 125 .

3. R. A. Dobbs, R. H. Wise, and R. B. Dean, Water Research, 6, 1173 (1973).

4. C. E. Van Hall and V. A. Stenger, Anal. Chem., 39, 503 (1967).

5. A. K. Burnham, G. V. Calder, J. S. Fritz, G. A. Junk, H. J. Svec, and R. Vick, J. Amer. Water Works Assoc., 65, 722 (1973).

6. G. A. Junk, J. J. Richard, M. D. Grieser, D. Witiak, J. L. Witiak, M. D. Arguello, R. Vick, H. J. Svec, J. S. Fritz, and G. V. Calder, J. Chromatogr., 29, 745 $(1974)$.

7. A. Tatata and J. S. Fritz, J. Chromatogr., 152, 329 (1978).

8. G. A. Junk and S. E. Stanley, Organics in Drinking Water. Part I: Listing of Identified Compounds. IS 3671, NTIS (July 1975).

9. W. B. Innes, W. E. Bambrick, and A. J. Andreatch, Arla 1. Cheill., 35, 1198 (1963).

10. R. M. Ikeda, D. E. Simmons, and J. D. Grossman, Ana 1. Chem., 36, 2188 (1964).

11. J. Janak and J. Novak, Chem. Listy, 1ㅡ, 1832 (1957).

12. T. Sato, N. Shimliki, and N. Mikami, Bunseki Kagaku, 14, 223 (1965).

13. B. A. Bierl, M. Beroza, and W. T. Ashton, Mikrochem. Acta, 1967, 637 (1967).

14. J. Fryka and J. Posp1s11, J. Chromatogr., 67, 366 (1972). 
15. D. A. Leathard and B. C. Shurlock, "Identification Techniques in Gas Chromatography", Wiley-Interscience, London, 1970, p. 66.

16. R. C. Chang, Ph.D. thesis, Iowa State University, Ames, Iowa (1976).

17. T. A. Bellar and J. J. Lichtenberg, J. Amer. Water Works Assoc., 66, 739 (1974).

18. M. J. Hartigan, H. D. Hoberecht, and J. E. Purcell, Amer. Lab., $\underline{5}(10), 36$ (1973).

19. C. D. Chriswell, I. D. Kissinger, and J. S. Fritz, Anal. Chem., 48, 1123 (1976).

20. J. S. Fritz and J. N. Story, Anal. Chem., 46, 825 (1974).

21. "Handbook of Chemistry and Physics", 5lst Edition, Chemical Rubber Publishing Co., Cleveland, Ohio, 1970-1, p. B-89.

22. H. M. McNair and E. J. Bonelli, "Basic Gas Chromatography, 5th Edition", Var1an Aerograph, Walnut Creek, Calif., 1965, p. 53.

23. C. D. Chriswell and J. S. Fritz, J. Chromatogr., 136, 371 (1977).

24. T. A. Bellar, J. J. Lichtenberg, and R. C. Kroner, J. Amer. Water Works Assoc., 66, 703 (1974).

25. Region V Joint Federal/State Survey of Organics and Inorganics in Selected Drinking Water Supplies (June 1975).

26. T. G. Tardiff, J. Amer. Water Works Assoc., 69, 658 (1977).

27. J. J. Rook, Wat. Treat. Exam., 23, 234 (1974).

28. J. J. Rook, J. Amer. Water Works Assoc., 68, 168 (1976).

29. F. C. Kopfler, R. G. Melton, R. D. Lingg, and W. E. Coleman, GC/MS Determination of Volatiles for the National Organics Reconnaissance Survey of Drinking Waters, U.S. Environmental Protection Agency (1975). 
30. B. Dowty, D. Carlisle, and J. L. Laseter, Science, 187, 75 (1975).

31. D. M. Coulson, J. Gas Chromatogr., 3, 134 (1965).

32. A. A. Nicholson and O. Meresz, Bull. Environ. Cont. and Toxic., 14, 453 (1975).

33. J. J. Rook, Water Treat. Exam., 21, 259 (1972).

34. J. P. Miere, J. Amer. Water Works Assoc., 69, 60 (1977).

35. J. J. Richard and G. A. Junk, J. Amer. Water Works Aşoc., 69, 62 (1977).

36. E. M. Moyers, Ph.D. thesis, Iowa State University, Ames, Iowa (1975).

37. "Standard Methods for the Examination of Water and Wastewater", I4th Edition, American Public Health Association, Washington, D.C., 1975, p. 332.

38. "Procedures, Chemical Lists, and Glassware for Water and Wastewater Analysis", 3rd Edition, Hach Chemical Company, Ames, Iowa, 1975, p. 2-29.

39. M. J. E. Golay, in V. J. Coates, H. J. Noebels, and I. S. Fagerson, "Gas Chromatography (1957 Lansing Symposium)", Academic Press, New York, 1958, p. 1.

40. F. W. Karasek, Research/Development, November 1975, p. 40 .

41. A. Zlatkis, H. P. Lichtenstein, and A. Tishbee, Chromatographia, $\underline{6}, 67$ (1973).

42. W. Bertsh, F. Shunbo, R. C. Chang, and A. Zlatkis, Chromatographia, I, 128 (1974).

43. M. Novotny and K. Tesarik, Chromatographia, 1, 332 (1968).

44. K. Tesarik and M. Novotny, Chromatographia, 2, 384 (1969).

45. G. Alexander and G. A. F. M. Rutten, Chromatographia, 6, 231 (1973).

46. G. Alexander and G. A. F. M. Rutten, Chromatographia, 8, $354(1975)$. 
47. J. D. Schieke, N. R. Comins, and V. Pretorius,

J. Chromatogr., 112, 97 (1975.).

48. J. D. Schieke, N. R. Comins, and V. Pretorius, Chromatographia, $\underline{8}, 354$ (1975).

49. L. S. Ettre and J. E. Purceil, Advan. Chromatogr., 10, $1(1974)$.

50. L. S. Ettre, "Open Tubular Columns, an Introduction", Perkin-Elmer, Norwalk, Conn., 1974, p. 2.

51. K. Grob and G. Grob, Chromatographia, 5, 3 (1972).

52. K. Grob and K. Grob, Jr., J. Chromatogr., 94, 53 (1974).

53. K. Grob and K. Grob, Jr., J. Chromatogr., 151, 311 (1978).

54. D. M. Oaks, H. Hartmann, and K. P. Dimick, Anal. Chem., 36, 1560 (i964).

55. E. Etzweiler and N. Neuner-Jahle, Chromatographia, $\underline{6}$, 503 (1973).

56. A. L. German and E. C. Horning, J. Chromatogr. Sci., II, 76 (1973).

57. M. Novotny, L. Blomberg, and K. D. Bartle,

J. Chromatogr. Sci., $\underline{8}, 390$ (1970).

58. F. Bauman and I. Gill, Varian Aerograph Research Notes, Feb. 1968.

59. P. R. Musty and G. Nickless, J. Chromatogr., 89, 185 (1973).

60. M. Ahnoff and B. Josefsson, Anal. Chem., 46, 658 (1974).

61. K. Grob, K. Grob, Jr., and G. Grob, J. Chromatogr., 106, 299 (1975).

62. R. L. Booth, J. N. English, and G. N. McDermett, J. Amer. Water Works Assoc., 57, 21.5 (1965).

63. R. W. Buelow, J. K. Carswell, and J. M. Symons,

J. Amer. Water Wọrks Assoc., 65, 57 (1973).

64. S. S. Kremen, Environ. Sc1. Technol., 9, 314 (1975). 
65. G. A. Junk, C. D. Chriswell, R. C. Chang,

L. D. Kissinger, J. J. Richard, J. S. Fritz, and

H. J. Svec, Z. Anal. Chem., 282, 331 (1976).

66. C. D. Chriswell, R. L. Ericson, G. A. Junk, K. W. Lee, J. S. Fritz, and H. J. Svec, J. Amer. Water Works Assoc., 69, 669 (1977).

67. J. P. Ryan and J. S. Fritz, J. Chromatogr. Sci., in press.

68. A. P. Swain, J. E. Cooper, and R. L. Stedman, Canc. Res., 29, 579 (1969).

69. F. G. Bock, A. P. Swain, and R. L. Stedman, Canc. Res., $\underline{29}, 584$ (1969).

70. M. Novotny, M. L. Lee, and K. D. Bartle, J. Chromatogr. Sci., 12, 606 (1974).

71. M. L. Lee, M. Novotny, and K. D. Bartle, Anal. Chem., 48, 405 (1976).

72. I. B. Rubin, M. R. Guerin, A. A. Hardigree, and

J. L. Epler, Environ. Res., 12, 358 (1976).

73. B. N. Ames, P. Sims, and P. L. Grover, Science, 176, 47 (1972).

74. P. A. Mills, J. Assoc. Off. Agr. Chem., 42, 734 (1959).

75. P. A. Mills, J. Assoc. Off. Anal. Chem., 51, 29 (1968).

76. R. L. Colemen, E. D. Lund, and P. E. Shaw, J. Agr. Food Chem., 20, 100 (1972).

77. J. Eisner, J. L. Iverson, A. K. Moyingo, and

D. Firestone, J. Assoc. Off. Agr. Chem., 48, 417 (1965).

78. J. Eisner and D. Firestone, J. Assoc. Off. Agr. Chem., $\underline{46}, 542$ (1963).

79. J. Eisner, J. L. Everson, and D. Firestone,

J. Assoc. Off. Agr. Chem., 49, 580 (1966).

80. P. W. Jones, A. P. Graffeo, R. Detrick, P. A. Clarcke, and R. J. Jakobson, USEPA Technical Manual \# 600/2-76072 (1976).

81. L. R. Synder, J. Chromatogr., $\underline{8}, 178$ (1.962). 
82. T.. R. Snyder and B. E. Buell, Anal. Chem., 40, 1295 (1968).

83. L. R. Snyder, B. E. Buell, and H. E. Howard, Anal. Chem., 4 10, 1303 (1968).

84. C. D. Chriswell, R. C. Chang, and J. S. Fritz; Anal. Chem., 47, 1325 (1975).

85. E. T. Gjessing and G. F. Lee, Environ. Sci. Technol., $\underline{1}, 631$ (1967).

86. A. R. Jones, M. R. Grerin, and B. R. Clark, Anal. Chem., 49, 1766 (1977).

87. H. J. Klimisch and L. Stadler, J. Chromatogr., 67, 291 (1972).

88. C. A. Streuli, J. Chromatogr., 56, 225 (1971).

89. H. H. Olert, Z. Anal. Chem., 244, 91 (1969).

90. W. Giger and C. Schaffer, Anal. Chem., 50, 243 (1978).

91. L. R. Snyder, J. Chromatogr., 6, 22 (1961).

92. L. R. Snyder, J. Chromatogr., 8, 319 (1962).

93. L. R. Snyder, J. Chromatogr., 12, 488 (1963).

94. "Standard Methods for the Examination of Water and Wastewater", 14th Edition, American Public Health Association, Washington, D.C., 1975, p. 555.

95. C. D. Chriswell, B, A. Glatz, H. J. Svec, and J. S. Fritz, presented at the Symposium on Application of Short-Term Bioassays in the Fractionation and Analysis of Complex Environmental Mixtures, Williamsburg, Virginia, Feb. 1978.

96. B. N. Ames, W. W. Durston, E. Yamasaki, and F. D. Lee, Proc. Nat. Acad. Sci. USA, 70, 2281 (1973).

97. J. MeCann, E. Choi, E. Yamasaki, and B. N. Ames, Proc. Nat. Acad. Sci. USA, 72, 5135 (1975).

98. J. McCann and B. N. Ames, Proc. Nat. Acad. Sci. USA, 73, 950 (1976).

99. E. Yamasaki and B. N. Ames, Proc. Nat. Acad. Sci. USA, 74, 3555 (1977). 
100. P. S. Pelroy and M. R. Peterson, presented at the Symposium on Application of Short-term Bioassays in the Fractionation and Analysis of Complex Environmental Mixtures, Williamsburg, Virginia, Feb. 1978.

10l. V. P. Kukreja and J. L. Bove, J. Environ. Sci. Health, Al1, 517 (1976).

102. B. N. Ames, J. McCann, and E. Yamasak1, Mutat. Res., 31, $347(1975)$.

103. B. A. Glatz, C. D. Chriswell, M. D. Arguello,

H. J. Svec, J. S. Fritz, S. M. Grimm, and M. A. Thomson, $\mathrm{J}$. Amer. Water Works Assoc., in press.

104. L. R. Snyder, J. Chromatogr., 11, 195 (1963).

105. "Handbook of Chemistry and Physics", 31st Edition, Chemical Rubber Publishing Company, Cleveland, Ohio, $1949 ;$ p. 877.

106. C. D. Chriswell, M. D. Arguello, M. J. Avery, R. L. Ericson, J. S. Fritz, G. A. Junk, L. D. Kissinger, K. W. Lee, J. J. Richard, H. J. Svec, and R. V1ck, presented at the $97 \mathrm{th}$. Annual Conference of the American Water Works Association, Anaheim, California, May, 1977.

107. E. A, Sigworth, J. Amer. Water Works Assoc., 49, 1507 (1957).

108. A. A. Rosen, C. I. Mashni, and R. S. Safferman, Proc. Water Treat. Exam., 10, 106 (1970).

109. D. R. Herzing, V. L. Snoeyink, and N. F. Wood, J. Amer. Water Works Assoc., 69, 223 (1977). 
ACKNOWLEDGEMENTS

The author is grateful for the guidance and Inspiration provided by Professor James S. Fritz.

The work on abstraction of amines from gas-chromatographic streams was a joint project with Colin D. Chriswell and was published in Analytical Chemistry.

I would like to thank Gary V. Austin for the elemental analysis of the precipitate from the water extract. Thanks are extended to Dr. Bonita A. Glatz, Mark A. Thomson, Sandra M. Grimm, and Deborah D. Wilson for the mutagenic testing of samples by the Ames Test.

I am sincerely grateful to the Ames Laboratory, the National Science Foundation, the American Water Works Association, and the Phillips Petroleum Company for the financial assistance that made this research possible.

The advice and assistance provided by members of Arlalytical Chemiotry Groups I and II was extremely helpful and sincerely appreclated.

Special thanks are extended to my wife, Susan, and daughter, Kerri, for their love and support during the course of this work. 